\author{
UNIVERSIDADE DE SÃO PAULO \\ FACULDADE DE ODONTOLOGIA DE BAURU
}

VITOR DE TOLEDO STUANI

Avaliação dos efeitos da descontaminação e sequencial migração de pré-osteoblastos em microimplantes de titânio em uma abordagem in vitro utilizando arcabouços produzidos por manufatura aditiva 

VITOR DE TOLEDO STUANI

\section{Avaliação dos efeitos da descontaminação e sequencial migração de pré-osteoblastos em microimplantes de titânio em uma abordagem in vitro utilizando arcabouços produzidos por manufatura aditiva}

Tese apresentada à Faculdade de
Odontologia de Bauru da Universidade de São
Paulo para obtenção do título de Doutor em
Ciências no Programa de Ciências
Odontológicas Aplicadas, na área de
concentração de Periodontia.

Orientadora: Profa. Dra. Adriana Campos Passanezi Sant'Ana

BAURU 
Stuani, Vitor

Avaliação dos efeitos da descontaminação e sequencial migração de pré-osteoblastos em microimplantes de titânio em uma abordagem in vitro utilizando arcabouços produzidos por manufatura aditiva I Vitor de Toledo Stuani. -- Bauru, 2020.

137 p. : il. ; $31 \mathrm{~cm}$.

Tese (Doutorado) -- Faculdade de Odontologia de Bauru, Universidade de São Paulo, ano de defesa.

Orientadora: Profa. Dra. Adriana Campos Passanezi Sant'Ana

Autorizo, exclusivamente para fins acadêmicos e científicos, a reprodução total ou parcial desta dissertação/tese, por processos fotocopiadores e outros meios eletrônicos.

Assinatura:

Data:

Comitê de Ética da FOB-USP

NÃO SE APLICA 
ERRATA 

FOLHA DE APROVAÇÃO 



$$
\text { DEDICATORIA }
$$

Dedico este trabalho a minha família. Sem o apoio de vocês, todas estas páginas seriam vazias. Mãe, pai e Tati, amo vocês.

Se cada gota de tinta destas folhas fossem um muito obrigado, com toda certeza eu precisaria escrever mais páginas.

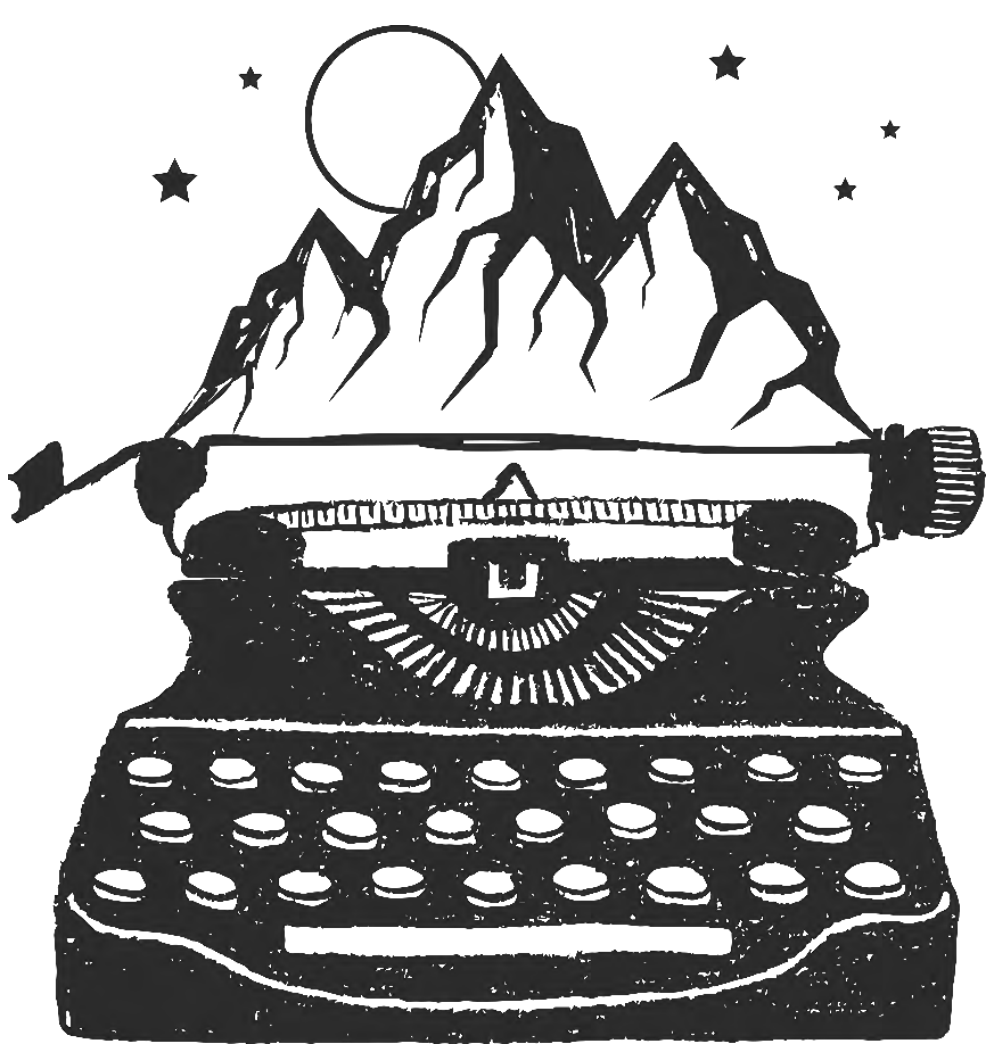




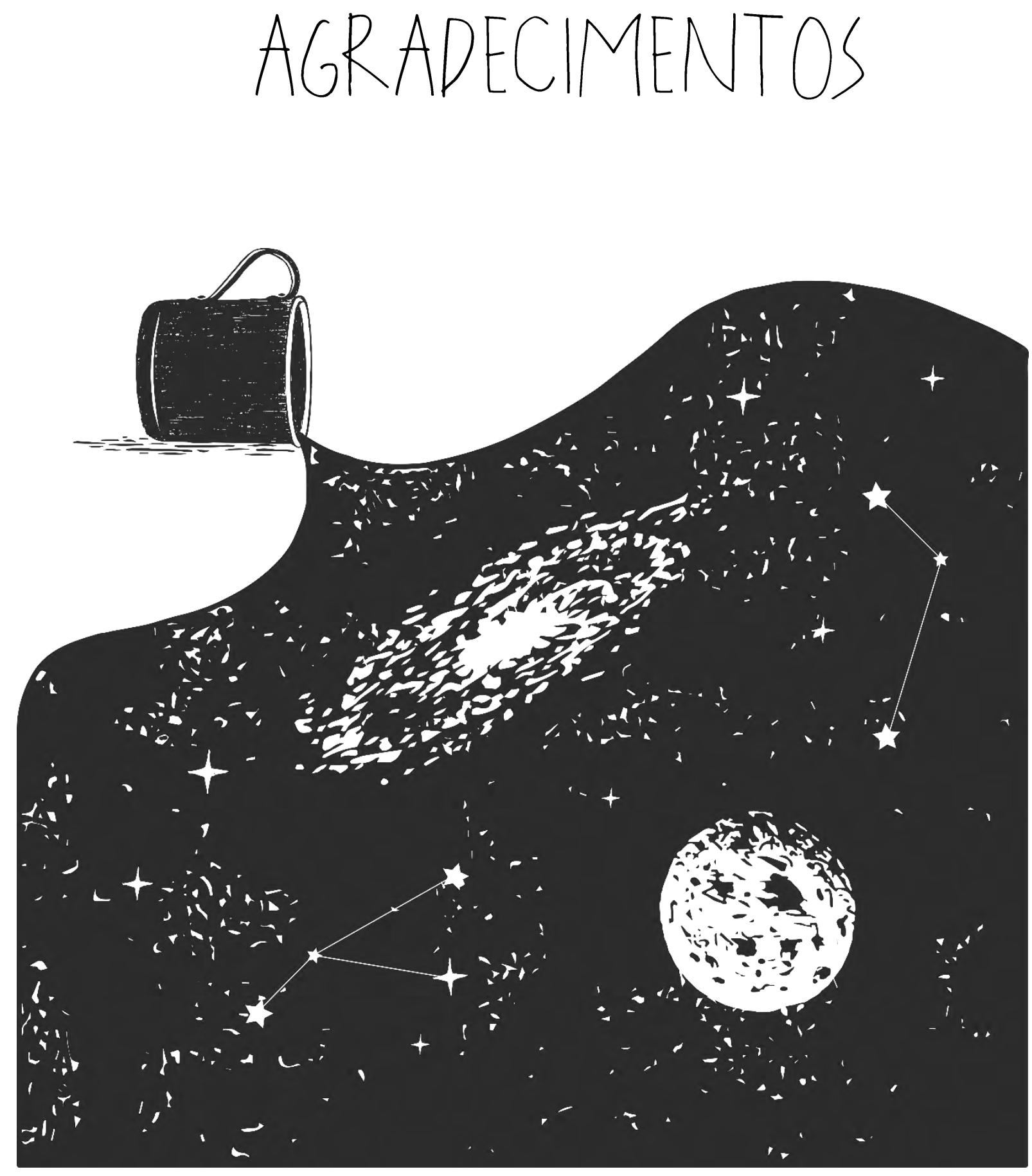

Carl Sagan, um dos mais notórios divulgadores científicos de nosso tempo, proferiu certa vez em sua série Cosmos que "A exploração está em nossa natureza. Começamos como andarilhos, e nós somos andarilhos ainda". Esta frase encerra em seu âmago a ânsia pelo desconhecido que eternamente norteou a humanidade. Sempre estamos e estaremos em uma jornada pessoal tateando por algo além do 

horizonte. É claro, esta citação pode ser interpretada perfeitamente de modo literal, como uma passagem que define um impulso nômade por viajar, cruzar o globo. Também serve perfeitamente como uma suposição poética de alguém que busca por seu lugar no mundo. Porém, como estamos tratando de Carl Sagan, gosto de imaginar que ele deixou impregnada nas entrelinhas de sua declaração um significado que remete a sua paixão pela ciência. Como pesquisadores, somos andarilhos, sempre em uma jornada infinita a mapear e expandir as fronteiras inexploradas do conhecimento.

Com a conclusão deste doutorado se encerra um dos ciclo mais marcantes de minha vida. Foi um período de aprendizado e crescimento, e perto destes é até injusto nomear obstáculos ou aflições. Ao longo de todos estes anos, e ainda mais claro agora, olhando em retrospecto, só consigo agradecer por todo amor e apoio que recebi. Sei dos privilégios que tenho e que me foram oferecidos para estar onde estou, e farei o possível para retribuir tudo que me foi ofertado.

Agradeço a Deus pela improbabilidade milagrosa de, entre centenas de bilhões de sóis e 13 bilhões de anos, ter nascido sob um teto amoroso em uma cidadezinha no interior em 1987. Este é meu maior tesouro.

Mãe, não importa o quanto eu escreva, nunca conseguirei expressar o quanto sou grato. Obrigado por ser um exemplo firme em minha vida, brilhando como farol a me guiar pelas incertezas do caminho. Sei que frente a qualquer desventura, sempre a verei neste estado misto de segurança e candura. Obrigado por todas as mensagens de boa noite, sempre devidamente encerradas por uns seis ou sete corações.

Pai, obrigado por todo o cuidado e atenção que sempre dedicou a mim. Desde criança sempre esteve cuidando de meus passos, se certificando pelos bastidores de que nada iria me causar mal. Sou muito feliz por ter você e seu carinho em minha vida. Você sempre será um grande parceiro de vida e de clínica.

Tati, espero que um dia eu consiga retribuir a você tudo aquilo que fez por mim. Seu espírito é leve e de total doação, e eu a admiro muito por isso. Conte comigo para tudo que precisar em sua vida. Não limite teus sonhos, pois tuas asas são grandes e seu voo é alto. Eu te amo, melhor irmã. 

Agradeço ao Vô Sylvio e Vó Tita, que mesmo não estando visíveis ao nosso lado, mantém suas presenças constantes em nossas vidas. O amor de vocês é como a ondulação gerada com o cair de uma rocha na superfície de um lago; mesmo já tendo se passado o impacto, se perpetua.

Agradeço aos meus tios Rodolfo, Lene, Marco e Renata por todo o carinho e por sempre acompanharem meus passos. É uma grande felicidade tê-los em minha vida.

Endereço aqui um agradecimento especial à Profa. Adriana Campos Passanezi Sant'Ana, que tive o prazer de chamar de orientadora durante 6 anos. Agradeço imensamente por toda a confiança que depositou em mim durante todo esse processo. Com absoluta certeza, isto foi primordial em minha caminhada. Seu jeito alegre e cuidadoso foram um refúgio muito bem vindo em meio à selva da vida acadêmica. Obrigado por todo o aprendizado, oportunidades e companhias em congressos.

Também gostaria de agradecer aos demais professores do departamento de Periodontia. Prof. Sebastião Greghi, Profa. Maria Lucia Rezende, Profa. Carla Damante e Profa. Mariana Zangrando, muito obrigado por todas as oportunidade que me foram dadas, pelos conhecimentos compartilhados e pelos bons anos de convívio.

Agradeço à Ivânia, Edilaine e Marcela pela constante ajuda, conversas, carinho e pipoca. Muito obrigado por tudo. Foi um prazer tê-las conhecido.

Outra figura marcante durante meu processo de formação na FOB-USP foi o Prof. Paulo Sérgio da Silva Santos. Deixo aqui o meu muito obrigado por ser uma constante inspiração de como manter o lado humano da odontologia e a firmeza da vida acadêmica.

Agradeço ao Prof. João Batista César Neto por todo seu trabalho junto ao Osteology Foundation, bem como por toda a orientação e amizade que me foi oferecida. Sua dedicação ao National Group e seus conselhos foram os ladrilhos que pavimentaram meu caminho para Harvard.

Obrigado a todos os amigos da pós-graduação, sem vocês os dias em Bauru seriam mais vazios, e meu celular mais silencioso. Contem comigo para o que 

precisarem. Espero que nossos reencontros nunca sejam precedidos por um "Nossa, quanto tempo!".

Agradeço aos meus amigos de longa data de Martinópolis. Mesmo com a vida tendo nos levado para caminhos diferentes, sempre os carregarei comigo.

Também gostaria de agradecer aos novos amigos que tive a oportunidade de conhecer durante minha estadia em Boston. Nossas conversas em português foram um delicioso oásis em meio a um deserto anglofônico.

Agradeço aos membros das equipes da secretaria, biblioteca, esterelização e limpeza da Faculdade de Odontologia de Bauru por proporcionarem um ambiente acolhedor para meu trabalho e estudo ao longo dos anos que aqui passei.

Agradeço a Faculdade de Odontologia de Bauru por ter me recebido tão bem e por ter me dado tanto. Também agradeço à CAPES por fornecer recursos que permitissem a realizacão deste doutorado.

I would like to give a special thanks to Osteology Foundation for awarding me with the Research Scholarship and giving me the opportunity to spend one year at Harvard School of Dental Medicine. It was an amazing and life-changing experience, and I'm sure that I'm a different researcher than I was before. Also, I would like to thank all the members from the Osteology Office for all the hard work and for always being so kind to me.

With the Research Scholarship, I had the unique opportunity to meet and be supervised by amazing researchers. Thank you, Dr. Kim, Dr. Masa, and Dr. Shigemi, for always being so kind. I will never forget all the opportunities and knowledge you provided me. I also want to say thanks for all the other friends I made along the way for the good time spent together, like Thomas Nguyen, all the perio residents, and all the members from the Nagai-Kim Lab (Kuwa, Yoshi, Jennifer, Kaho, Ayaka, Wonwoo, Shy). 



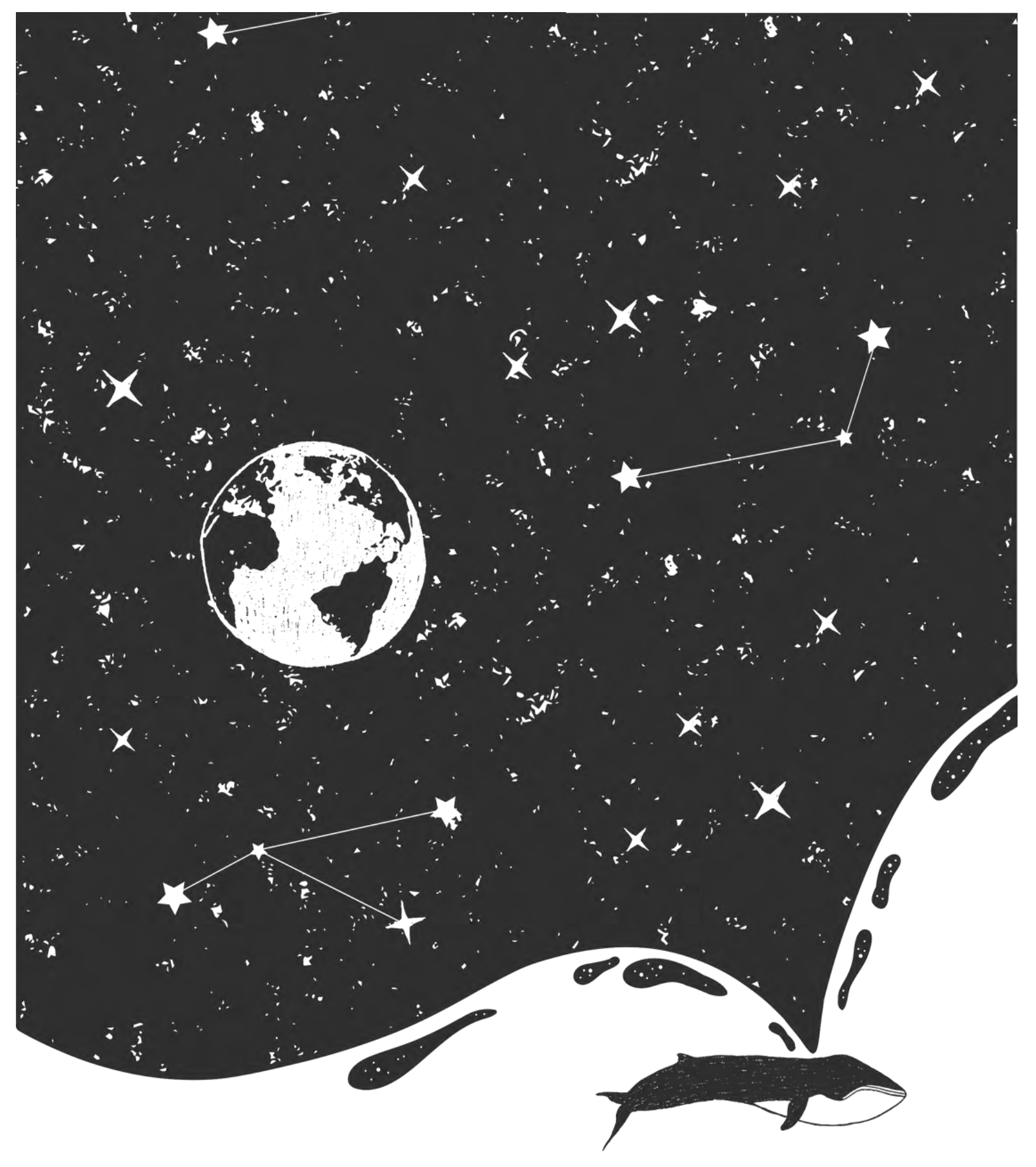

AS FOR ME, I AM TORMENTED WITH AN EVERLASTING ITCH FOR THINGS REMOTE. I LOVE TO SAll FORBIDEN SEAS. AND LAND ON BARBAROUS COASTS: 



\section{RESUMO}

A peri-implantite é um desafio clínico atual, sendo que a complexidade desse cenário aumenta ao considerarmos que um mesmo protocolo de descontaminação pode levar a resultados diferentes dependendo das características da superfície do implante tratado. O objetivo deste estudo foi utilizar um novo modelo in vitro para avaliar a migração de pré-osteoblastos, o potencial de descontaminação do titânio, mudanças na rugosidade da superfície, alterações químicas e modificações na molhabilidade de microimplantes de titânio após o uso de diferentes protocolos de descontaminação. Para isto, foram utilizados no experimento 120 microimplantes de titânio lisos (L) e 120 rugosos $(R)$. Para o grupo controle, foram selecionados aleatoriamente 15 microimplantes $L$ e $15 R$ ( $L-C / R-C)$, enquanto que os demais foram incubados em cultura de Escherichia coli. Em seguida, os microimplantes contaminados foram tratados de acordo com 7 protocolos de descontaminação diferentes, sendo: submersão em EDTA gel a 24\% (EDTA; n=15), submersão em clorexidina a 4\% (CX; $\mathrm{n}=15)$, limpeza com gaze embebida em clorexidina a 4\% (GCX; $n=15)$, limpeza com gaze embebida em água ultrapura (GMQ; $n=15)$, raspagem com cureta metálica (RA; $n=15)$, uso de escova de titânio $(E T i ; n=15)$ e implantoplastia (IP; $n=15)$. As áreas contaminadas remanescentes foram avaliadas por imagens de microscopia eletrônica de varredura (MEV), a composição química foi determinada por espectroscopia por dispersão em energia (EDS), a molhabilidade pela técnica do menisco e a rugosidade superficial por meio de um perfilador óptico. Após, os microimplantes foram inseridos em arcabouço impresso tridimensionalmente e preenchido com uma cultura 3D de células pré-osteoblásticas (MC3T3-E1 subclone 14). A migração celular foi avaliada por ensaio de luminescência após 24, 72 e 120 h. Como resultado observou-se maior concentração de bactérias no grupo R-C do que no L-C ( $p<0,0001)$. Ao comparar microimplantes $L$ e $R$ dos grupos experimentais com seus respectivos grupos $C$, os melhores resultados de descontaminação foram obtidos nos grupos GCX, RA, ETi e $I P$, sem diferença entre esses protocolos $(p<0,05)$. Alterações na rugosidade da superfície foram observadas após todos os tratamentos, com os grupos L-IP e R-IP apresentando a superfície mais lisa e menos hidrofílica dentre todos $(p<0,05)$. Com exceção do protocolo IP, todos os outros grupos apresentaram maior hidrofilia em microimplantes $R$ do que $L(p<0,003)$. Todos os protocolos de descontaminação 

resultaram em menor porcentagem de Ti superficial quando comparado ao grupos controles $L-C$ ou R-C $(p<0,002)$. Em relação à migração celular, não foi observada diferença entre os grupos $R$ às $24 \mathrm{~h}(\mathrm{p}>0,05)$, mas os valores nos grupos L-IP e L-CX foram estatisticamente inferiores ao do grupo $L-C(p<0,05)$. Às $120 \mathrm{~h}$, não houve diferença estatística entre os grupos L-C, L-EDTA, L-GCX, L-RA e L-ETi $(p>0,05)$ e entre os grupos R-C, R-EDTA e R-GCX ( $p>0,05)$. Assim, pode-se concluir que todos os protocolos avaliados levaram a alguma mudança na rugosidade, molhabilidade e/ou deposição química superficial, sendo que os grupos GCX, RA, ETi e IP apresentaram o melhor potencial de descontaminação tanto em microimplantes $L$ quanto em R. A migração celular, por sua vez, demonstrou melhor resultados com os protocolos EDTA, GCX, RA e ETi nos microimplantes $L$ e EDTA e GCX nos R. A junção de ambos os resultados sugere uma indicação do uso dos protocolos GCX, RA e ETi em superfícies lisas e GCX nas rugosas.

Palavras-chave: Peri-implantite. Descontaminação. Técnicas in vitro. 



\begin{abstract}
Evaluation of decontamination effects and sequential pre-osteoblast migration to titanium microimplants in an in vitro approach using scaffolds produced by additive manufacturing
\end{abstract}

Peri-implantitis is a current clinical challenge and the complexity of this scenario increases considering that the same treatment can lead to different outcomes depending on the implant surface characteristics. The objective of this study was to use a new in-vitro model to assess titanium decontamination, surface roughness, chemical changes, wettability and preosteoblast migration after using different decontamination protocols. It was used 120 smooth (S) and 120 rough (R) titanium microimplants at the experiment. For the control group, $15 \mathrm{~S}$ and $15 \mathrm{R}$ microimplants (R-C/S-C) were randomly selected, while the others were incubated in Escherichia coli culture. Then, 7 different decontamination protocols were used: 24\% EDTA gel submersion (EDTA; $n=15), 4 \%$ chlorhexidine submersion (CHL; ; $n=15)$, surface cleaning with gauze soaked in $4 \%$ chlorhexidine $(\mathrm{GCHL} ; n=15)$, surface cleaning with gauze soaked in ultrapure water (GUW; $n=15$ ), scaling with metallic curette (SC; $\mathrm{n}=15)$, titanium brush ( $\mathrm{TiB} ; \mathrm{n}=15)$ and implantoplasty (IP; $\mathrm{n}=15)$. Remaining contaminated areas were assessed by scanning electron microscopy (SEM) images. The chemical composition was investigated by EDS, wettability by meniscus technique and roughness by an optical profiler. After, microimplants were inserted in a 3D-printed scaffold imbibed with a 3D-cell culture of preosteoblasts (MC3T3-E1 subclone 14). Cellular migration was assessed with luminescence assay after 24, 72 and $120 \mathrm{~h}$. As result, a higher bacteria concentration was observed in R-C than in S-C $(p<0.0001)$. When comparing $S$ and $R$ experimental groups with their respective control groups, the best results were obtained with GCHL, S, TiB and IP protocols, with no difference between them $(p<0.05)$. Changes in surface roughness were observed after all treatments, with S/R-IP presenting the smoother and lesser hydrophilic surface $(\mathrm{p}<0.05)$. Apart from IP protocol, all the other $\mathrm{R}$ groups were more hydrophilic than $\mathrm{S}$ microimplants $(p<0.003)$. All decontamination protocols resulted in lower percentage of superficial Ti when compared to S/R-C $(p<0.002)$. Regarding cell migration, no 

difference was observed between $R$ groups at $24 h(p>0,05)$, but the values at groups S-IP and S-CHL were statistically inferior than S-C $(p<0,05)$. At $120 \mathrm{~h}$, there was no statistical difference between the groups S-C, S-EDTA, S-CHL, S-GCHL and S-SC ( $p>0.05$ ), or between the groups R-C, R-EDTA and R-GCX ( $p>0.05)$. Thus, it can be concluded that all decontamination protocols resulted in changes in roughness, wettability and chemical composition, with GCHL, SC, TiB an IP presenting the best decontamination potential for both $\mathrm{S}$ and $\mathrm{R}$ microimplants. On the other hand, cell migration assay showed better results with the protocols EDTA, GCHL, SC and ETi for $S$ microimplants, and EDTA and GCHL for the R. The junction of those results suggest an indication of the protocols GCX, SC and ETi for smooth surfaces and GCX for rough.

Key words: Periimplantitis. Decontamination. In vitro techniques. 



\section{LISTA DE FIGURAS}

Figura 1 - $\quad$ Aspecto macroscópico dos microimplantes lisos (L) e rugosos (R). 71

Figura 2 - $\quad$ Aspecto microscópico dos microimplantes lisos (L) e rugosos (R).. 72

Figura 3 - Microimplantes condicionados para o tratamento de superfície com duplo ataque ácido.

Figura 4 - Microimplantes condicionadas em incubação com suspenção de E. coli.

Figura 5 - Instrumentais utilizados para alguns dos protocolos de descontaminação mecânicos. 75

Figura 6 - Composição dos grupos controles e dos grupos experimentais. .... 75

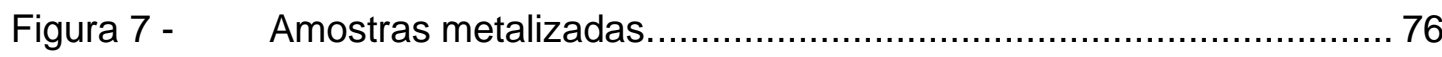

Figura 8 - $\quad$ A: imagem obtida por microscopia eletrônica de varredura com magnificação de 5.000 x, EHT de 8 kV e o detector SE2; B: bactérias demarcadas manualmente; $C$ : ajuste de threshold de 0 , evidenciando as bactérias em branco e o substrato em preto. 77

Figura 9 - Processo de submersão e emersão do microimplante para mensuração do menisco 79

Figura 10 - Sítios de seleção para avaliação de topografia superficial. .............. 80

Figura 11 - Diagrama do arcabouço projetado para o experimento................... 81

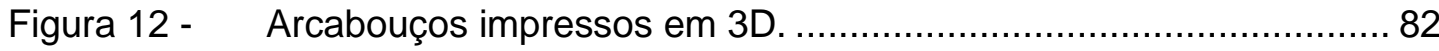

Figura 13 - Microimplante posicionado em arcabouço impresso em 3D demonstrando sua fidelidade com o planejamento digital.............. 82

Figura 14 - $\quad$ Preparo da suspensão de plaquetas............................................. 83

Figura 15 - $\quad$ Remoção do microimplante do arcabouço................................... 85

Figura 16 - Superfície dos microimplantes após descontaminação com cureta metálica. 90 

Figura 17 - Superfície dos microimplantes após descontaminação com escova de titânio. 90

Figura 18 - $\quad$ Superfície dos microimplantes após implantoplastia .......................99 90

Figura 19 - Imagens de microscopia eletrônica de varredura dos microimplantes

L e R antes e após os protocolos de descontaminação ... 91

Figura 20 - À esquerda, imagem de microscopia eletrônica de varredura retratando a cobertura bacteriana em microimplantes não descontaminados (controle) e submetidos a descontaminação utilizando diferentes protocolos. À direita, a presença de E. coli foi evidenciada em branco para realização do cálculo porcentual.. ..... 92

Figura 21 - Avaliação do ângulo do menisco formado pela submersão e emersão dos microimplantes 95

Figura 22 - Reconstruções da superfície dos microimplantes obtidas com

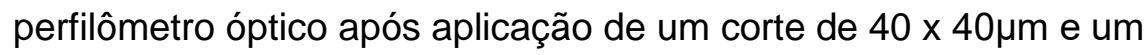
filtro Gaussiano de $25 \mu \mathrm{m}$.

Figura 23 - MC3T3-E1 subclone 14 aderidas na superfície de implantes descontaminados ou nunca contaminados após migração a partir de arcabouços impressos em 3D 



\section{LISTA DE TABELAS}

Tabela 1 - Porcentagem de cobertura bacteriana sobre a superfície dos microimplantes nos grupos controle (sem descontaminação) e experimentais (após a descontaminação) .................................... 89

Tabela 2 - Porcentagem de massa dos elementos químicos superficiais avaliados por EDS.

Tabela 3 - $\quad$ Porcentagem atômica dos elementos químicos superficiais avaliados

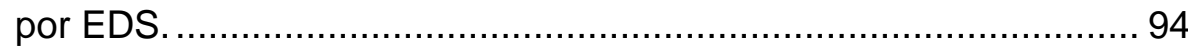

Tabela 4 - Molhabilidade avaliada pela técnica do menisco............................ 96

Tabela 5 - $\quad$ Parâmetros topográficos tridimensionais avaliados por perfilômetro óptico

Tabela 6 - Parâmetros topográficos bidimensionais avaliados por perfilômetro óptico

Tabela 7 - Valores de luminescência obtidos com o ensaio de migração celular de arcabouço impresso em 3D para a superfície de microimplantes descontaminados ou nunca contaminados 



\section{LISTA DE ABREVIATURA E SIGLAS}

$\begin{array}{ll}\% & \text { por cento } \\ < & \text { menor que } \\ \pm & \text { maior que } \\ \circledR & \text { mais ou menos } \\ \mu m & \text { marca registrada } \\ \text { A.u. } & \text { micrômetro } \\ \text { ACD } & \text { citrato ácido dextrose } \\ \text { Al } & \text { alumínio }\end{array}$

atomic \% porcentagem de átomos

AV voltagem de aceleração

BIC integração osso e implante (Bone Implant Contact)

C carbono

Ca cálcio

$\mathrm{CaCl}_{2} \quad$ cloreto de cálcio

CAPES Coordenação de Aperfeiçoamento de Pessoal de Nível Superior

CFU unidade formadora de colônia (Colony Forming Unit)

$\mathrm{Cl} \quad$ cloro

$\mathrm{CO}_{2} \quad$ dióxido de carbono

CX clorexidina

E. coli Escherichia coli

EDS Espectroscopia de raios $X$ por dispersão em energia

EDTA ácido etilenodiamino tetra-acético

EHT alta tensão eletrônica (Electron High Tension) 



\begin{tabular}{|c|c|}
\hline ETi & escova de titânio \\
\hline EUA & Estados Unidos da América \\
\hline FDI & Federação Dentária Internacional \\
\hline FOB & Faculdade de Odontologia de Bauru \\
\hline FPA & formalina-ácido propiônico-álcool etílico \\
\hline g & grama \\
\hline G & gravidade \\
\hline GCX & gaze embebida em clorexidina \\
\hline GMQ & gaze embebida em água ultrapura \\
\hline $\mathrm{h}$ & hora \\
\hline $\mathrm{H}_{2} \mathrm{O}_{2}$ & peróxido de hidrogênio \\
\hline $\mathrm{H}_{2} \mathrm{SO}_{4}$ & ácido sulfúrico \\
\hline $\mathrm{HCL}$ & ácido clorídrico \\
\hline HEMA & 2-hidroximetilmetacrilato \\
\hline IL-1 $\beta$ & interleucina $1 \beta$ \\
\hline $\mathrm{inHg}$ & polegada de mercúrio \\
\hline IP & implantoplastia \\
\hline $\mathrm{kV}$ & quilovolt \\
\hline $\mathrm{L}$ & microimplante liso \\
\hline LB & Luria Bertani \\
\hline M & massa molar \\
\hline $\mathrm{m}^{3}$ & metro cúbido \\
\hline $\mathrm{mA}$ & miliampère \\
\hline МС3Т3-E1 & linhagem celular de pré-osteoblastos oriundos da clavária de Mus musculus \\
\hline MEV & microscópio eletrônico de varredura \\
\hline $\mathrm{mL}$ & mililitro \\
\hline
\end{tabular}





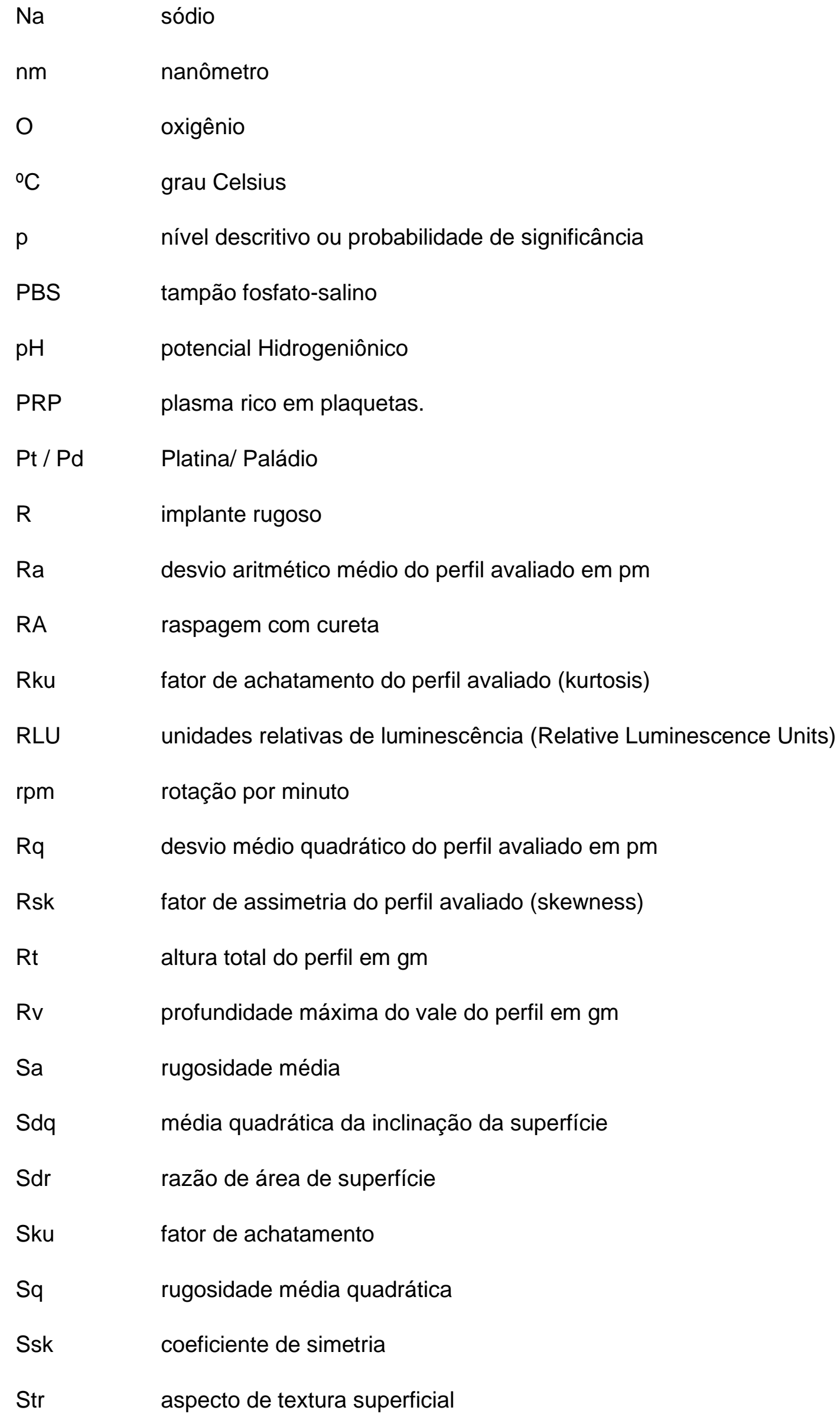



amplitude entre o mais alto pico e o mais profundo vale

$\mathrm{Ti}$

titânio

TNF- $\alpha$

fator de necrose tumoral $\alpha$

TPO

óxido de difenil(2 4 6-trimetilbenzoil)fosfina

USP Universidade de São Paulo

$w t \% \quad$ porcentgem de peso

a-MEM meio mínimo essencial 



\section{SUMÁRIO}

\begin{tabular}{|c|c|c|}
\hline 1 & INTRODUÇÃO & 35 \\
\hline 2 & REVISÃO DE LITERATURA & 41 \\
\hline 2.1 & Saúde peri-implantar & 43 \\
\hline 2.2 & Peri-implantite & 43 \\
\hline 2.3 & Opções de tratamento para a peri-implantite & 48 \\
\hline 2.3.1 & Agentes químicos & 51 \\
\hline 2.3 .2 & Agentes físicos & 53 \\
\hline 2.4 & $\begin{array}{l}\text { A reosseointegração em superfícies modificadas por protocolos de } \\
\text { descontaminação }\end{array}$ & 56 \\
\hline 2.5 & Metodologias alternativas para modelos in vitro & 62 \\
\hline 3 & PROPOSIÇÃO & 65 \\
\hline 4 & MATERIAIS E MÉTODOS & 69 \\
\hline 4.1 & Obtenção e preparo dos microimplantes & 71 \\
\hline 4.2 & Cultura e inoculação de Escherichia coli (E. coli) & 73 \\
\hline 4.3 & Descontaminação de superfície & 74 \\
\hline 4.4 & Avaliação da contaminação e descontaminação bacteriana & 76 \\
\hline 4.5 & Espectroscopia de raios $X$ por dispersão em energia (EDS) & 78 \\
\hline 4.6 & Molhabilidade & 78 \\
\hline 4.7 & Microtopografia superficial & 79 \\
\hline 4.8 & Produção dos arcabouços impressos em 3D & 80 \\
\hline 4.9 & Preparo dos microimplantes para o ensaio de migração celular & 83 \\
\hline 4.10 & Ensaio de migração de pré-osteoblastos & 84 \\
\hline 4.11 & Análise estatística & 85 \\
\hline 5 & RESULTADOS & 87 \\
\hline 5.1 & Descontaminação & 89 \\
\hline 5.2 & Avaliação da composição química superficial & 93 \\
\hline 5.3 & Molhabilidade & 95 \\
\hline 5.4 & Rugosidade & 96 \\
\hline 5.5 & Migração celular & 100 \\
\hline 6 & DISCUSSÃO & 103 \\
\hline 7 & CONCLUSÃO & 117 \\
\hline 8 & REFERÊNCIA & 121 \\
\hline
\end{tabular}





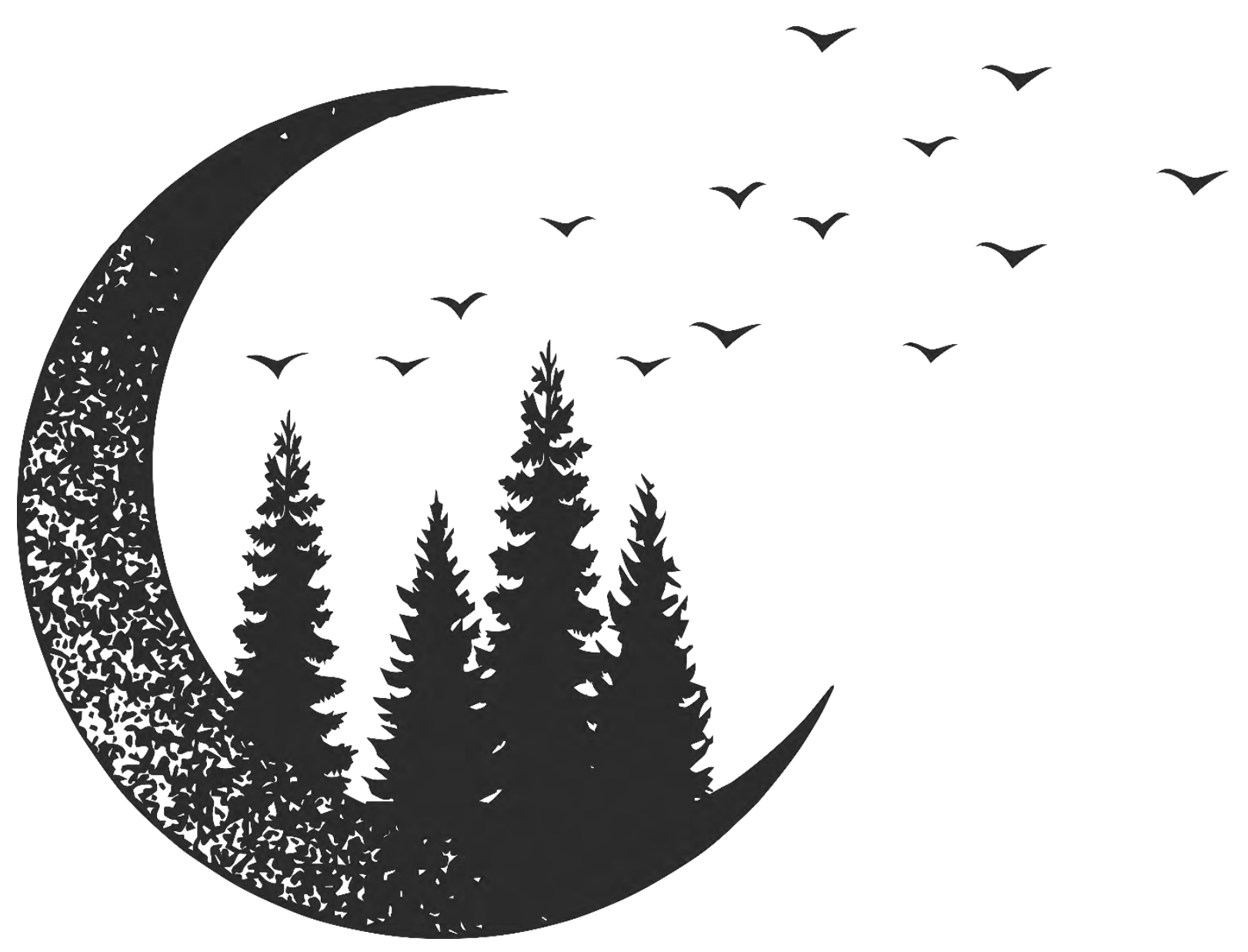

INTRODUCÁO 



\section{INTRODUÇÃO}

No século passado, a introdução dos implantes osseointegrados como alternativa para a reposição dentária revolucionou a maneira de encararmos a reabilitação oral. A aceitação crescente por este tipo de tratamento se deve em parte às altas taxas de sobrevivência dos implantes, observando-se valores entre 92,8 \% e 97,1 \% em controles de 10 anos (ALBREKTSSON; DONOS; WORKING, 2012; TING et al., 2018). No entanto, o conceito de sucesso de tratamento é mais amplo do que o a definição de sobrevivência, contamplando não só a manutenção do implante no sítio de instalação, mas também a preservação de uma saúde peri-implantar mesmo frente a constante exposição microbiana na cavidade bucal (DAUBERT; WEINSTEIN, 2019).

Já nos primeiros 30 minutos após a instalação de um implante, pode-se notar a formação de um biofilme em sua superfície (FURST et al., 2007; DAUBERT; WEINSTEIN, 2019). Esta formação ocorre de maneira diferente do observado na superfície dentária graças à influência de diferentes aspectos físicos e químicos da superfície do implante. Além disso, diferentes superfícies irão atuar de maneira única conforme sua rugosidade, composição química, pureza do titânio e energia livre superficial (DAUBERT; WEINSTEIN, 2019). Em consequência deste cenário, a perpetuação da presença do biofilme leva a um contínuo desafio bacteriano aos sítios peri-implantares que, combinado a uma resposta imunológica exacerbada, pode resultar na peri-implantite (MOMBELLI; LANG, 1994; HEITZ-MAYFIELD; LANG, 2010).

A peri-implantite é um processo mediado por uma rede de citocinas próinflamatórias que acomete os tecidos peri-implantares (SMEETS et al., 2014; SCHMINKE et al., 2015; WU, X. et al., 2019), levando à formação de bolsas, sangramento, supuração e perda de suporte ósseo (LINDHE; MEYLE; GROUP, 2008; RENVERT; POLYZOIS; MAGUIRE, 2009). A instalação e progressão deste quadro é diretamente dependente da presença de microrganismos, sendo notada predominantemente uma microbiota anaeróbica gram-negativa (MOMBELLI; LANG, 1998; LEONHARDT; RENVERT; DAHLEN, 1999; RENVERT; POLYZOIS; MAGUIRE, 2009). 
Atualmente, a peri-implantite tem sido razão de grande preocupação na rotina clínica. Um dos motivos é sua alta prevalência, atingindo cerca de 9,25\% dos implantes instalados e 19,83\% dos pacientes (LEE, C. T. et al., 2017). Contudo, estes valores podem estar super ou subestimados, visto que há uma falta de consenso entre os levantamentos epidemiológicos quanto aos critérios que determinam uma periimplantite (LEE, C. T. et al., 2017).

Alguns dos possíveis fatores que contribuem para estes valores expressivos de prevalência são o aumento na demanda por tratamentos envolvendo reabilitações com implantes dentários e o nível variado de treinamento dos profissionais que oferecem estes serviços (DAUBERT et al., 2015; DERKS et al., 2016; FLETCHER et al., 2017). Além disto, a noção de que implantes de superfícies rugosa favorecem a atividade osteoblástica e o processo de osseointegração levaram à maioria das empresas a oferecerem quase que exclusivamente implantes com este tipo de superfície em seus catálogos (BARFEIE; WILSON; REES, 2015). No entanto, é sabido que superfícies rugosas também favorecem o acúmulo de biofilme quando expostas ao meio bucal (BERMEJO et al., 2019), predispondo assim quadros de mucosite peri-implantar e peri-implantite (MADI et al., 2018).

Um segundo ponto que gera preocupação quanto ao aumento da prevalência da peri-implantite é a incerteza de qual o melhor tratamento para estes casos (TING et al., 2018). Devido às suas similaridades etiológicas com a doença periodontal, o que se observa é uma tendência pela utilização de protocolos baseados no tratamento da periodontite. No entanto, esta lógica não é precisa e uma transcrição direta dos resultados obtidos na descontaminação da superfície dentária não pode ser feita para a descontaminação de implantes (RENVERT; POLYZOIS; MAGUIRE, 2009). Assim, embora diferentes abordagens já tenham sido descritas na literatura, nenhuma é tida como a ideal (SMEETS et al., 2014; TING et al., 2018).

Um aspecto comum a todas estas modalidades de tratamento está na tentativa de controle da inflamação peri-implantar através da supressão bacteriana local, envolvendo tanto a remoção do biofilme quanto a descontaminação e condicionamento da superfície implantar (MOMBELLI, 2002). Para isto, na maioria dos casos um acesso cirúrgico à superfície do implante é necessário (RENVERT et al., 2019). Em seguida, para realizar a descontaminação, diversos métodos mecânicos e químicos já foram utilizados isoladamente ou em combinação, como o uso de curetas 
metálicas ou plásticas, pontas ultrassônicas, jateamento abrasivo, laser, implantoplastia, clorexidina, ácido cítrico, tetraciclina, ácido etilenodiamino tetraacético (EDTA), soro fisiológico, entre outros (DAUBERT; WEINSTEIN, 2019).

Contudo, embora realmente promovam a descontaminação com maior ou menor eficiência, estes tratamentos têm o potencial de alterar a superfície dos implantes ao promover ranhuras, derretimento e deposição química, influenciando na viabilidade do implante e na resposta celular (DAUBERT; WEINSTEIN, 2019). Assim, é de extrema importância compreender o impacto das técnicas de descontaminação e desintoxicação sobre a superfície do implante, visto que a eficácia do controle bacteriano de um protocolo não está diretamente relacionada a sua capacidade de restaurar a biocompatibilidade desta superfície (SCHWARZ et al., 2005; SCHWARZ et al., 2006a; KOTSAKIS et al., 2016).

O desfecho ideal do tratamento da peri-implantite é regenerar o osso perdido e obter reosseointegração entre a superfície do implante descontaminada e o novo osso formado. A reosseointegração pode ser definida como evidência histológica de novo contato entre osso e implante em uma superfície previamente contaminada (FLETCHER et al., 2017). O objetivo de se buscar a reosseointegração é propiciar uma maior estabilidade do nível ósseo a longo prazo, visto que o selamento promovido pelo tecido mole na interface com o implante é fraco, podendo ser clinicamente transcrito como um risco aumentado à inflamação (ATSUTA et al., 2016).

Devido à necessidade de evidência histológica, ensaios clínicos randomizados não podem verificar a ocorrência da reosseointegração. Como alternativa, muitos artigos avaliam o preenchimento do defeito ósseo por meio de imagens radiográficas ou cirurgias de reentrada como uma maneira de identificar a resposta óssea a diferentes protocolos de descontaminação e terapias regenerativas (SCHWARZ et al., 2013; FROUM; ROSEN, 2014). Contudo, estudos pré-clínicos (KOLONIDIS et al., 2003; PERSSON et al., 2004; ALHAG et al., 2008) e escassos relatos de caso (WOHLFAHRT et al., 2011; FLETCHER et al., 2017; KIM, S.; HU; JUNG, 2018) já demonstraram histologicamente a possibilidade de se obter reosseointegração de superfícies previamente contaminadas.

De acordo com estudos pré-clínicos sobre terapias regenerativas, a reosseointegração é um fenômeno imprevisível, ocorrendo em 1 a 84\% da área 
tratada e atingindo menos de 1,2 mm da altura do implante (ALHAG et al., 2008; RENVERT; POLYZOIS; MAGUIRE, 2009). Além disto, a reosseointegração não é alcançada em boa parte dos implantes, sendo comumente notada a presença de uma cápsula de tecido conjuntivo entre a superfície de titânio e o osso (PERSSON et al., 1999; SCHWARZ et al., 2006a). Por este motivo, o uso de estudos in vitro que buscam mimetizar aspectos do ambiente clínico são interessantes para compreender como as dinâmicas de contaminação e descontaminação podem impactar na biocompatibilidade da superfície do implante.

A realização de estudos pré-clínicos é imperativa para investigar como os tecidos peri-implantares interagem com a superfície descontaminada do implante antes de desenvolver estudos clínicos randomizados; no entanto, eles envolvem altos custos e preocupações éticas. Por este motivo, estudos in vitro são fundamentais para coletar informações preliminares que serão usadas para guiar a metodologia de futuros experimentos pré-clínicos, reduzindo o número de animais utilizados e o custo da investigação.

A metodologia proposta neste estudo busca criar um sistema mais fiel à apresentação física da interface osso-implante do que os protocolos utilizando discos de titânio. Fazendo uso deste sistema metodológico, o objetivo deste estudo foi avaliar qual protocolo de descontaminação está relacionado a maior migração de préosteoblastos partindo de um arcabouço impresso tridimensionalmente até a superfície descontaminada de microimplantes de titânio. Além disto, foi avaliado o potencial de descontaminação destes diferentes protocolos, bem como as mudanças de rugosidade, composição química e molhabilidade que promoveram nas superfícies tratadas. 
REVISÁO DE LITERATURA 



\section{REVISÃO DE LITERATURA}

\subsection{Saúde peri-implantar}

O advento dos implantes osseointegrados como alternativa reabilitadora revolucionou a abordagem direcionada ao tratamento de pacientes parcial ou totalmente edêntulos. A aceitação e popularização deste tipo de tratamento se deve em grande parte a sua alta previsibilidade, com níveis de sucesso na faixa dos $92,8 \%$ aos 97,1\% em controles de 10 anos (ALBREKTSSON; DONOS; WORKING, 2012; SRINIVASAN et al., 2014).

Histologicamente, o que se sabe sobre as características de um sítio periimplantar saudável é em sua maioria baseado em achados de estudos em animais. Do ponto de vista ósseo, um implante apresenta-se idealmente osseointegrado. Isto significa a presença de uma conexão estrutural e funcional direta entre osso vivo e a superfície carregada do implante (BRANEMARK et al., 1977).

Comparado ao tecido periodontal, é possível destacar um epitélio juncional comumente mais longo e a ausência de inserção de fibras do tecido conjuntivo ao longo do implante (BERGLUNDH et al., 2018). Além disto, há menor vascularização na região entre a margem óssea e o epitélio juncional, bem como uma redução no número de fibroblastos e a presença de fibras colágenas densamente compactadas (LIN; CHAN; WANG, 2013; BERGLUNDH et al., 2018).

A margem gengival ao redor do implante pode ser composta por mucosa ceratinizada ou não ceratinizada (WU, Q. et al., 2015). Nesta região, as fibras colágenas do tecido conjuntivo se posicionam paralelamente à superfície do implante, propiciando maior vulnerabilidade frente à inflamação induzida por placa (BERGLUNDH et al., 1991; BUSER et al., 1992). A presença de faixa de tecido ceratinizado pode atenuar este efeito, reduzindo a probabilidade de quadros de periimplantite (LIN; CHAN; WANG, 2013; WU, Q. et al., 2015).

Segundo Berglundh et al. (BERGLUNDH et al., 2018), um tecido periimplantar saudável é caracterizado pela ausência de eritema, sangramento a sondagem, tumefação e supuração. 


\subsection{Peri-implantite}

Atualmente sabe-se que a peri-implantite é uma doença multifatorial complexa, tendo vários fatores atrelados à perda óssea marginal. Dentre eles, é possível destacar a corrosão e os danos na superfície do implante, a sobrecarga oclusal e a presença de material cimentador no sulco gengival (FU; HSU; WANG, 2012; MOUHYI; DOHAN EHRENFEST; ALBREKTSSON, 2012; KORSCH; OBST; WALTHER, 2014). Contudo, há um consenso na literatura de que o acúmulo de biofilme seja o ponto chave para o estabelecimento da peri-implantite (MOMBELLI; LANG, 1994; HEITZ-MAYFIELD; LANG, 2010).

Desde sua instalação, o implante é exposto ao meio bucal e, com isto, a um constante desafio bacteriano. Isto pode ser facilmente exemplificado pelo fato de que nos primeiros 30 minutos após sua implantação, já é possível notar a formação do biofilme em sua superfície (FURST et al., 2007). Além disso, nas semanas seguintes pode-se notar o estabelecimento de microbiota associada à peri-implantite (VAN WINKELHOFF et al., 2000; QUIRYNEN et al., 2006). Contudo, é importante frisar que a formação do biofilme sobre a superfície implantar não corresponde a uma sequência de processos análogos às ocorridas na superfície dentária, visto que há diferenças físicas e químicas entre estes elementos (LANG; BERGLUNDH; WORKING GROUP 4 OF SEVENTH EUROPEAN WORKSHOP ON, 2011). De fato, características como a composição química, rugosidade e energia superficial podem levar a padrões de adesão bacteriana distintos até mesmo entre diferentes tipos de implante (HAN et al., 2016).

De modo geral, implantes com superfície rugosa tendem a uma maior formação de biofilme quando comparados a implantes lisos (ROMEO; GHISOLFI; CARMAGNOLA, 2004; QUIRYNEN et al., 2006; SUBRAMANI et al., 2009). Alguns autores, no entanto, ponderam que a condição periodontal influencia mais na qualidade do biofilme e na proporção de colonizadores iniciais do que as características da superfície do implante em si (MARTINEZ-HERNANDEZ; OLIVARES-NAVARRETE; ALMAGUER-FLORES, 2016). Contudo, vale ressaltar que ainda assim existem peculiaridades quanto à composição da microbiota peri-implantar quando comparada à periodontal (DAUBERT; WEINSTEIN, 2019). 
Em sítios peri-implantares saudáveis, o biofilme é colonizado predominantemente por cocos e bastonetes gram-positivos (FURST et al., 2007). Este perfil é alterado nas regiões de peri-implantite, apresentando em sua maioria uma colonização polimicrobiana gram-negativa anaeróbica facultativa ou estrita (CERBASI, 2010; CHARALAMPAKIS et al., 2012). Mesmo com muitos esforços sendo feitos para discriminar a composição bacteriana de biofilmes em sítios periimplantares saudáveis ou doentes, não há um consenso quanto a um tipo bacteriano isolado capaz de perturbar a microbiota peri-implantar e levar a um quadro de disbiose (DAUBERT; WEINSTEIN, 2019).

Outro aspecto do biofilme que merece atenção é sua capacidade de promover alterações eletro-condutivas na superfície do implante, levando à geração espontânea de eletricidade e corrosão do titânio (POZHITKOV et al., 2015; SRIDHAR et al., 2015). Este fenômeno pôde ser observado clinicamente por Safioti et al. (2017), quando coletaram o biofilme de 30 pacientes em 20 sítios com implantes saudáveis e 20 em regiões de peri-implantite. Ao fim do estudo, foram encontrados níveis de titânio quase oito vezes superiores no material oriundo das áreas doentes $(p=0,033)$.

Após a formação do biofilme sobre a superfície do implante, a periimplantite é desencadeada em decorrência de uma resposta imuno-inflamatória excessiva do hospedeiro (MOMBELLI; LANG, 1994; HEITZ-MAYFIELD; LANG, 2010). Frente ao desafio bacteriano ocasionado pelo biofilme, o sistema imune mobiliza neutrófilos, células $T$, células $B$ e macrófagos, induzindo uma resposta inflamatória local no sítio afetado (FERNANDES; GOMES, 2016). Em seguida, a manutenção da doença e a destruição tecidual é ocasionada por um desequilíbrio entre citocinas próinflamatórias e anti-inflamatórias (FERNANDES; GOMES, 2016). Somado a isto, a interação entre células imuno-inflamatórias e o tecido ósseo libera enzimas, subprodutos e citocinas relacionadas ao dano ósseo (CERBASI, 2010; FERNANDES; GOMES, 2016). Desta forma, este tecido peri-implantar torna-se caracterizado por uma vascularização intensa e a presença de infiltrado de células inflamatórias, como linfócitos, macrófagos e células plasmáticas, sendo constantemente acompanhado pela presença de defeitos ósseos circunferenciais (LINDHE et al., 1992; LEONHARDT; RENVERT; DAHLEN, 1999; PERSSON et al., 2001b).

Visto que a relação da peri-implantite com o acúmulo de placa é claro, seria lógico evitar o uso de implantes com superfícies favoráveis a esta adesão. No entanto, 
com a noção de que superfícies rugosas também favorecem a estabilidade primária, a atividade osteoblástica, a síntese da matriz extracelular e a mineralização óssea, houve uma mudança de paradigma na implantodontia que terminou por preconizar o uso quase que exclusivo deste tipo de superfície (ALBREKTSSON; WENNERBERG, 2004; GUTWEIN; WEBSTER, 2004; MEIRELLES et al., 2007). Para transformar a superfície de um implante liso em rugosa, são aplicados processos que resultam em alterações físico-químicas e que levam a modificações de rugosidade e tensão superficial, aumentando assim sua afinidade com o tecido ósseo (ALBREKTSSON; WENNERBERG, 2004; GUTWEIN; WEBSTER, 2004; WENNERBERG et al., 2011; SCHWARTZ-FILHO et al., 2012; BERMEJO et al., 2019). Em decorrência disto, atualmente, a maioria dos implantes encontrados nos catálogos das empresas apresentam superfícies rugosas (BARFEIE; WILSON; REES, 2015). Este uso quase que exclusivo de implantes rugosos pode ter parte na crescente prevalência da periimplantite observada atualmente (TARNOW, 2016). No entanto, os valores de prevalência ainda podem ser questionados pois são comuns na literatura discussões quanto a precisão dos estudos epidemiológicos envolvendo a peri-implantite.

Em sua revisão sistemática com metanálise sobre a prevalência da mucosite peri-implantar e da peri-implantite, Lee et al. (2017) destacaram as diferentes medidas entre a margem óssea e o limite coronal da porção intra-óssea do implante que os autores adotaram para definir um quadro de peri-implantite. Como esperado, concluíram que estas divergências podem mascarar os resultados dos levantamentos epidemiológicos. Esta falta de unidade entre os autores chega a atingir até mesmo os resultados de revisões sistemáticas, visto que os critérios de inclusão e exclusão adotados nestes artigo podem resultar na análise de pesquisas distintas.

Em seu estudo, Atieh et al. (2013) observaram a prevalência da periimplantite em $9,6 \%$ dos implantes e $18,8 \%$ dos pacientes, enquanto que a da mucosite peri-implantar em 30,7\% e em 63,4\%, respectivamente. Derks et al. (2015), por sua vez, encontraram uma prevalência de peri-implantite em $22 \%$ dos pacientes e de mucosite peri-implantar em 43\%. Já para Lee et al. (2017), foi observada a prevalência de peri-implantite em $9,25 \%$ dos implantes e $19,83 \%$ dos pacientes, e de muscosite peri-implantar em $29,48 \%$ dos implantes e $46,83 \%$ dos pacientes. 
Devido a essa divergência de definições, esforços têm sido feitos visando unificar conceitos para padronizar a linguagem e a produção científica. Segundo o último proceedings do Workshop Mundial para a Classificação das Doenças e Condições Periodontais e Peri-Implantares (BERGLUNDH et al., 2018) o diagnóstico da peri-implantite baseia-se na presença de sangramento e/ou supuração à sondagem, aumento da profundidade de sondagem quando comparado a exames anteriores e a presença de perda óssea superior àquela observada após o remodelamento inicial. Estes critérios deixam claro um ponto fraco da classificação, que é a necessidade de acesso aos achados clínicos e radiográficos de controles periódicos, o que muitas vezes não corresponde à rotina clínica. Nestes cenários, a peri-implantite pode ser baseada na presença de sangramento e/ou supuração à sondagem, profundidade de sondagem $\geq 6 \mathrm{~mm}$ e nível ósseo $\geq 3 \mathrm{~mm}$, apicalmente posicionado em relação a parte mais coronal da porção intra-óssea do implante.

Em uma recente revisão de revisões sistemáticas, Ting et al. (2018) elencaram alguns dos principais achados relacionados à peri-implantite, sendo:

1) A maior ocorrência de peri-implantite é após 5 anos de função;

2) Há maior ocorrência de peri-implantite em pacientes com periodontite agressiva, periodontite crônica e/ou com histórico de periodontite;

3) Há maior ocorrência de peri-implantite em fumantes;

4) Há maior liberação de IL-1 $1 \beta$ e TNF- $\alpha$ em sítios com peri-implantite;

5) O perfil microbiológico da peri-implantite é diferente do encontrado na periodontite;

6) O diabetes descompensado e as doenças cardiovasculares são doenças de risco para a peri-implantite, mas não a artrite reumatoide;

7) Qualquer intervenção não-cirúrgica, isolada ou não, apresenta resultados mais promissores do que apenas o debridamento;

8) O tratamento cirúrgico pode reduzir a profundidade de sondagem;

9) A regeneração óssea guiada é imprevisível no tratamento da periimplantite; 
10) Diferentes combinações de procedimentos para tratamentos cirúrgicos ou não-cirúrgicos podem ser efetivas no tratamento da peri-implantite;

11) Não há evidência de que uma opção terapêutica seja mais efetiva do que outra no tratamento da peri-implantite;

12) A implementação de terapia de controle em pacientes de risco é fundamental para reduzir a ocorrência de peri-implantite;

13) Mais estudos clínicos randomizados que adotem definições padronizadas de peri-implantite são necessários para avaliar todos as opções de intervenção.

\subsection{Opções de tratamento para a peri-implantite}

Embora uma variedade de abordagens já tenha sido descrita para o tratamento de peri-implantite, todas apresentam em comum o mesmo foco em controlar a inflamação a partir da descontaminação bacteriana e a detoxificação da superfície do implante (MADI et al., 2018). Para isto, Mombelli (2002) aponta a importância de cinco pontos na elaboração de terapias para resolução da periimplantite, sendo:

- Remoção e/ou perturbação do biofilme bacteriano na bolsa periimplantar;

- Descontaminação e condicionamento da superfície do implante;

- Remoção de sítios desfavoráveis a higienização oral;

- Estabelecimento de um regime de controle de placa efetivo;

- Regeneração e reosseointegração do implante descontaminado.

Assim, de forma ampla, duas grande ramificações englobam as possibilidade de tratamento da peri-implantite: a remoção do implante e início de um novo planejamento implantodôntico, ou a preservação do implante com a utilização de técnicas conservadoras, ressectivas ou regenerativas em conjunção com procedimentos de descontaminação da superfície implantar (RENVERT; POLYZOIS; MAGUIRE, 2009; MADI et al., 2018). Visto que esta tese se baseia nos efeitos da 
descontaminação da superfície de implantes, apenas a segunda via de tratamentos será abordada nesta revisão de literatura.

É possível dizer que as modalidades terapêuticas propostas para a descontaminação peri-implantar se baseiam em preceitos adotados para o controle da periodontite (RENVERT; ROOS-JANSAKER; CLAFFEY, 2008). Isto se deve às similaridades etiológicas e de progressão de ambas as doenças (RENVERT; POLYZOIS; MAGUIRE, 2009; SMEETS et al., 2014). No entanto, é impossível transcrever o sucesso e a previsibilidade de tratamento imposto à superfície radicular aos resultados que seriam obtidos com sua aplicação em implantes. Diferenças anatômicas óbvias, como a presença de roscas e rugosidade elevada, afastam o cenário clínico entre implantes e dentes. Além disto, a própria singularidade química apresenta sua influência (RENVERT; POLYZOIS; MAGUIRE, 2009). Assim, ao contrário do arsenal de possibilidades utilizado na debridação e biomodificação da superfície radicular, a seleção de técnicas para implantes deve ser considerada com mais cautela, visto que podem promover alterações na superfície ao riscar, derreter ou depositar resíduos sobre o implante, comprometendo sua biocompatibilidade (DAUBERT; WEINSTEIN, 2019).

Ao optar por preservar o implante em seu sítio de implantação, é possível englobar os tratamentos de controle da peri-implantite em dois grandes grupos, sendo um não-cirúrgico e outro cirúrgico (SUBRAMANI; WISMEIJER, 2012; MADI et al., 2018). Segundo Subramani et al. (2012), quatro pontos devem ser contemplados pelas terapias não-cirúrgicas, sendo:

1) A implementação de um efetivo controle de placa, que deverá ser rigorosamente adotado pelo paciente;

2) A utilização de meios mecânicos de debridamento, como curetas, pontas ultrassônicas, taças de borracha e pasta de polimento;

3) Adoção de um regime de bochechos diários com agentes antimicrobianos suplementados por uma aplicação local de géis ou soluções antibacterianas;

4) Utilização de antibioticoterapia sistêmica ou local utilizando dispositivos de liberação lenta. 
Embora as terapêuticas não-cirúrgicas sejam bem empregadas em quadros iniciais de peri-implantite, estudos demonstram que o tratamento cirúrgico apresenta resultados mais promissores, visto que a utilização de retalhos favorece o acesso e a descontaminação do sítio (CLAFFEY et al., 2008; RENVERT; ROOSJANSAKER; CLAFFEY, 2008). Roccuzzo et al. (2017) incluíram em sua revisão sistemática 20 ensaios clínicos randomizados com pelo menos 6 meses de controle e concluíram que as terapias não-cirúrgicas não foram úteis no tratamento de defeitos intraósseos, enquanto que a terapia cirúrgica facilitou o debridamento subgengival e reduziu a profundidade de sondagem. Ainda assim, um recente consenso da FDI (Federação Dentária Internacional) sugere a adoção inicial de uma terapia nãocirúrgica para permitir ao profissional avaliar a resposta cicatricial do tecido e o comprometimento do paciente em aderir ao regime de higiene bucal (RENVERT et al., 2019).

Os métodos cirúrgicos, por sua vez, podem envolver procedimentos ressectivos ou regenerativos. As técnicas ressectivas utilizam-se da ressecção óssea e reposicionamento de tecido mole a fim de reduzir a bolsa peri-implantar e favorecer a higienização do implante e do componente protético pelo paciente e pelo profissional (DAUBERT; WEINSTEIN, 2019). Por este motivo, são indicadas em sítios com pouca perda óssea a fim de não resultar em comprometimentos estéticos severos, como a exposição dad cinta metálica do implante (SUBRAMANI; WISMEIJER, 2012). Assim, em situações de maior perda óssea, procedimentos regenerativos são indicados. Independentemente da abordagem de escolha, o debridamento do defeito ósseo e a descontaminação do implante são necessários em ambos os casos (MADI et al., 2018). Ainda assim, terapias cirúrgicas também apresentam uma previsibilidade limitada, sendo observado por Leonhardt et al. (1999) em estudo clínico um sucesso de cerca de $60 \%$ dos casos tratados.

Para a descontaminação do implante, vários protocolos podem ser empregados, como a utilização de digluconato de clorexidina, ácido cítrico, jateamento com abrasivos, escovas rotatórias, laser, gazes embebidas ou não em solução antimicrobiana, entre outros (WETZEL et al., 1999; PERSSON et al., 2001b; PERSSON et al., 2001a; VALDERRAMA; WILSON, 2013; VALDERRAMA et al., 2014; TOMA et al., 2018). No entanto, não existe na literatura nenhum consenso sobre qual 
tratamento seja superior aos demais (ESPOSITO; GRUSOVIN; WORTHINGTON, 2012).

Algumas teorias que buscam justificar a baixa eficácia do tratamento da peri-implantite afirmam que o biofilme não é completamente removido de superfícies rugosas (DAUBERT; WEINSTEIN, 2019), sendo que mesmo um pequeno remanescente da contaminação pode reduzir a energia superficial do implante e comprometer a adesão celular (KASEMO, 1983; OLEFJORD; HANSSON, 1993; SENNERBY; LEKHOLM, 1993). Além disto, existe a sugestão de que haja uma formação rápida de um novo biofilme após sua remoção, podendo esse processo ser mais veloz do que o da cicatrização do tecido peri-implantar (DAUBERT; WEINSTEIN, 2019).

Outro argumento para justificar esta eficácia limitada é que apenas a descontaminação do implante não é o suficiente para a resolução da peri-implantite, sendo que os métodos utilizados para esta finalidade, tanto químicos quanto físicos, podem comprometer a biocompatibilidade do implante (SCHWARZ et al., 2006a; KOTSAKIS et al., 2016). Nos próximos tópicos desta revisão, serão exploradas as opções de tratamento avaliadas neste estudo bem como as possíveis modificações superficiais que podem inflingir aos implantes.

\subsubsection{Agentes químicos}

Muitos protocolos de descontaminação se baseiam na premissa básica da utilização de agentes antimicrobianos. Para isto, uma grande gama de soluções já foi avaliada, como a clorexidina, o ácido cítrico, o peróxido de hidrogênio, o ácido fosfórico e diversos antibióticos (MOMBELLI, 2002; SUBRAMANI; WISMEIJER, 2012; VALDERRAMA et al., 2014; TING et al., 2018).

A clorexidina é um dos agentes antimicrobianos mais utilizados na periodontia devido à sua eficácia contra periodontopatógenos (EICK et al., 2011), sendo também observado um potencial de descontaminação em implantes (GOSAU et al., 2010). Esta solução é uma bisbiguanida catiônica de amplo espectro antibacteriano, alta adsorção nos tecidos bucais, baixa toxicidade e ação bacteriostática contínua (GOSAU et al., 2010). Seu uso na Odontologia é justificável 
por reduzir a formação do biofilme, comprometer a adesão bacteriana aos tecidos bucais e induzir a lise das bactérias (FIORELLINI; PAQUETTE, 1992). Este fenômeno se dá pelo aumento da permeabilidade da membrana celular bacteriana acompanhado pela coagulação das macromoléculas citoplasmáticas intracelulares (GOFFIN, 1998).

Embora apresente baixa citotoxicidade, o efeito da clorexidina é influenciado pela sua concentração e tempo de exposição. Deste modo, quando em concentrações altas ou longa exposição, ela pode afetar a viabilidade de osteoblastos ao inibir a proliferação celular e a síntese de colágeno, aumentar o $\mathrm{Ca}^{2+}$ intracelular, aumentar o stress oxidativo, perturbar a função mitocondrial e induzir a morte celular (GIANNELLI et al., 2008; LEE, T. H. et al., 2010). No entanto, Verdugo et al. (2011) não observaram alterações fenotípicas ou citotoxicidade em osteoblastos expostos à clorexidina $0,2 \%$ por 1 minuto e clorexidina $1 \%$ por 30 segundos.

Ao utilizar a clorexidina como material de irrigação ou meio de imersão, resultados de moderada ou baixa descontaminação costumam ser observados (KOBAN et al., 2011; NTROUKA et al., 2011; KOTSAKIS et al., 2016; ROMANOS et al., 2016). Embora alguns autores sugiram que não haja diferença na eficácia do uso da clorexidina em superfícies lisas ou rugosas (NTROUKA et al., 2011), outros sugerem que a presença de depressões e micro-fossas nas superfícies rugosas pode prejudicar o desempenho da solução ao dificultar seu acesso às bactérias (CAl et al., 2019).

Outro agente químico explorado no tratamento da peri-implantite é o EDTA (WOHLFAHRT et al., 2012; MACHTEl et al., 2016). O uso do EDTA na Odontologia se baseia principalmente em seu potencial quelante, sendo aplicado em procedimentos regenerativos para a remoção de smear layer antes da utilização de biomateriais (BHUTDA; DEO, 2013). Em estudo pré-clínico em cães, Machtei et al. (2016) utilizaram EDTA 24\% para descontaminar implantes previamente induzidos à peri-implantite por meio de ligaduras. O método demonstrou relativa eficácia, visto que após 3 meses foi observada nova formação óssea em todos os grupos experimentais e controle. Por usa vez, Wohlfahrt et al. (2012) conduziram um estudo clínico randomizado onde realizaram procedimentos regenerativos em 32 sítios previamente com peri-implantite. Estes implantes tiveram suas superfícies debridadas com curetas de titânio e receberam uma aplicação de EDTA $24 \%$ por 2 minutos, seguida por 
lavagem com soro fisiológico. Após 12 meses, este protocolo levou a uma redução média de 2,6 $\mathrm{mm}$ da profundidade de sondagem. Por outro lado, outros estudos apontam para uma ineficácia no uso do EDTA como agente antimicrobiano (ARWEILER et al., 2002; NTROUKA et al., 2011; HENDERSON et al., 2013), contraindicando seu uso em casos de peri-implantite.

Embora o uso de agentes químicos antimicrobianos seja capaz de reduzir a carga bacteriana, aparentemente ele não é efetivo sem a associação com um debridamento mecânico (HALLMON; REES, 2003; GOSAU et al., 2010; KRAYER; LEITE; KIRKWOOD, 2010). Isto porque o debridamento mecânico combinado à utilização de agentes químicos pode auxiliar na remoção de cálculo, biofilme e tecido de granulação, criando um efeito sinérgico entre as abordagens (SUBRAMANI; WISMEIJER, 2012).

\section{$\underline{\text { 2.3.1 Agentes físicos }}$}

A utilização de abordagens físicas busca perturbar a organização do biofilme mecanicamente como forma de descontaminar a superfície do implante. Para isto, alguns autores recomendam o uso de curetas plásticas, de carbono ou de resina pois elas não geram danos significativos à superfície dos implantes (RUHLING et al., 1994; AUGTHUN; TINSCHERT; HUBER, 1998; MENGEL et al., 1998; VALDERRAMA; WILSON, 2013). Contudo, também é observada uma ineficácia na remoção do biofilme com esta abordagem (AUGTHUN; TINSCHERT; HUBER, 1998). Toma et al. (2018) não observaram diferença no volume de biomassa encontrado em discos tratados com curetas plásticas comparado a discos não descontaminados. Além disso, embora não promovam ranhuras na superfície, Louropoulou et al. (2015) observaram a deposição de material plástico nos implantes após a raspagem de superfícies rugosas. De forma semelhante, Yang et al. (2015) também observaram a deposição de detritos recobrindo entre $10 \%$ a 20\% das superfícies avaliadas.

Ao contrário das curetas plásticas ou de titânio, a utilização de curetas metálicas pode danificar o implante ao aplainar superfícies, criar ranhuras e remover arestas e irregularidades (RUHLING et al., 1994; MENGEL et al., 1998; HALLMON; REES, 2003). Mengel et al. (1998) observaram remoção de 0,83 $\mu \mathrm{m}$ de material superficial após utilizar curetas metálicas por 20 segundos, em comparação aos 
$0,19 \mu$ m observados com o uso de curetas de titânio e ultrassom com pontas plásticas. Alguns autores afirmam que modificações superficiais que reduzam a rugosidade podem ter caráter benéfico ao diminuir o potencial de adesão bacteriana ao implante (DUARTE et al., 2009). Por outro lado, outros pesquisadores também supõem que a presença de ranhuras pode facilitar a colonização bacteriana (SUBRAMANI; WISMEIJER, 2012). De qualquer modo, mesmo apresentando melhor desempenho que as curetas plásticas, a utilização de curetas metálicas parece ter um potencial limitado de descontaminação devido ao acesso prejudicado pelo formato das roscas e a rugosidade das superfícies (AUGTHUN; TINSCHERT; HUBER, 1998; CHARALAMPAKIS et al., 2012; VALDERRAMA; WILSON, 2013).

Buscando por um método mecânico efetivo e que não levasse a modificações drásticas de superfície, alguns autores investigaram o uso de escovas de titânio. Toma et al. (TOMA et al., 2018) não encontraram mudanças na rugosidade de discos tratados com escovas de titânio, embora ranhuras pudessem ser observadas nas imagens de microscopia eletrônica de varredura. Este resultado está de acordo com o observado por outros autores (JOHN; BECKER; SCHWARZ, 2014), sugerindo que a técnica é uma alternativa que contempla tanto a descontaminação quanto a preservação da integridade superficial do implante. Além disto, a associação do uso de escovas de titânio com outros métodos, como a terapia fotodinâmica antimicrobiana, parece ser benéfica (WIDODO et al., 2016).

Outra técnica que vem sendo constantemente investigada por conta de seus princípios lógicos para o controle da peri-implantite é a implantoplastia (ROMEO et al., 2005; ROMEO et al., 2009; MATARASSO et al., 2014; SCHWARZ et al., 2017; SAFFARPOUR et al., 2018). O objetivo da implantoplastia é aplainar a superfície do implante a partir da remoção de suas roscas e polimento de sua superfície em regiões de defeitos ósseos com potencial limitado de regeneração (SAFFARPOUR et al., 2018). Desta forma, a superfície resultante é descontaminada e ao mesmo tempo se torna menos propensa ao acúmulo de biofilme (RAMEL et al., 2016), visto que superfícies lisas não favorecem esta adesão (ROMEO; GHISOLFI; CARMAGNOLA, 2004; QUIRYNEN et al., 2006; SUBRAMANI et al., 2009). Segundo observado por Toma et al. (2018) a rugosidade obtida após a implantoplastia de discos de Ti pode ser inferior até mesmo que a de discos lisos que não receberam nenhuma intervenção. 
No entanto, esta é uma técnica sensível e está sujeita a uma série de complicações, como a destruição da conexão pilar-implante, o enfraquecimento estrutural do implante, o superaquecimento dos tecidos peri-implantares, o risco aumentado de reações inflamatórias tardias por causa da deposição de detritos nos tecidos peri-implantares e a pigmentação da mucosa em decorrência destas partículas (AUGTHUN; TINSCHERT; HUBER, 1998; ROMEO et al., 2005; SHARON et al., 2013; STAVROPOULOS et al., 2019). Alguns achados histológicos descreveram uma deposição de leve a moderada de partículas de Ti nos tecidos peri-implantares, estando associado a um infiltrado de células inflamatórias crônico (SCHWARZ et al., 2011a). Embora seja esperada a deposição de detritos nos tecidos circundantes, não se sabe efetivamente quais efeitos adversos podem decorrer disto (AUGTHUN; TINSCHERT; HUBER, 1998; SCHWARZ et al., 2011a; VALDERRAMA; WILSON, 2013). Outra incógnita é se a superfície desgastada do implante irá formar nova camada de óxidos ou não (VALDERRAMA; WILSON, 2013).

Várias metodologias já foram utilizadas para realizar a implantoplastia, não existindo um consenso quanto a quais brocas e qual sequência utilizar (VALDERRAMA; WILSON, 2013; RAMEL et al., 2016). Contudo, a qualidade das brocas diamantadas, os tipos de pontas de polimento utilizadas e a sequência de aplicação destes componentes pode afetar o grau de polimento obtido com o tratamento (RAMEL et al., 2016; TOMA et al., 2018).

Esta técnica demonstrou-se uma alternativa biologicamente viável para 0 tratamento de implantes com exposição de roscas (SCHWARZ; JOHN; BECKER, 2017), porém as informações quanto ao seu desempenho clínico a longo prazo ainda são limitadas (STAVROPOULOS et al., 2019). Da mesma forma que observado com o uso de escovas de titânio, Toma et al. (2018) observaram uma presença estatisticamente inferior de biofilme nos discos de Ti que receberam implantoplastia quando comparado aos grupos tratados com curetas plásticas e discos não descontaminados, resultante da remoção de grande parte do biofilme.

Buscando abordagem mais simples e menos agressivas ao implante, alguns pesquisadores observaram o potencial de descontaminação no uso de gazes embebidas em soro fisiológico ou agentes antimicrobianos (SCHOU et al., 2003; PERSSON et al., 2004; YOU et al., 2007; SCHWARZ et al., 2011a). Persson et al. (2004) compararam o efeito do uso de laser de $\mathrm{CO}_{2}$ conjugado a $\mathrm{H}_{2} \mathrm{O}_{2}$ com os 
resultados obtidos apenas com o debridamento com algodão embebido em soro fisiológico. Ao fim do estudo, não foram observadas diferenças estatísticas entre os grupos. Com isto, é possível sugerir que a simples fricção entre implante e gaze é o suficiente para induzir a remoção bacteriana, sendo uma vantagem a sua fácil adaptação à macrotopografia do implante. Suarez et al. (2013) também encontraram valores de lipopolisacarídeos estatisticamente inferiores na superfície de implantes limpos por 1 minuto em gazes embebidas em soro fisiológico do que implantes não descontaminados.

Tendo em vista os resultados favoráveis obtidos com a friç̧ão de gazes embebidas em algo sem princípios antibacterianos, parece sensato inferir um efeito benéfico na associação deste debridamento mecânico com um agente antimicrobiano, como a clorexidina (SCHOU et al., 2003; SCHWARZ et al., 2005; SCHWARZ et al., 2006a). Desta forma, o uso de gazes embebidas em agentes antimicrobianos tem apresentado bons resultados em muitos estudos, sendo capaz de reduzir a carga bacteriana dependendo da solução selecionada e do tipo de superfície de implante tratado (PERSSON et al., 1999; SCHOU et al., 2003; SUBRAMANI; WISMEIJER, 2012; VALDERRAMA; WILSON, 2013).

\subsection{A reosseointegração em superfícies modificadas por protocolos de descontaminação}

A reosseointegração pode ser definida como uma evidência histológica de contato direto entre o osso e a superfície de um implante previamente contaminado, sem interposição de tecido mole (FLETCHER et al., 2017). O objetivo final do tratamento da peri-implantite não é apenas o preenchimento do defeito ósseo, mas também a reosseointegração da superfície tratada (KIM, S.; HU; JUNG, 2018). Isto se justifica pelo fato de que sem a reosseointegração há uma maior probabilidade de recorrência da peri-implantite (SUBRAMANI; WISMEIJER, 2012), visto que o selamento com tecido mole corresponde a uma interface fraca e predisposta à inflamação (ATSUTA et al., 2016).

De maneira análoga à osseointegração, implantes rugosos apresentaram melhor desempenho na reosseointegração do que os lisos (WETZEL et al., 1999; SHIBLI et al., 2003; PERSSON et al., 2004; SENNERBY et al., 2005). Persson et al. 
(PERSSON et al., 2001b) sugeriu que a reosseointegração era mais facilmente obtida em superfícies rugosas pois elas fornecem melhor suporte para o coágulo após a cirurgia e facilitam a adesão osteoblástica durante o processo cicatricial.

Como mencionado anteriormente, alguns procedimentos de descontaminação, em especial as abordagens físicas como a implantoplastia ou o uso de curetas metálicas, modificam a rugosidade superficial do implante. Uma maior rugosidade favorece a diferenciação e migração de osteoblastos, bem como a produção da matriz óssea (NOVAES et al., 2010; GARG; BEDI; GARG, 2012; NADDEO et al., 2015), porém também é um fator crítico na formação e manutenção do biofilme (ZHAO et al., 2005; MELLADO-VALERO et al., 2013). Isto é justificado pelo fato de que superfícies rugosas fornecem maior área superficial e nichos para o acúmulo do biofilme, evitando a ação de forças mecânicas durante o processo inicial de adesão (QUIRYNEN et al., 2006). Por outro lado, superfícies lisas são mais favoráveis às células epiteliais e fibroblastos (KONONEN et al., 1992). Este raciocínio é importante pois, com isto, é possível afirmar que as mudanças microtopográficas promovidas pelos processos de descontaminação podem influenciar o tipo de tecido que será formado ao redor do implante após o procedimento regenerativo (NADDEO et al., 2015). Por este motivo, protocolos de descontaminação que preservem a rugosidade do implante são interessantes.

Após a descontaminação, várias abordagens com ou sem o uso de exertos ósseos e membranas foram testadas para se conseguir uma reosseointegração, porém os resultados geralmente não foram eficazes (MADI et al., 2018). Inicialmente especulou-se que a reosseointegração de um implante previamente contaminado era impossível (ERICSSON et al., 1996; PERSSON et al., 1996; PERSSON et al., 1999), porém o fenômeno já foi observado em modelos animais, atingindo uma alta variabilidade e ocorrendo em 1 \% a 84 \% da área tratada (PERSSON et al., 2004; SCHWARZ et al., 2006b). Comumente, o que se observa é um crescimento ósseo na região periférica do defeito (ERICSSON et al., 1996; PERSSON et al., 1996; HANISCH et al., 1997; PERSSON et al., 1999), sendo aparentemente limitado verticalmente a 1,2 $\mathrm{mm}$ do implante (PERSSON et al., 2004).

Visto que a constatação de reosseointegração depende de achados histológicos, estudos em humanos constantemente utilizam o preenchimento do defeito ósseo observado radiograficamente ou em cirurgias de reentrada como 
parâmetro para avaliar a resposta óssea ao tratamento avaliado. Ainda assim, é importante destacar que o preenchimento do defeito não corresponde necessariamente à reosseointegração, visto que frequentemente foi observada a formação de uma cápsula de tecido conjuntivo interposta entre tecido ósseo e implante (PERSSON et al., 1999; SCHWARZ et al., 2006b).

Acredita-se que a dificuldade em se obter uma reosseointegração se deva à presença de bactérias e/ou seus subprodutos na superfície do implante (VALDERRAMA; WILSON, 2013). Por este motivo, além de descontaminar a superfície do implante, também é necessário detoxificá-la a fim de recuperar a sua biocompatibilidade. $\mathrm{Na}$ presença de um microambiente imunoinflamatório, foi observado comprometimento da atividade dos osteoblastos que inibiu o processo de reosseointegração (MATZELLE et al., 2012). Isto pode ser ilustrado pelo fato de que vários estudos obtiveram a eliminação da inflamação e o preenchimento do defeito ósseo com sucesso, mas ainda assim conseguiram péssimos resultados quanto à reosseointegração (ERICSSON et al., 1996; PERSSON et al., 1996; PERSSON et al., 1999; PERSSON et al., 2001a). Por este motivo, há necessidade de melhor compreensão dos fatores que regem o sucesso da reosseointegração além da descontaminação da superfície (RENVERT; POLYZOIS; MAGUIRE, 2009).

Atualmente sabe-se que as alterações superficiais promovidas pelos procedimentos de descontaminação podem comprometer a resposta biológica dos tecidos peri-implantares durante o processo de cicatrização (MOUHYI et al., 1998; SCHWARZ et al., 2005; SCHWARZ et al., 2006a; KONSTANTINIDIS et al., 2015; LOUROPOULOU; SLOT; VAN DER WEIJDEN, 2015; WHEELIS et al., 2016). Por este motivo, não é possível predizer a resposta biológica após a descontaminação superficial baseado unicamente na efetividade da remoção bacteriana (SCHWARZ et al., 2005; SCHWARZ et al., 2006a).

Como mencionado, todo tratamento da peri-implantite se baseia no princípio de que a doença seria desencadeada pela presença bacteriana no biofilme aderido à superfície do implante (SUBRAMANI; WISMEIJER, 2012). Deste modo, a molhabilidade, a composição química e a rugosidade superficial são pontos que merecem consideração, visto que apresentam impacto na formação deste biofilme (SUBRAMANI et al., 2009). Por este motivo, as modificações dessas características 
após o tratamento de descontaminação são importantes quando pensamos que elas podem favorecer a instalação de um novo biofilme.

A molhabilidade, avaliada pelo ângulo de contato de um líquido com a superfície do implante, influencia a formação e desenvolvimento do biofilme (TOMA et al., 2018), sendo que essa formação é prejudicada em superfícies mais hidrofílicas (OKADA et al., 2008). Isto ocorre porque as bactérias colonizam mais facilmente superfícies hidrofóbicas e não polares (TEUGHELS et al., 2006). Além disto, a hidrofilicidade do implante pode acelerar a osseointegração e influenciar positivamente na área de contato osso-implante (BIC) (RUPP et al., 2006; SCHWARZ et al., 2009; DONOS et al., 2011; LANG et al., 2011; SARTORETTO et al., 2015). Por este motivo, parece prudente evitar protocolos que reduzam a hidrofilia do implante.

Uma propriedade interessante que favorece o uso do Ti na implantodontia seria a presença de uma camada de óxidos que é naturalmente formada em sua superfície na presença de ar ou meio aquoso (SWAMINATHAN; GILBERT, 2012). Esta camada previne a ocorrência de corrosão na superfície e contribuiu com a rugosidade superficial do implante (WHEELIS et al., 2016). A utilização de soluções ácidas pode levar à delaminação e fresagem química desta camada de óxido (SUITO et al., 2013). Com o aumento de íons $\mathrm{H}^{+}$no meio, é desencadeado um processo de oxidação da superfície do implante (SATO, N., 1989). Visualmente, a camada oxidada do Ti apresenta uma cor violácea devido à presença do estado oxidado trivalente $\left(\mathrm{Ti}^{3+}\right)$, sendo convertido para um tom amarelado quando alterado para o estado oxidado tetravalente $\left(\mathrm{Ti}^{4+}\right.$ ) (WHEELIS et al., 2016). Assim, mudanças na coloração poderiam ser um sinal indicativo de corrosão (SWAMINATHAN; GILBERT, 2012; WHEELIS et al., 2016).

Devido ao seu pH de aproximadamente 5, o uso da clorexidina pode mostrar sinais de danos à camada de óxido do implante (WHEELIS et al., 2016). Esta corrosão pode ser potencializada pelo efeito sinergético da ativação mecânica junto à exposição ao ácido, como no caso de fricção de gazes com soluções ácidas (RODRIGUES et al., 2009; WHEELIS et al., 2016). Isto ocorre porque a aplicação contínua de forças mecânicas prejudica o processo de repassivação da camada de óxido (MATHEW et al., 2012; SUITO et al., 2013; WHEELIS et al., 2016). Com a corrosão do implante, alguns autores sugeriram que a dissolução de íons metálicos poderia favorecer a ocorrência de mucosite peri-implantar e peri-implantite ao induzir 
a inflamação (RODRIGUES et al., 2013; WILSON; VALDERRAMA; RODRIGUES, 2014). Esta dinâmica também foi observada por Bhola et al. (BHOLA, R. et al., 2011; BHOLA, S. M. et al., 2013), que concluíram que essa corrosão da superfície de titânio aumentava com o tempo de exposição.

Outra modificação superficial que merece atenção é a presença de detritos na superfície do implante após procedimentos de descontaminação. Estes detritos poderiam inibir a adesão de citocinas e células, interferindo na reosseointegração (LOUROPOULOU; SLOT; VAN DER WEIJDEN, 2015; YANG; PARK; KO, 2015; LEE, J. B. et al., 2019). Possivelmente a deposição de detritos plásticos e a baixa eficácia na descontaminação foram responsáveis por curetas plásticas apresentarem baixos níveis de reosseointegração, mesmo quando associado ao uso de metronidazol em gel (SCHWARZ et al., 2006b; LOUROPOULOU; SLOT; VAN DER WEIJDEN, 2015; YANG; PARK; KO, 2015).

De forma semelhante, a deposição química superficial poderia prejudicar a adesão celular, comprometendo a biocompatibilidade do implante (MOUHYI et al., 1998; SCHWARZ et al., 2003; LOUROPOULOU; SLOT; VAN DER WEIJDEN, 2015). Krozer et al. (1999) observaram em estudos in-vitro a formação de uma película densa e estável com 7 a $10 \mathrm{~nm}$ na superfície do implante após o uso de agentes antimicrobianos, sugerindo que sua presença possa comprometer a formação óssea na região. Dentre os agentes químicos testados por Kotsakis et al. (2016), a clorexidina foi a responsável pelo maior impacto na biocompatibilidade do implante após sua descontaminação. A citotoxicidade da clorexidina também foi explorada por outros grupos, sendo os resultados encontrados semelhantes (GIANNELLI et al., 2008; LEE, T. H. et al., 2010). Este efeito adverso possivelmente decorreu da adsorção da clorexidina na superfície do implante, resultando em liberação gradual nos tecidos adjacentes (KOZLOVSKY et al., 2006; RYU et al., 2015).

Esta substantividade foi bem ilustrada por alguns estudos, que encontraram considerável deposição de elementos residuais da clorexidina na superfície do implante após o seu uso (KOZLOVSKY et al., 2006; KOTSAKIS et al., 2016). Contudo, Kotsakis et al. (KOTSAKIS et al., 2016) destacaram que o impacto na atividade celular se deu em sua proliferação, mas as células que proliferaram apresentaram atividade e fenótipo celular semelhante ao grupo controle. Vale destacar que a irrigação após o 
uso da clorexidina não é capaz de evitar sua adsorção ao titânio (KOZLOVSKY et al., 2006).

Embora não seja possível avaliar a reosseointegração em estudos clínicos randomizados, alguns artigos demonstraram sucesso no preenchimento de defeitos ósseos em sítios de peri-implantite através da descontaminação com clorexidina seguida por regeneração óssea guiada. Lehmann et al. (LEHMANN et al., 1992) observaram ganho de 4 a 5 mm após 5 meses da remoção da membrana. Hammerle et al. (HAMMERLE et al., 1995) também obtiveram sucesso com essa abordagem, mesmo o ganho sendo reduzido para 1,5 a 3,6 mm após 1 ano da remoção da membrana. Estes resultados estão de acordo com o observado por outros estudos que obtiveram a reosseointegração após o uso de clorexidina previamente a um procedimento regenerativo (WETZEL et al., 1999; YOU et al., 2007).

Alguns estudos indicaram que o debridamento do sítio com peri-implantite apenas com gaze embebidas soro fisiológico poderia aumentar o potencial de reosseointegração. Segundo Persson et al. (PERSSON et al., 1999), 64 \% de regeneração foi obtida após o debridamento de implantes com algodão embebido em soro fisiológico. Já em outros estudos, este valor atingiu o valor de 85\% (PERSSON et al., 2001a; PERSSON et al., 2004).

Variados estudos utilizaram solução salina para a descontaminação do implante e encontraram níveis de reosseointegração semelhante aos outros grupos experimentais (KOLONIDIS et al., 2003; PERSSON et al., 2004; ALHAG et al., 2008). Em estudo pré-clínico com cães, Persson et al. (PERSSON et al., 2004) compararam o tratamento de sítios com peri-implantite utilizando uma combinação de laser de $\mathrm{CO}_{2}$ com $\mathrm{H}_{2} \mathrm{O}_{2}$ e outro grupo experimental utilizando algodão embebido em soro fisiológico. Foi observado entre os grupos valores semelhantes de BIC, medidas histométricas e medidas morfométricas do tecido ósseo peri-implantar. Além disso, a porcentagem de reosseointegração em implantes lisos e rugosos foi de $21 \%$ e 82 \% quando utilizado o laser de $\mathrm{CO}_{2} \mathrm{com} \mathrm{H}_{2} \mathrm{O}_{2}$, e $22 \%$ e $84 \%$ quando utilizado o algodão embebido em soro fisiológico, demonstrando a eficácia desta técnica. Em outros estudos, foi feita a associação do uso de algodão embebido em soro fisiológico com antibioticoterapia sistêmica, sendo prescrito metronidazol com amoxicilina por 17 dias (PERSSON et al., 1999; PERSSON et al., 2004). Como resultado, observaram a reosseointegração 
tanto em implantes lisos quanto em rugosos, sendo significantemente superior nos últimos.

\subsection{Metodologias alternativas para modelos in vitro}

Alguns autores estipulam que haja no mercado mais de 1.300 diferentes tipos de implantes, possuindo variadas formas, dimensões, materiais, geometria de conexão e características superficiais (ESPOSITO; ARDEBILI; WORTHINGTON, 2014). Ainda assim, estes valores provavelmente estão subestimados, visto que não há levantamentos mais recentes disponíveis. É válido destacar que estes números merecem atenção pois, como já mencionado nesta revisão, diferentes superfícies de implante podem reagir de maneira singular quando expostas a um mesmo protocolo de descontaminação. Por isto, embora os resultados de uma pesquisa avaliando uma determinada superfície sirvam de parâmetro para os resultados esperados em superfícies similares, é aconselhável que cada tipo implante seja devidamente testado. Ao associar este fato a grande gama de protocolos de descontaminação disponíveis para avaliação, podemos concluir que há a necessidade de um enorme número de experimentos.

Em uma revisão sobre estudos in vitro focados no tratamento da periimplantite, Benli et al. (2019) concluíram que usualmente são utilizados como corpo de prova discos de titânio, implantes e superfícies de titânio. Estas superfícies são contaminadas por diferentes tipos de biofilme ou bactérias planctônicas, como a Aggregatibacter actinomycetemcomitans, Porphyromonas gingivalis, Streptococcus oralis, Escherichia coli, Actinomyces viscosus, Staphyloccus aureus, Treponema denticola, entre outras (BENLI et al., 2019). Embora apresente suas vantagens, a utilização de discos de titânio não consegue mimetizar morfologicamente o desafio clínico. Outra limitação nestas metodologias é que depositar células ósseas sobre uma superfície horizontal não corresponde à condição clínica. Por este motivo, a utilização de métodos de engenharia de tecidos para a confecção de arcabouços que possam replicar a interface osso-implante parece uma opção interessante.

Um ponto chave da engenharia de tecido ósseo é a utilização de arcabouços. Estas estruturas podem mimetizar a matriz extracelular do osso nativo, fornecendo um meio favorável para a adesão e proliferação celular (BRUNELLO et 
al., 2016). Idealmente, este material deve ser biocompativel, osteocondutivo, biomimético e possuir propriedades mecânicas adequadas (ASADI-EYDIVAND et al., 2016).

Várias técnicas já foram empregadas na produção de arcabouços, como a lixiviação de sais, evaporação de solvente, colagem de fibras, processos de separação de fase e laminação de membrana, mas nenhum método controla por completo as propriedades estruturais, porosidade e reprodutividade do material (LEE, S. J. et al., 2016). Além disto, utilizam solventes orgânicos que podem influenciar negativamente a proliferação e diferenciação celular (LEE, S. J. et al., 2016). A fim de superar estes obstáculos, métodos de manufatura aditiva estão sendo cada vez mais utilizados.

Vários processos de produção constituem formas de manufatura aditiva, dentre elas a impressão 3D, a esterolitografia, a fusão e deposição de material e a sinterização a laser seletivo (BRUNELLO et al., 2016). O processo de manufatura aditiva é caracterizado pela fabricação de uma estrutura sólida em camadas sobrepostas a partir de um modelo digital. Estas camadas são formadas por meio de deposição extrusiva, solidificação, polimerização, sinterização ou colagem do material (SEARS et al., 2016). Além disto, estas técnicas permitem que o operador determine com precisão o tamanho e configuração dos poros, criando uma porosidade superficial controlada e interconectada, elevando assim a área superficial, a adesão de osteoblastos, a penetração celular, a difusão de nutrientes, a adesão e adsorção de proteínas e biofatores e também propiciando uma melhor organização espacial para o crescimento celular e produção da matriz extracelular (FINI et al., 2003; SATO, M.; WEBSTER, 2006). Poros com diâmetro entre $150 \mu \mathrm{m}$ e $500 \mu \mathrm{m}$ parecem ser 0 tamanho ideal para manter estas propriedades e não comprometer a força mecânica do arcabouço (MUSCHLER; NAKAMOTO; GRIFFITH, 2004; AMINI; LAURENCIN; NUKAVARAPU, 2012).

Devido às similaridades químicas com a fase mineral do tecido ósseo, os fosfatos de cálcio, como a hidroxiapatita e o $\beta$-fosfato tricálcio, são bastante empregados na regeneração óssea (COX et al., 2015). Também são um material atraente devido à sua grande disponibilidade, bioatividade, biocompatibilidade, hidrofilicidade e osteocondução (WOODARD et al., 2007). Contudo, sua estrutura é frágil, de pouca maleabilidade e fraca força mecânica (HENCH, 1991; KIM, H. W. et al., 2005). Por 
este motivo, é comum a combinação de dois ou mais materiais para se conseguir um efeito sinergético (ASA'AD et al., 2016). Polímeros biodegradáveis constantemente são utilizados com esta finalidade junto às biocerâmicas. Sua eleição é decorrente de sua alta biocompatibilidade, bom reconhecimento celular, interações celulares melhoradas e hidrofilicidade (NAIR; LAURENCIN, 2007; EL-SHERBINY; YACOUB, 2013). Dentre estes polímeros, o poliuretano parace ser um bom candidato para estudos celulares, mostrando boa biocompatibilidade e propriedades mecânicas (SHIE et al., 2017). 


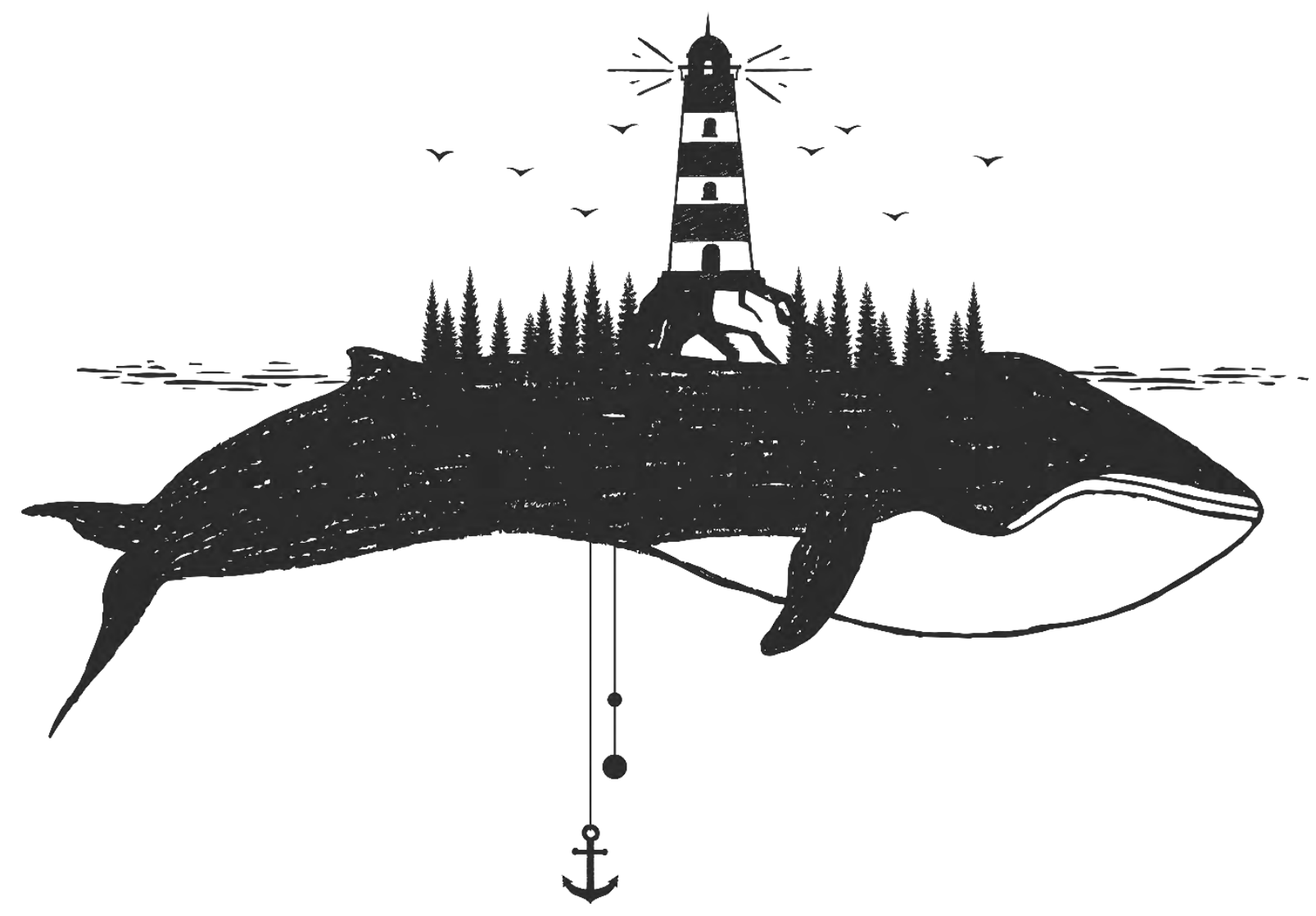

PROPOSICÁO 



\section{PROPOSIÇÃO}

O objetivo primário deste estudo é avaliar por meio de um método de luminescência a migração de pré-osteoblastos de um arcabouço impresso em 3D para a superfície de microimplantes descontaminados por protocolos distintos.

Os objetivos secundários deste estudo são:

- Determinar o potencial de descontaminação de cada um dos protocolos avaliados através da contagem bacteriana em imagens de microscopia eletrônica de varredura;

- Avaliar alterações químicas superficiais em após cada tratamento por meio de espectroscopia por dispersão em energia;

- Averiguar variações na microtopografia do implante promovidas pelas técnicas de descontaminação utilizando um perfilômetro óptico;

- Analisar mudanças na molhabilidade após a descontaminação por meio da mensuração do ângulo de emersão do microimplante utilizando a técnica de menisco. 



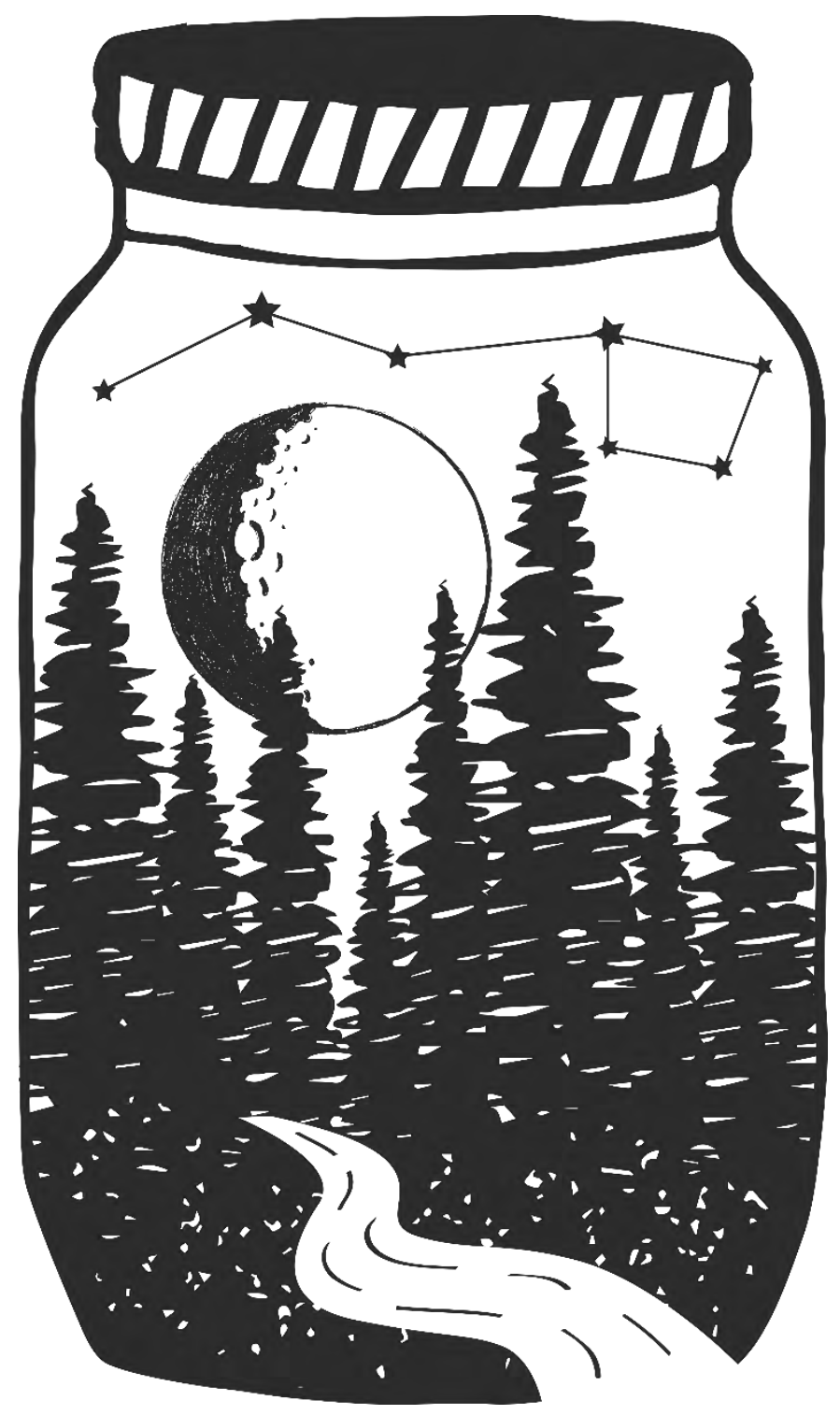

MATERIAIS E MÉTODOS 



\section{MATERIAL E MÉTODOS}

\subsection{Obtenção e preparo dos microimplantes}

Neste estudo foram utilizados 240 microimplantes de titânio (Stabilok, Fairfax Dental Inc. ${ }^{\circledR}$, Inglaterra) de $0,76 \mathrm{~mm}$ de diâmetro e $4 \mathrm{~mm}$ de altura. A opção pelo uso destes microimplantes foi motivada pelo fato de seu potencial de osseointegração já ter sido demonstrado em estudos pré-clínicos prévios (DONOS; KOSTOPOULOS; KARRING, 2002; DONOS et al., 2005; TABASSUM et al., 2011).

Os microimplantes foram lavados em agitação ultrassônica em ciclos sequenciais de 8 minutos utilizando água ultrapura Mili-Q (EMD Millipore, EUA), 100\% etanol, $100 \%$ acetona e $50 \%$ etanol. Em seguida, os microimplantes secaram a $37^{\circ} \mathrm{C}$ durante $24 \mathrm{~h}$ (WANDIYANTO et al., 2019). Destes, metade teve sua topografia preservada, sendo tratados como microimplantes de superfície lisa (L) (Figuras 1 e 2).

Os demais microimplantes receberam um condicionamento ácido duplo, feito pela submersão em $1 \mathrm{M} \mathrm{H}_{2} \mathrm{SO}_{4}$ por $72 \mathrm{~h}$ e $1 \mathrm{M} \mathrm{HCL}$ por $30 \mathrm{~h}$ (WANDIYANTO et al., 2019) (Figura 3), sendo após isto considerados microimplantes de superfície rugosa (R) (Figuras 1 e 2). Por fim, um novo processo de lavagem foi aplicado para remoção de contaminantes conforme protocolo já descrito. Antes de seu uso, todos microimplantes foram esterilizados em autoclave.

Figura 1 - Aspecto macroscópico dos microimplantes lisos (L) e rugosos (R).

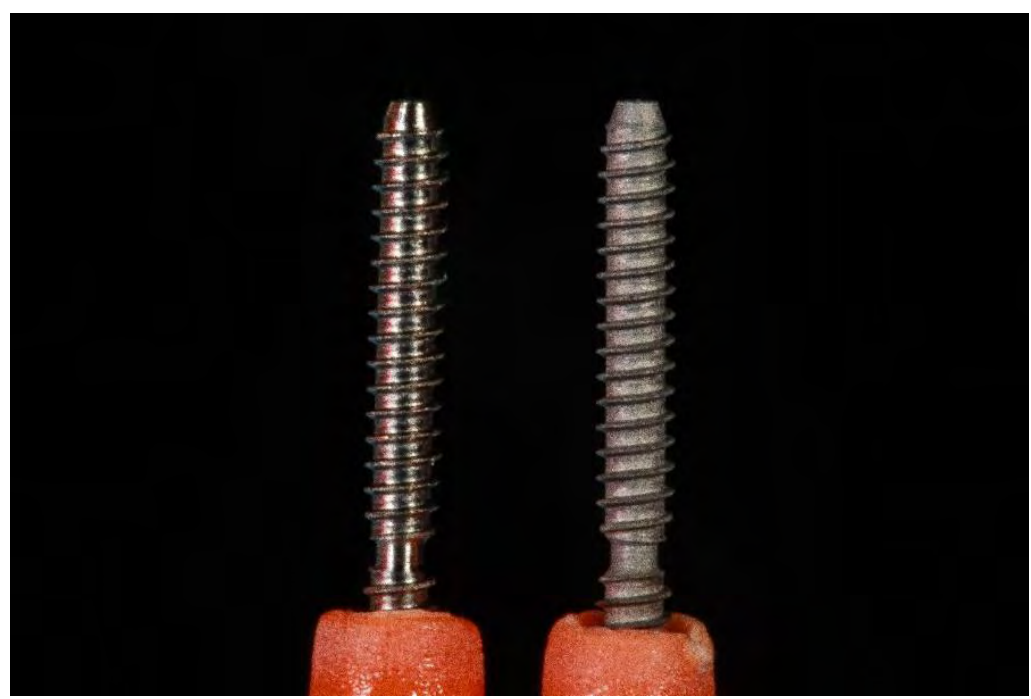


Figura 2 - Aspecto microscópico dos microimplantes lisos (L) e rugosos (R) obtidos com microscopia eletrônica de varredura.

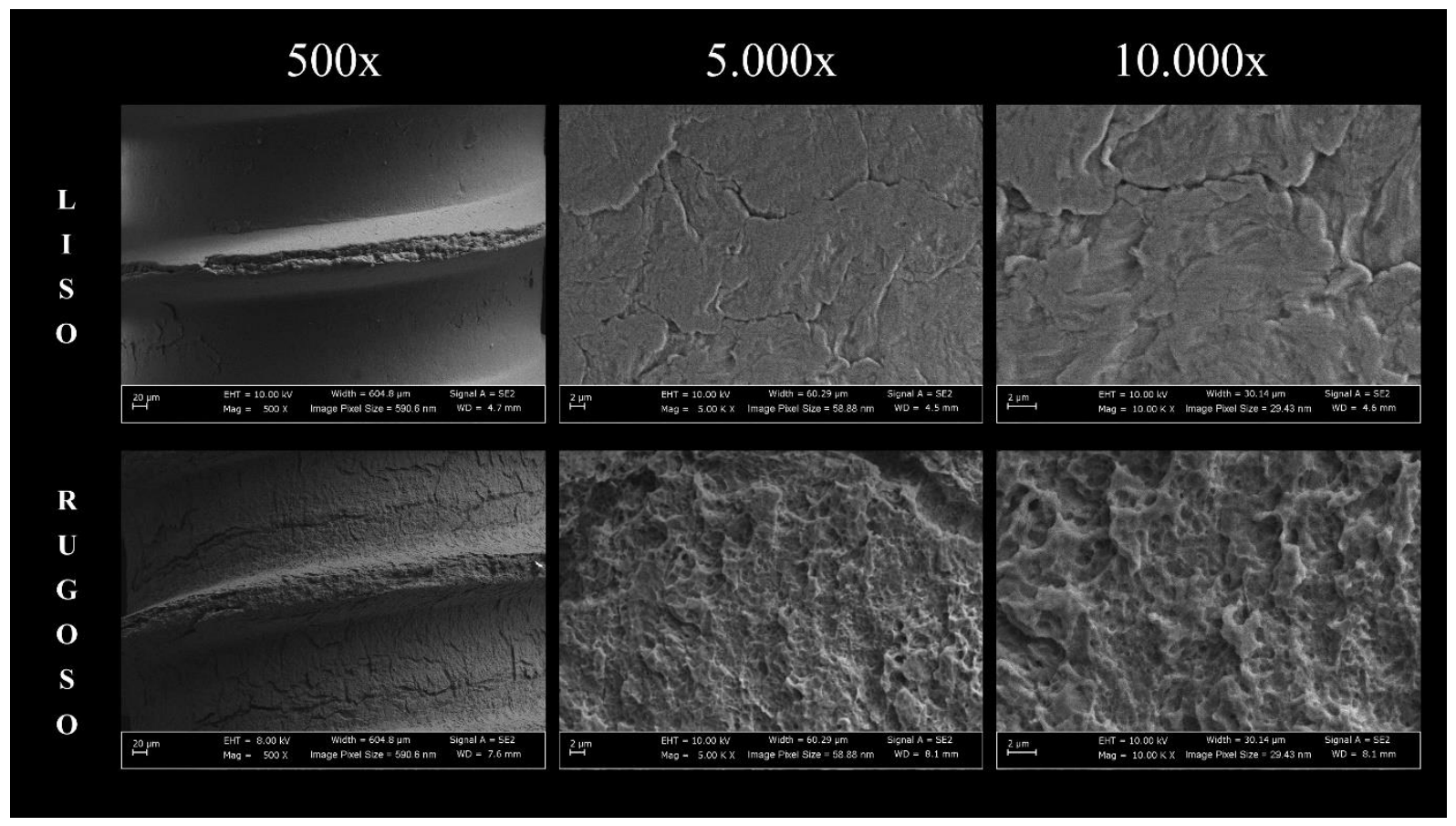

Figura 3 - Microimplantes condicionados para o tratamento de superfície com duplo ataque ácido.

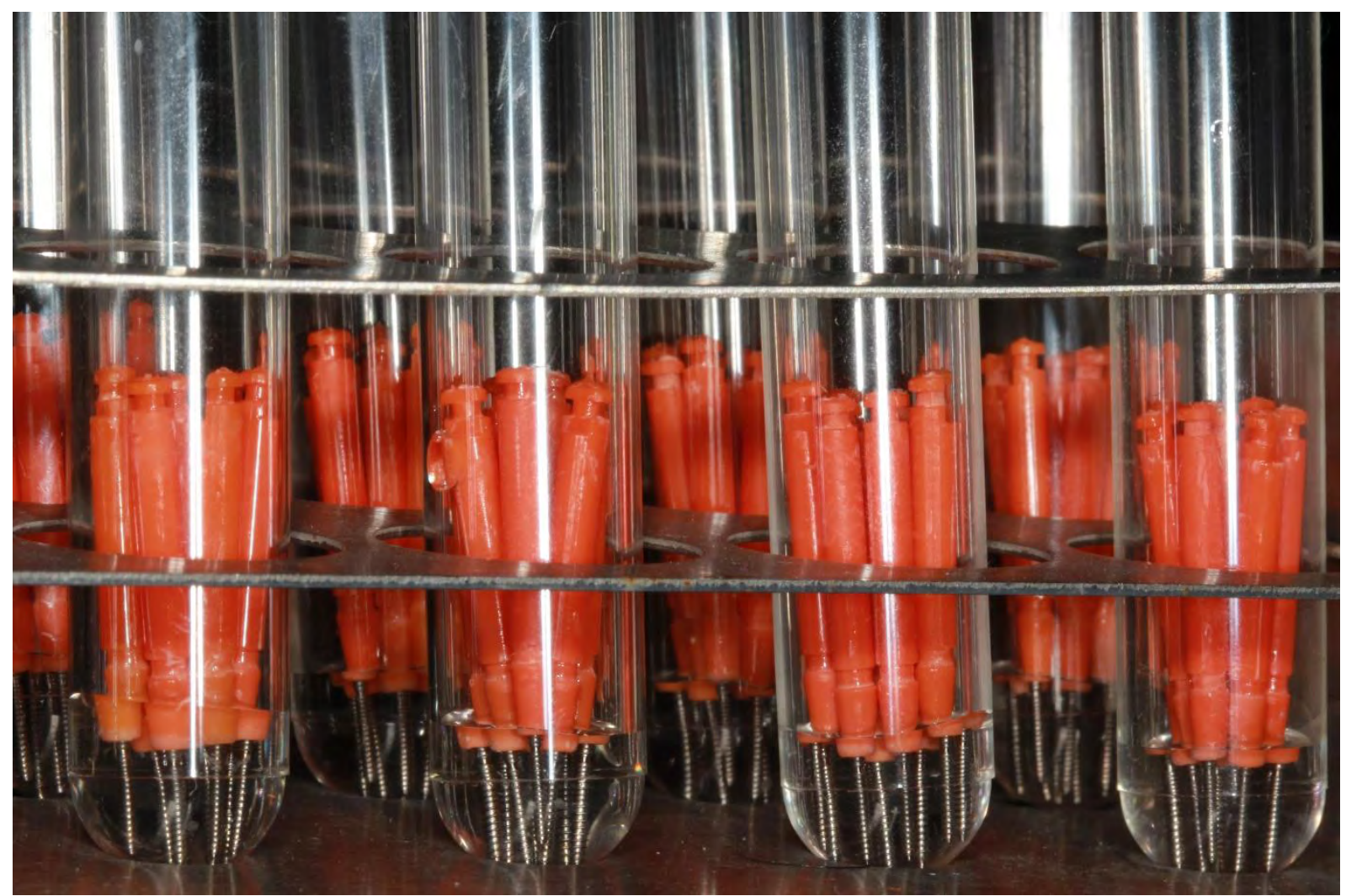




\subsection{Cultura e inoculação de Escherichia coli (E. coli)}

Para a cultura e inoculação, $1 \mathrm{~mL}$ de solução de estoque de $E$. coli preservada em $-80^{\circ} \mathrm{C}$ foi transferida para $9 \mathrm{~mL}$ de meio LB (Luria Bertani) e incubada a $28^{\circ} \mathrm{C}$ em agitação de $250 \mathrm{rpm}$ durante $24 \mathrm{~h}$. A concentração bacteriana foi avaliada em triplicata através da leitura da absorbância do meio em $600 \mathrm{~nm}$, sendo em seguida ajustada para $10^{7} \mathrm{CFU} / \mathrm{mL}$ através da diluição em LB. Para a inoculação, 108 microimplantes $L$ e $108 \mathrm{R}$ foram acomodados em uma placa de 6 poços com $3 \mathrm{~mL}$ da suspenção bacteriana a $37^{\circ} \mathrm{C}$ e $100 \mathrm{rpm}$ durante $24 \mathrm{~h}$ (Figura 4). Destes, 3 microimplantes $L$ e $3 R$ foram aleatoriamente reservados para futura avaliação do nível de contaminação inicial, sendo denominados como grupos controle (L-C e R-C, Figura 5). Para os grupos controles (L-C e R-C) das avaliações de microtopografia, molhabilidade, composição química superficial e migração celular foram reservados os 12 microimplantes $L$ e os $12 \mathrm{R}$ não contaminados restantes.

Figura 4 - Microimplantes condicionadas em incubação com suspenção de E. coli.

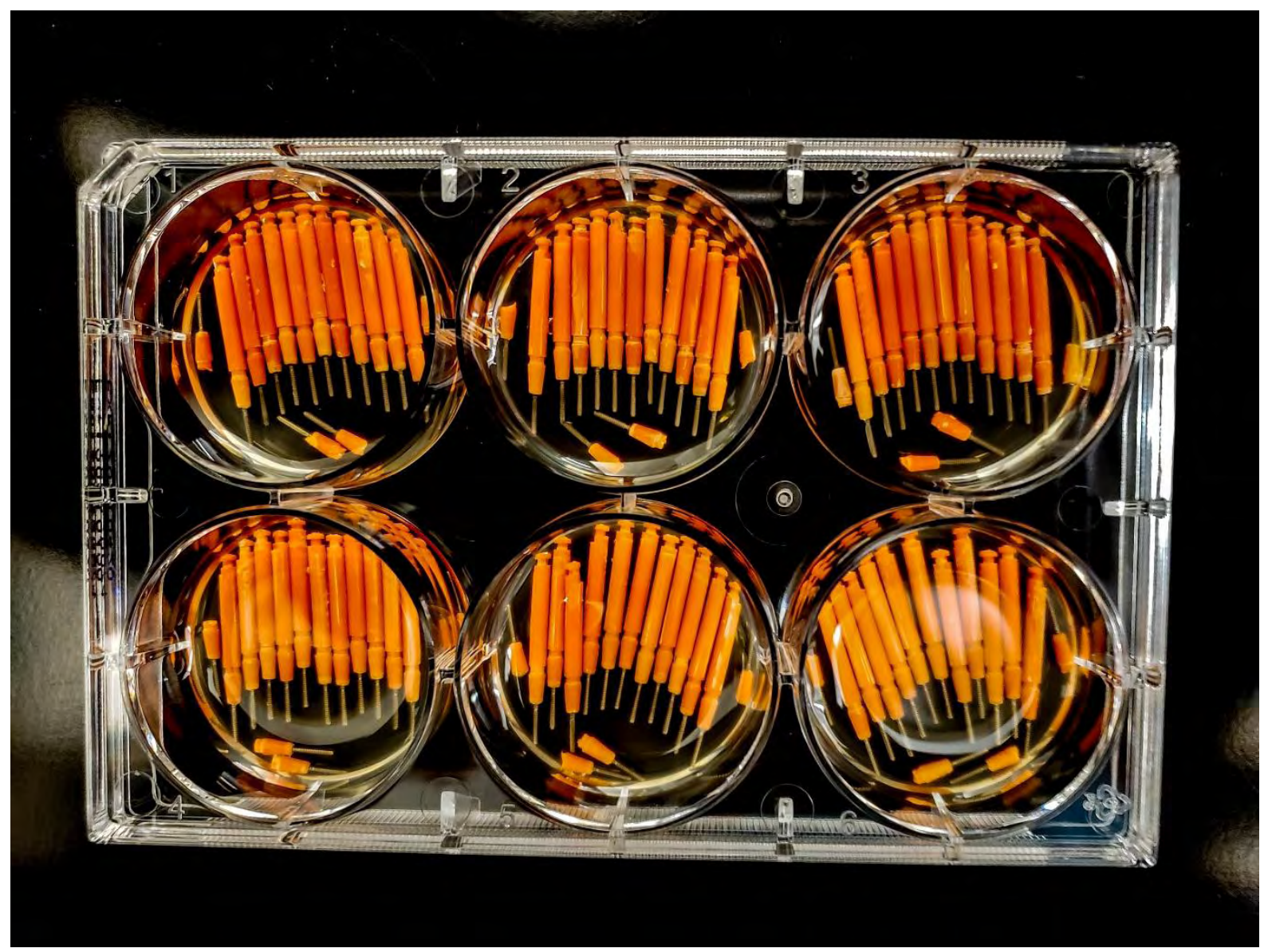




\subsection{Descontaminação de superfície}

Os demais 105 microimplantes contaminados $L$ e os $105 \mathrm{R}$ foram aleatoriamente divididos entre 7 diferentes protocolos de descontaminação, sendo:

1) Submersão em ácido etilenodiamino tetra-acético $24 \%$ (EDTA): submersão em PrefGel ${ }^{\circledR}$ (Straumann ${ }^{\circledR}$, Suíça) por 2 minutos, seguido por uma lavagem em tampão fosfato-salino (PBS) por 1 minuto.

2) Submersão em clorexidina $2 \%$ (CX): submersão em clorexidina $2 \%$ (Vista Dental Products, EUA) por 2 minutos, seguido por uma lavagem em PBS por 1 minuto.

3) Fricção com gaze embebida em clorexidina $2 \%$ (GCX): limpeza utilizando uma gaze embebida em clorexidina $2 \%$ (Vista Dental Products, EUA) durante 1 minuto, seguido por uma lavagem em PBS por 1 minuto.

4) Fricção com gaze embebida em água ultrapura (GMQ): limpeza utilizando uma gaze embebida em água ultrapura (Mili-Q, EUA) durante 1 minuto, seguido por uma lavagem em PBS por 1 minuto.

5) Raspagem com cureta metálica (RA): raspagem com cureta metálica Gracey (Hu-Friedy, EUA) ao longo de toda a superfície, seguido por uma lavagem em PBS por 1 minuto (Figura 5A).

6) Limpeza com escova de titânio (ETi): limpeza com escovas de titânio (RotoBrush-Titanium, Salvin, EUA) feita com irrigação constante e a 900 rpm, seguido por uma lavagem em PBS por 1 minuto (Figura 5B).

7) Implantoplastia (IP): as roscas dos microimplantes foram desgastadas utilizando brocas diamantadas cilíndricas de granulação média 856L/016M (Strauss Diamond Instruments Inc., EUA) e polidas com polidores universais de silicone $\mathrm{H} 4$ (Strauss Diamond Instruments Inc., EUA), seguido por uma lavagem em PBS por 1 minuto (Figura 5C).

Todos os procedimentos foram realizados com magnificação de $2,7 \times \mathrm{e}$ iluminação com fotóforo (PeriOptix, EUA). Ao fim desta fase do experimento, 14 diferentes grupos experimentais foram definidos, sendo 7 constituídos por 
microimplantes de superfícies lisas (L-EDTA, L-CX, L-GCX, L-GMQ, L-RA, L-ETi e LIP) e 7 de rugosas (R-EDTA, R-CX, R-GCX, R-GMQ, R-RA, R-ETi e R-IP) (Figura 6).

Figura 5 - Instrumentais utilizados para alguns dos protocolos de descontaminação mecânicos; A: cureta Gracey (Hu-Friedy, EUA); B: escova de titânio (RotoBrush-Titanium, Salvin, EUA); C: brocas diamantadas cilíndricas de granulação média 856L/016M (Strauss Diamond Instruments Inc., EUA) e polidores universais de silicone H4 (Strauss Diamond Instruments Inc., EUA), respectivamente.

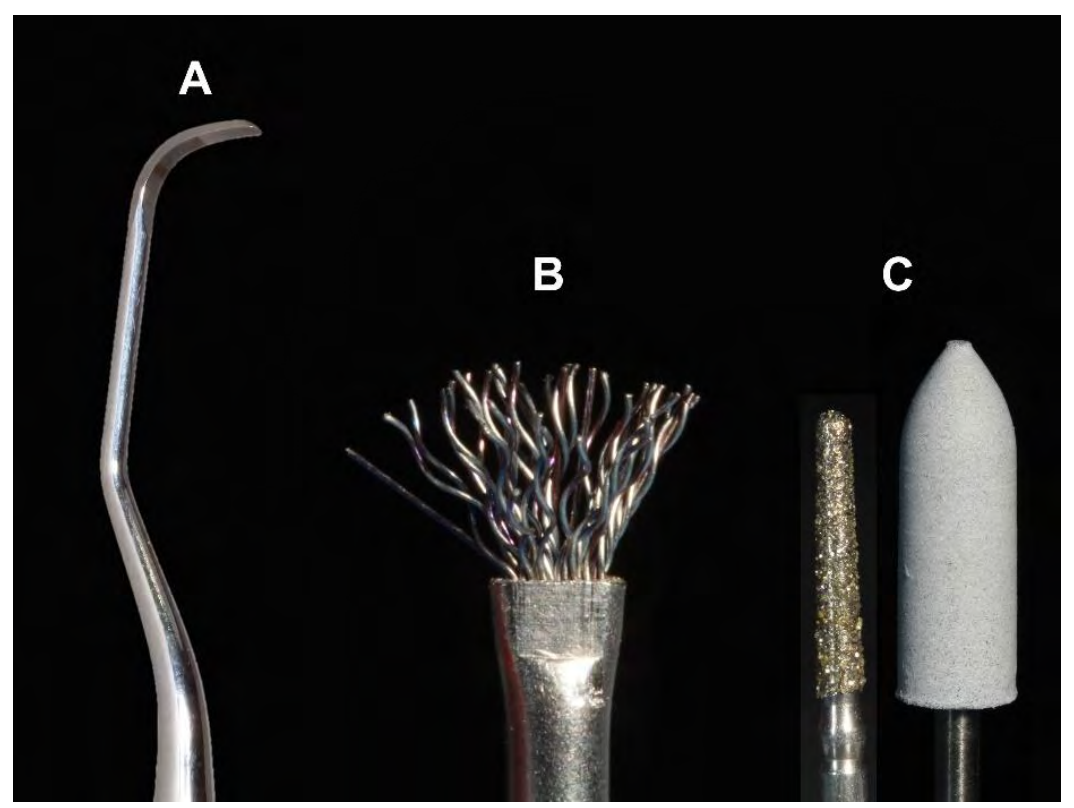

Figura 6 - Composição dos grupos controles, formado por microimplantes não descontaminados, e dos grupos experimentais, formado por microimplantes descontaminados com diferentes protocolos.

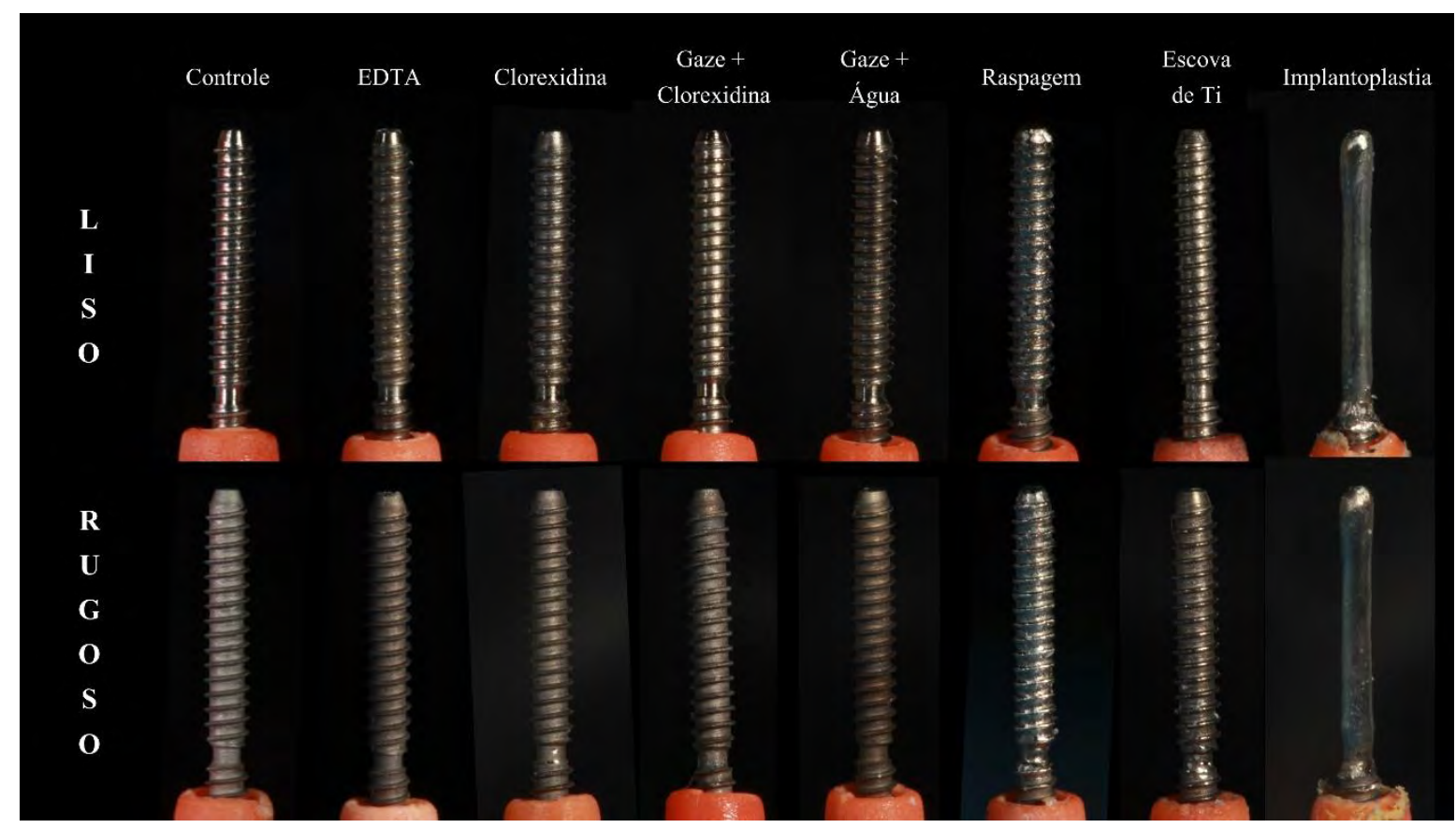




\subsection{Avaliação da contaminação e descontaminação bacteriana}

Para realizar a contagem bacteriana após a descontaminação, 3 microimplantes de cada grupo foram selecionados aleatoriamente. Para o grupo controle, a mesma quantidade de implantes não descontaminados foi utilizada (L-C e R-C). As amostras foram fixadas através de submersão sequencial por 20 minutos em 4 \% formalina-ácido propiônico-álcool etílico (FPA), 70 \% álcool, 80 \% álcool, 90 \% álcool, $95 \%$ álcool, $100 \%$ álcool e novamente $100 \%$ álcool. Em seguida, os microimplantes foram metalizados em um SEM 105T S Metal Suputter Coater (Quorum, EUA) com uma camada de $5 \mathrm{~nm}$ de Pt / Pd na proporção 80:20 em uma corrente de $40 \mathrm{~mA}$ e densidade de 19,56 g/m³ (Figura 7).

Figura 7 - Amostras metalizadas condicionadas para análise no microscópio eletrônico de varredura.

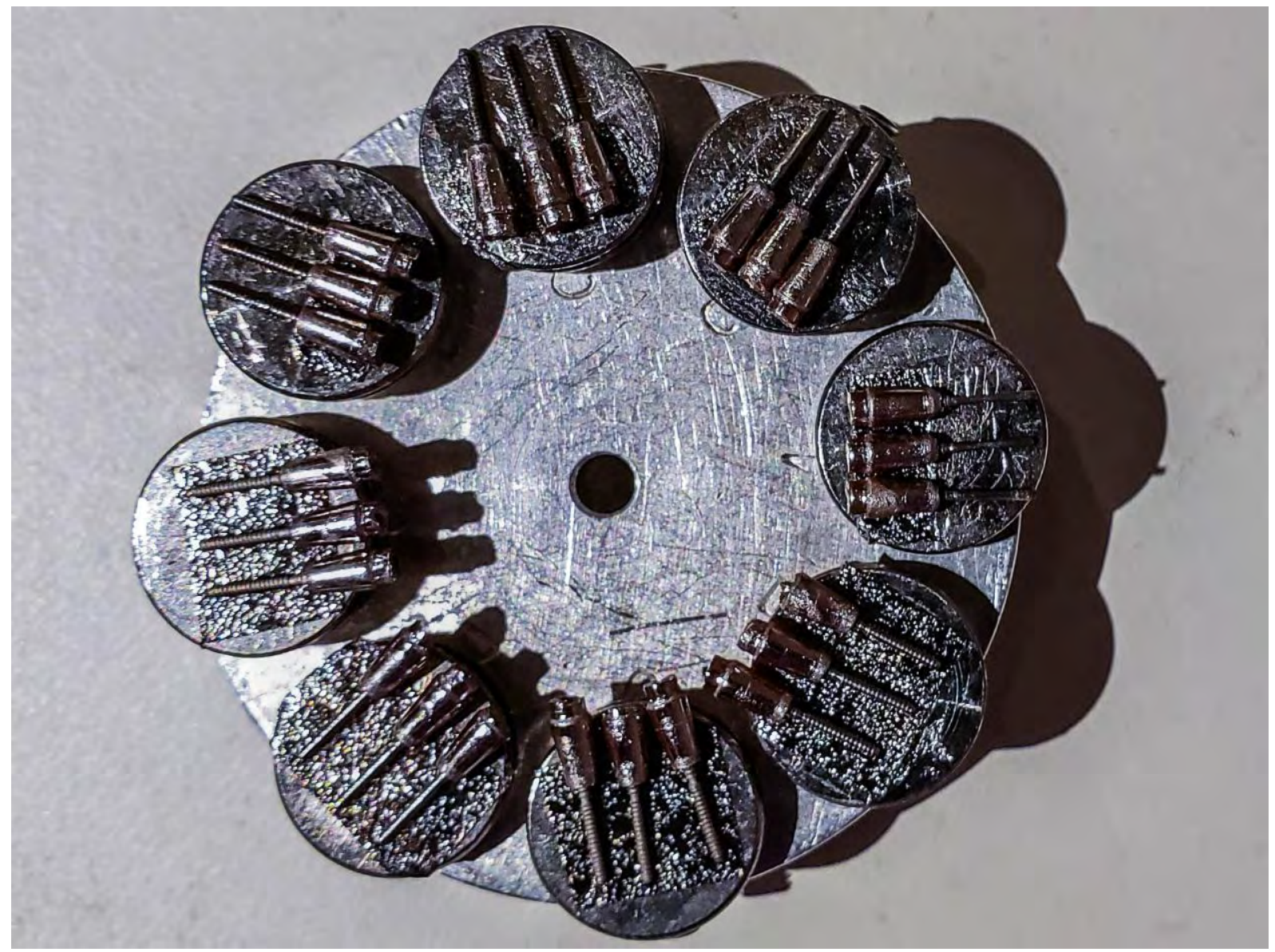

Por meio de um microscópio eletrônico de varredura (FESEM Supra 55VP, Zeiss, Alemanha), 3 imagens foram obtidas de cada amostra, sendo selecionada um 
vale na região cervical, um na central e outro na apical do microimplante. Foi adotada uma magnificação de 5.000 x, EHT de 8 kV e o detector SE2. Ao fim da análise, 9 imagens por grupo foram obtidas (Figura 8A).

Utilizando um iPad (Apple, EUA) e uma apple pencil (Apple, EUA), as bactérias foram manualmente destacadas em cada uma das imagens (Figura 8B). Em seguida, elas foram convertidas em arquivos de 8-bits utilizando o software ImageJ ( $\mathrm{NIH}, \mathrm{EUA})$ e receberam um ajuste de threshold de 0 , simplificando as imagens ao preto (superfície) e branco (bactérias) (Figura $8 \mathrm{C}$ ). Por fim, foi calculada a porcentagem da fase branca em cada uma das imagens. Os microimplantes descontaminados não utilizados nesta análise foram esterilizados para os experimentos seguintes.

Figura 8 - A: imagem obtida por microscopia eletrônica de varredura com magnificação de 5.000 x, EHT de 8 kV e o detector SE2; B: bactérias demarcadas manualmente; C: ajuste de threshold de 0 , evidenciando as bactérias em branco e o substrato em preto.

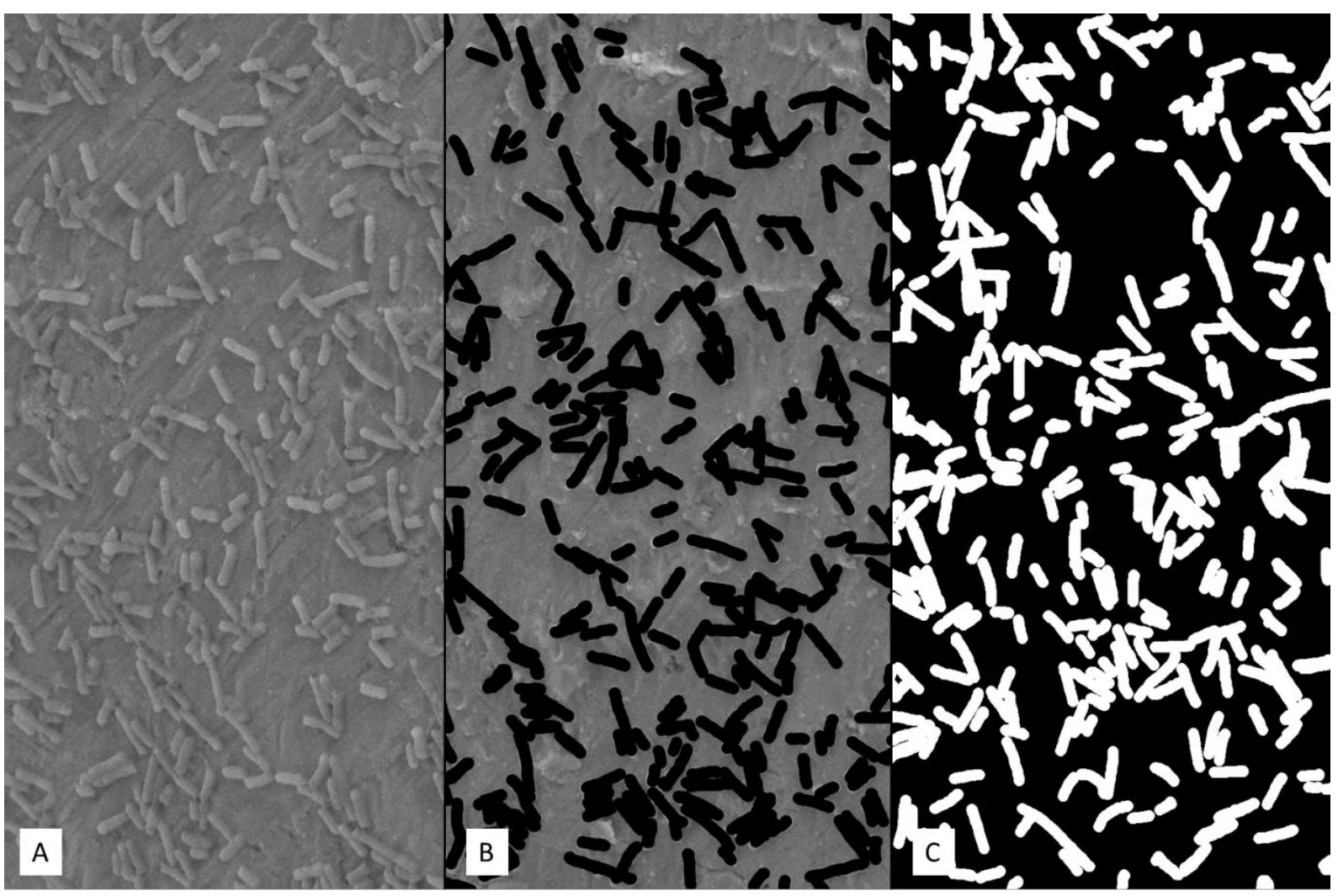




\subsection{Espectroscopia de raios X por dispersão em energia (EDS)}

A avaliação da composição química da superfície dos microimplantes foi realizada em 3 amostras aleatoriamente selecionadas de cada grupo. Para isto, foi utilizada a técnica espectroscopia de energia dispersiva em um JEOL 9700F SEM (Jeol, Japão) com uma voltagem de aceleração (AV) de $10 \mathrm{kV}$, magnificação de $1.000 \mathrm{x}$, corrente da sonda 13 e detector LED. Foi realizada uma leitura na região central de cada microimplante e registrados os valores de porcentagem de peso (wt \%) e de átomos (atomic \%) de cada elemento encontrado.

\subsection{Molhabilidade}

Para a avaliação da molhabilidade, 3 microimplantes de cada grupo foram utilizados. Para isto, foi adotado o método do menisco. Brevemente, o microimplante foi fixado em posição vertical enquanto que um recipiente contendo água ultrapura foi movimentado verticalmente para submergir e emergir o microimplante (Figura 9A, 9B e 9C). O processo foi repetido 3 vezes com cada amostra, sendo registrada uma fotografia ao final de cada ciclo. Com isto, ao fim do experimento foram obtidas 9 imagens por grupo.

Utilizando o software Image ( $\mathrm{NIH}, \mathrm{EUA})$, os ângulos formados entre a superfície do microimplante e o menisco foram registrados a direita e a esquerda de cada amostra, totalizando 18 mensurações por grupo. A fim de remover o impacto que a refração da água poderia exercer sobre os resultados, optou-se por obter o ângulo do menisco através da mensuração do ângulo externo entre menisco e microimplante, subtraindo o valor encontrado de $180^{\circ}$ (Figura 9D).

As medidas foram realizadas por um único operador com calibração feita com 20\% da amostra e 1 mês de intervalo entre as medições, obtendo-se um valor de coeficiente de correlação intraclasse de 0,82. 
Figura 9. Processo de submersão e emersão do microimplante para mensuração do menisco formado pela água na superfície da amostra; A: microimplante fixado na posição vertical sobre recipiente com água ultra pura; B: recipiente elevado com pinça clínica para promover a submersão do microimplante; C: recipiente sendo recolocado na posição iniciando, emergindo o microimplante e levando à formação dos meniscos; D: mensuração do ângulo do menisco utilizando o software ImageJ (NIH, EUA).

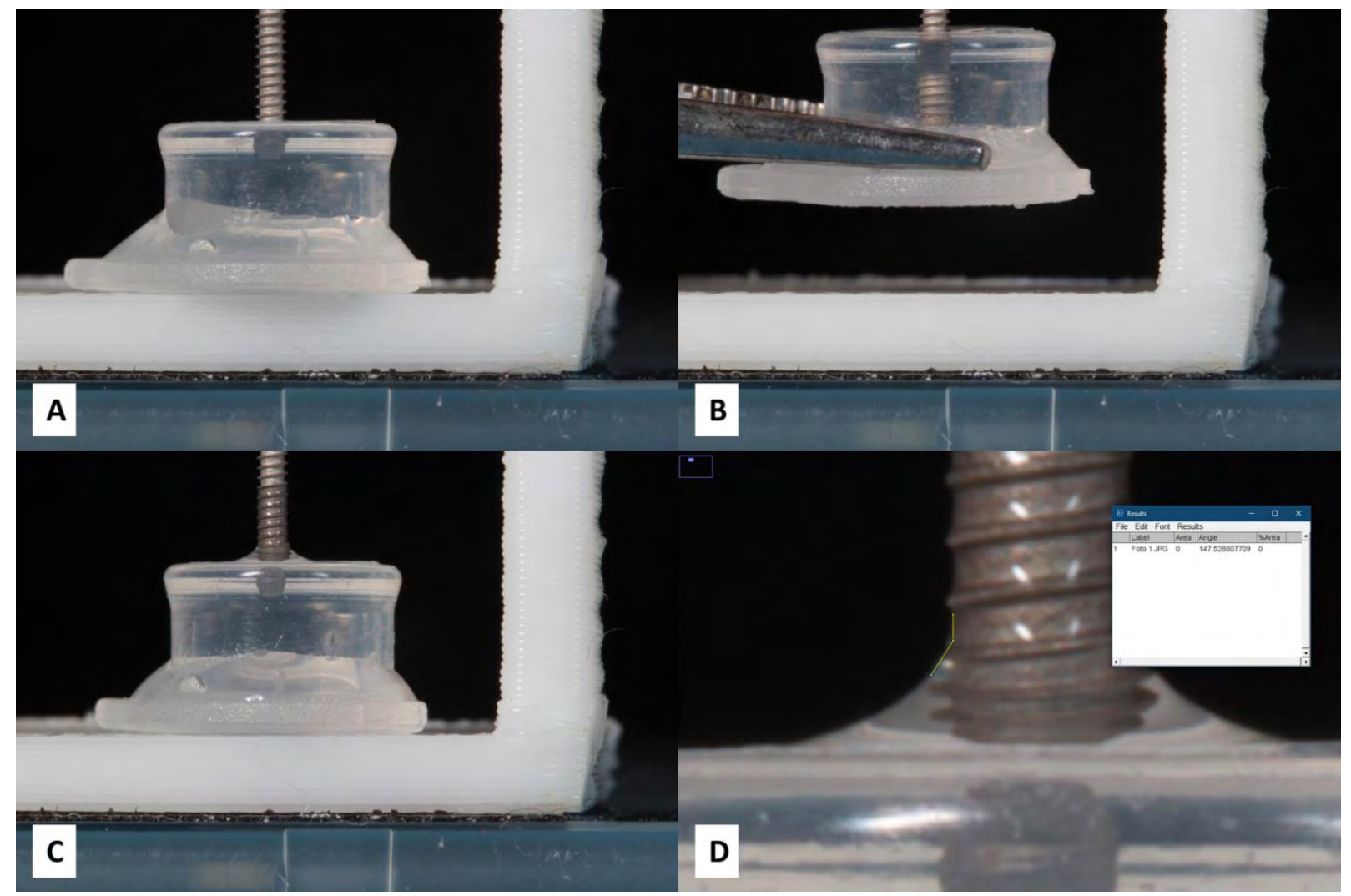

\subsection{Microtopografia superficial}

Para a avaliação dos parâmetros de rugosidade, foram adotadas as recomendações preconizadas por Wennerberg e Albrektsson (2000). Assim, 3 microimplantes de cada grupos foram aleatoriamente selecionados e avaliados em um perfilômetro óptico CCI HD (Taylor Hobson, Inglaterra). Cada amostra teve 9 sítios avaliados, sendo eles 3 vales, 3 flancos e 3 arestas (Figura 10). Os arquivos decorrentes do processo foram analisados utilizando o software TalyMap Surface Analysis (Taylor Hobson, Inglaterra), sendo aplicado um recorte de 40 x $40 \mu \mathrm{m}$ e a aplicação de um filtro gaussiano de $25 \mu \mathrm{m}$. A topografia foi analisada por meio de parâmetros tridimensionais (Sq, Ssk, Sku, Sz, Sa, Str, Sdq e Sdr) e os parâmetros bidimensionais ( $\mathrm{Ra}, \mathrm{Rq}, \mathrm{Rv}, \mathrm{Rt}$, Rsk e Rku) conseguidos pela somatória dos perfis nos sentidos Leste-Oeste e Norte-Sul. 
Figura 10. Sítios de seleção para avaliação de topografia superficial

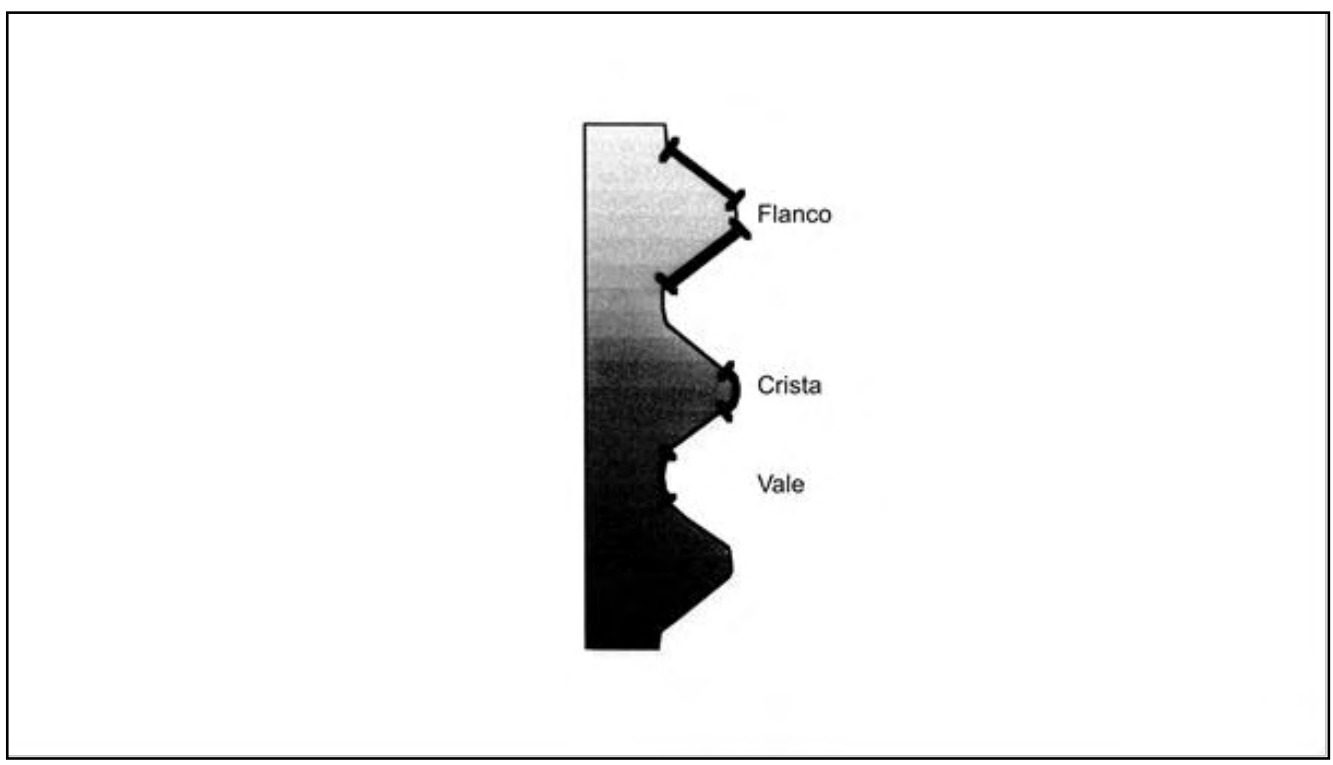

FONTE: Adaptado de WHEELIS, S. E.; GINDRI, I. M.; VALDERRAMA, P.; WILSON, T. G., JR.; HUANG, J.; RODRIGUES, D. C. Effects of decontamination solutions on the surface of titanium: investigation of surface morphology, composition, and roughness. Clin Oral Implants Res, v. 27, n. 3, p. 329-340, 2016.

\subsection{Produção dos arcabouços impressos em 3D}

O material utilizado como base para a impressão dos arcabouços foi preparado de acordo com protocolo previamente descrito (SHIE et al., 2017). Brevemente, poliuretano fotopolimerizável à base de água (LUX 260, Alberdingk Boley, Alemanha) e poliuretano termoplástico à base de água (U 2101, Alberdingk Boley, Alemanha) foram misturados em partes iguais em alta velocidade e aquecidos a $130{ }^{\circ} \mathrm{C}$ durante $1,5 \mathrm{~h}$ para remoção da água. Em seguida, foi adicionado à solução 1,5\% óxido de difenil(2 4 6-trimetilbenzoil)fosfina (TPO, Ciba, Suíça) para agir como fotoiniciador, e 2\% de ácido hialurônico (1900kD HÁ, Suvenyl, Chugai Pharmaceutical, Japão) diluído em 2-hidroximetilmetacrilato (HEMA, Sigma-Aldrich, USA) a fim de favorecer a migração celular. Por fim, o material foi novamente misturado brevemente a $70{ }^{\circ} \mathrm{C}$ e armazenado para futuro uso. A seleção deste material para este protocolo se baseou em sua biocompatibilidade e resistência mecânica já comprovados (SHIE et al., 2017). 
Os arcabouços foram projetados utilizando o software Autodesk MeshMixer (Autodesk Inc., EUA). Para isto, foi modelada uma estrutura de 4,875 mm de altura e com 2,145 mm de largura e espessura, com poros de $325 \mu \mathrm{m}$ e treliça interna com $130 \mu \mathrm{m}$ de espessura (Figura 11). Uma base com $1 \mathrm{~mm}$ de altura foi projetada para permitir a manipulação do arcabouço, contando também com planos e aberturas para o escoamento do material durante o processo de impressão, uma abertura superior para a introdução do microimplante, uma abertura inferior para a injeção do hidrogel e travas inferiores para limitar a penetração do microimplante (Figura 11).

Figura 11. Diagrama do arcabouço projetado para o experimento.

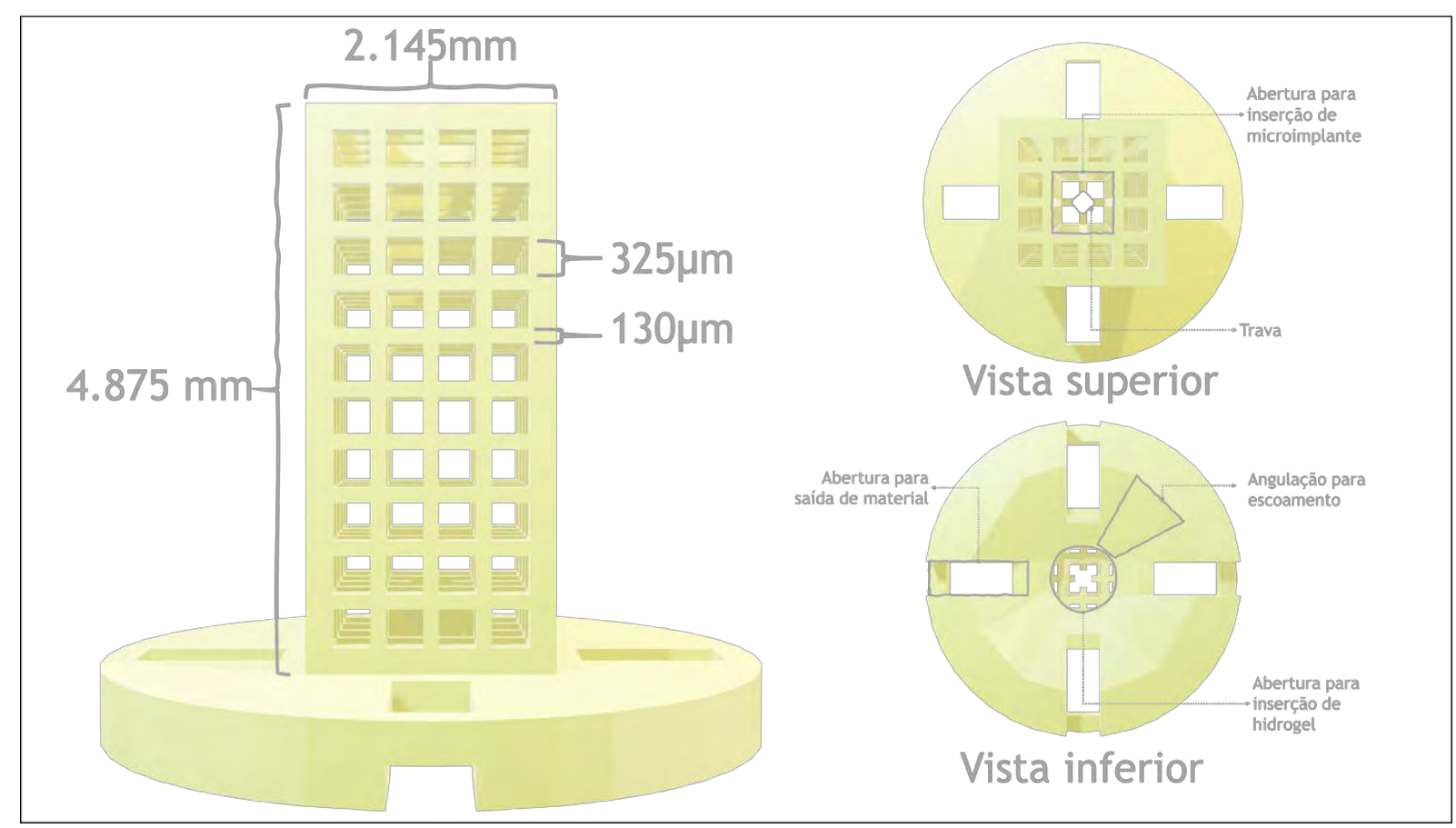

Os arcabouços foram então impressos utilizando uma impressora Miicraft 125 3D-printer (Miicraft $\AA$, Taiwan) que opera por meio de uma técnica de processamento digital de luz (Figure 12 e 13). 
Figura 12 - Arcabouços impressos por meio de técnica de processamento digital de luz.

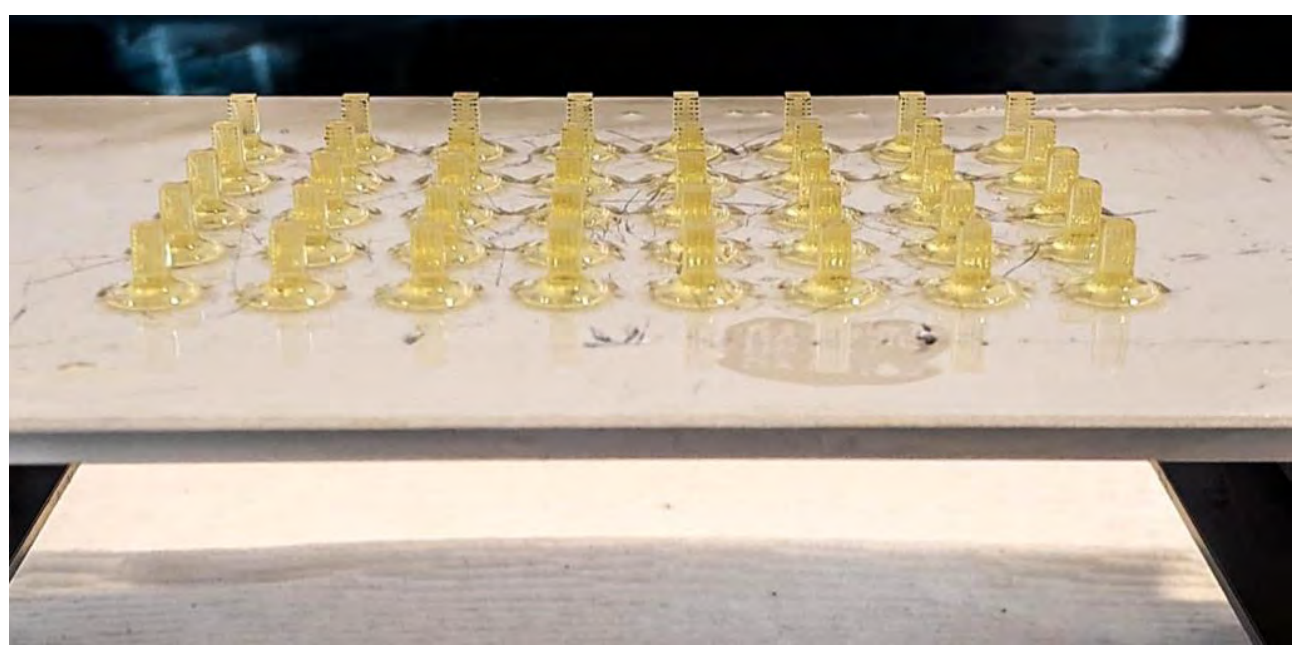

Figura 13 - Microimplante posicionado em arcabouço impresso em 3D demonstrando sua fidelidade com o planejamento digital.

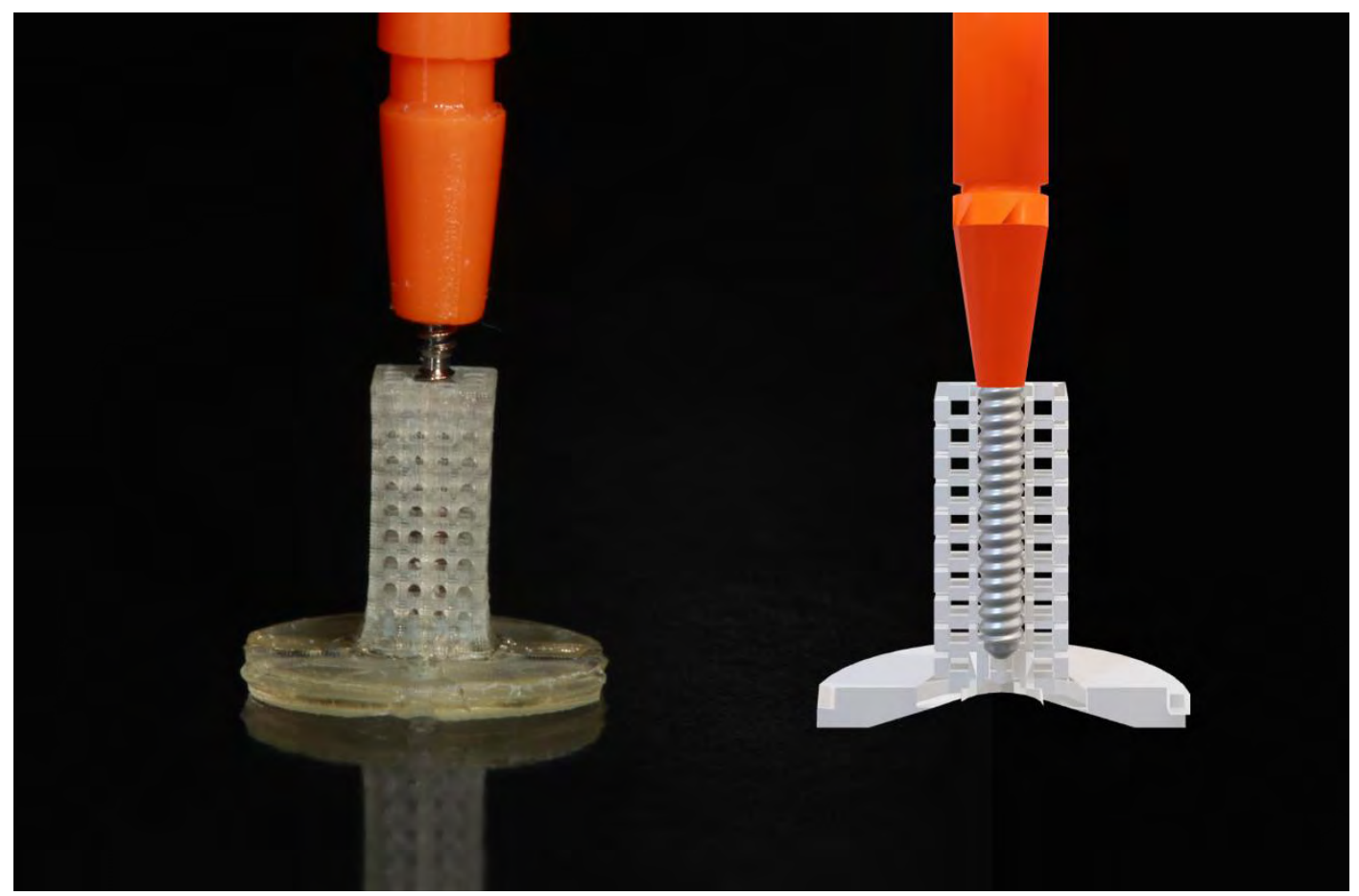

Após a impressão, os arcabouços receberam duas incisões verticais em seu topo utilizando uma lâmina 15c para permitir a futura remoção dos microimplantes. Antes de seu uso, todos os arcabouços foram lavados em uma submersão em álcool em agitação ultrassônica durante 30 minutos e deixado para secar por 24 h. Em seguida, receberam um tratamento de detoxificação, sendo submersos em água 
ultrapura e mantidos por 30 minutos em uma câmara de vácuo a $25 \mathrm{inHg} \mathrm{e} 120^{\circ} \mathrm{C}$. Por fim, todos os arcabouços foram esterilizados em autoclave.

\subsection{Preparo dos microimplantes para o ensaio de migração celular}

A fim de garantir um agente ativo que propiciasse a migração celular, foi utilizada uma suspenção de plaquetas obtidas com a produção de PRP (plasma rico em plaquetas). Para isto, $500 \mathrm{~mL}$ de sangue total humano com $A C D$ solução $A$ (BiolVT®, EUA) (Figura 14A) foram centrifugados a $1.000 \mathrm{G}$ por 2 minutos e 15 segundos (Figura 14B). Em seguida, o sobrenadante foi utilizado em uma segunda centrifugação a $1.000 \mathrm{G}$ por 5 minutos (Figura 14C). O pellet foi isolado e posteriormente ressuspenso em plasma pobre em plaquetas (Figura 14D).

Figura 14 - A: sangue total humano com ACD solução $A$ (BiolVT $\AA$, EUA); B: aspecto após a centrifugação a $1.000 \mathrm{G}$ por 2 minutos e 15 segundos; C: aspecto após a centrifugação do sobrenadante a $1.000 \mathrm{G}$ por 2 minutos e 15 segundos, com o pellet ao fundo do tubo; D: PRP obtido após isolar e ressuspender o pellet em plasma pobre em plaquetas.

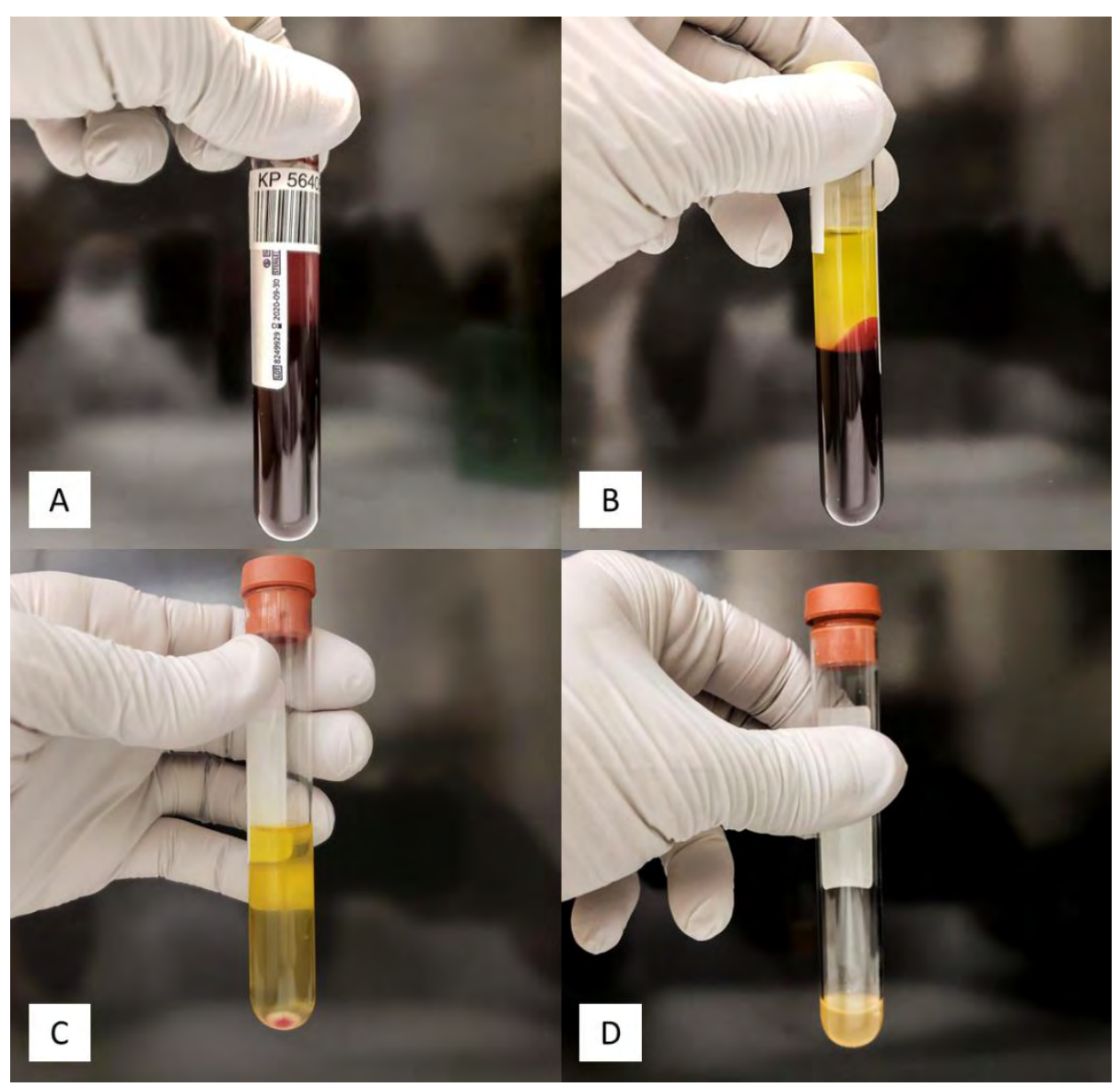


Os microimplantes foram mantidos na suspenção de plaquetas junto a uma solução de $\mathrm{CaCl}_{2}$ diluída em PBS em uma final concentração de 14,3 mg/mL em um agitador orbital a $250 \mathrm{rpm} \mathrm{e} 37{ }^{\circ} \mathrm{C}$ durante $3 \mathrm{~h}$. Desta forma, os fatores de crescimento liberados pelas plaquetas ativadas pelo $\mathrm{CaCl}_{2}$ se aderiram a superfície dos microimplantes, viabilizando a migração celular. Antes de seu uso, os microimplantes foram lavados por 5 minutos com PBS.

\subsection{Ensaio de migração de pré-osteoblastos}

Pré-osteoblastos de calota de ratos (MC3T3-E1 subclone 14) foram cultivados em meio mínimo essencial (a-MEM, Sigma-Aldrich, EUA) suplementado com $10 \%$ PBS e $1 \%$ penicilina-estreptomicina, e incubados a $37{ }^{\circ} \mathrm{C}$ em ambiente com $5 \% \mathrm{CO}_{2}$. Frente à confluência, as células foram desaderidas de seu frasco por meio de métodos enzimáticos e transferidas para um novo meio. Um hidrogel injetável foi preparado com uma concentração final de $2 \times 10^{5}$ células $/ \mathrm{mL}$ misturando $50 \mu \mathrm{L}$ de $\alpha$ MEM, $100 \mu \mathrm{l}$ de VitroGel 3D (TheWell Bioscience, EUA) e $100 \mu \mathrm{L}$ de VitroGel 3D Dilution Solution (TheWell Bioscience, EUA).

O hidrogel foi injetado através da abertura na base do arcabouço (Figura 11) e mantido e repouso por 15 minutos. Após, os microimplantes foram inseridos com movimento rotatório e levados para um poço em uma placa de cultura de adesão ultrabaixa de 96-poços (Corning ${ }^{\circledR}$ Costar ${ }^{\circledR}$, United States of America) e gentilmente preenchido com $250 \mu \mathrm{L}$ de $\alpha$-MEM. O meio de cultura foi substituído dia sim, dia não.

Para a remoção dos microimplantes dos arcabouços, uma leve pressão foi aplicada na base da estrutura, resultando em sua quebra (Figura 15). Em seguida, os microimplantes foram lavados em PBS por 5 minutos para remover células não aderidas.

A migração celular foi avaliada utilizando o kit CellTiter-Glo (Promega, EUA) após 24, 72 e 120 h utilizando 3 microimplantes de cada grupo e a cada período. Para isto, os microimplantes foram colocados em uma nova placa de 96 poços, sendo adicionado $200 \mu \mathrm{L}$ de novo meio e $200 \mu \mathrm{L}$ da solução CellTiter-Glo®, sendo mantido em agitador orbital por 10 minutos e em repouso por outros 5 . Por fim, o meio foi coletado para leitura em triplicada de sua luminescência. 
Um implante de cada grupo e a cada período avaliado foi fixado e metalizado conforme protocolo já descrito para obtenção de imagens de microscopia eletrônica de varredura.

Figura 15 - Após aplicar leve pressão em sua base, os microimplantes puderam ser removidos sem danificar as células.

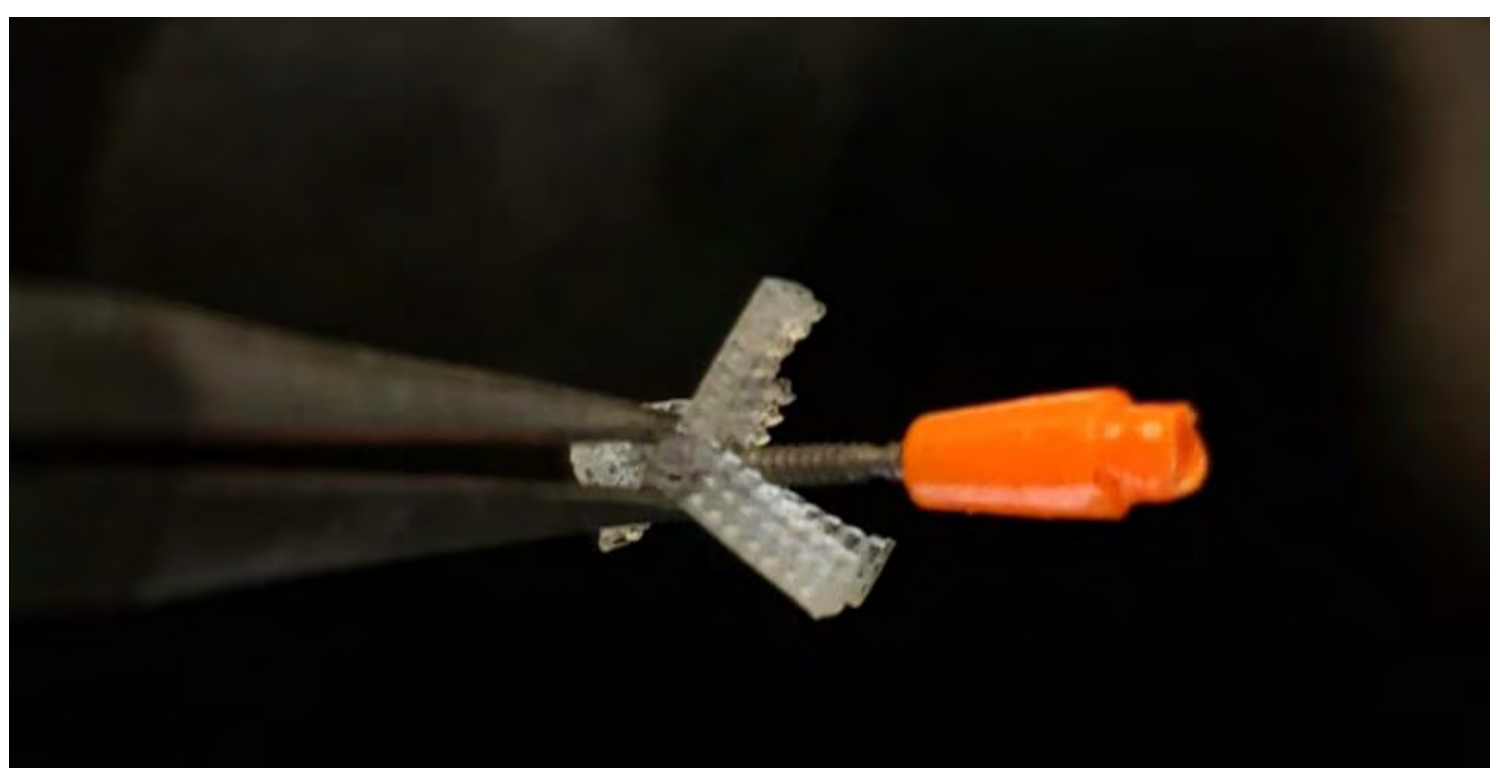

\subsection{Análise estatística}

A análise estatística foi realizada utilizando o software GraphPad Prism 7.0 para Windows adotando um nível de significância de 5\%. A comparação entre grupos experimentais e controles foi feita com ANOVA post hoc Tukey's multiple comparisons test. Para a comparação entre implantes $\mathrm{S}$ e $\mathrm{R}$ que receberam um mesmo tipo de tratamento, foi utilizado teste-T. 



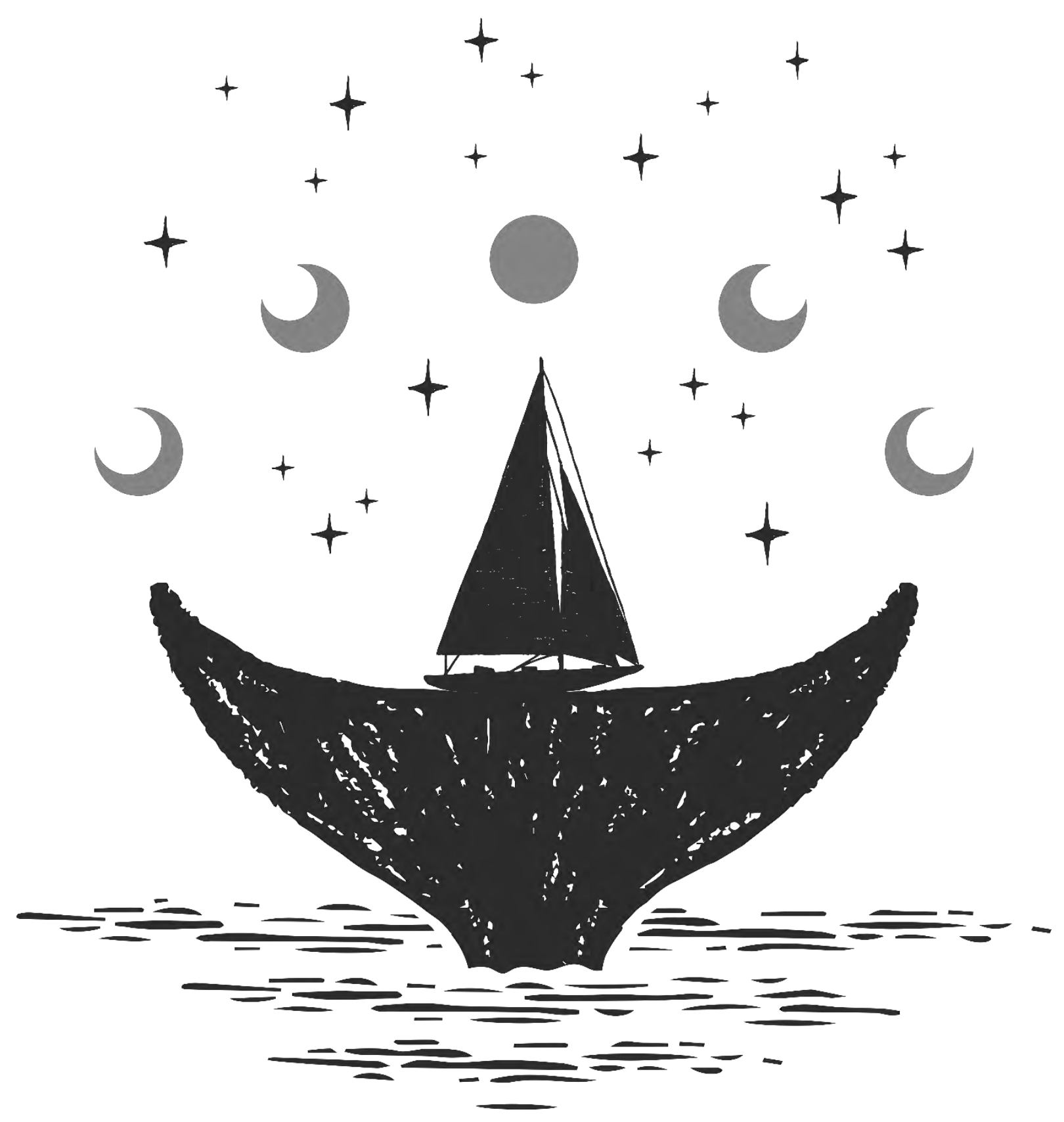

RESULTADOS 



\section{RESULTADOS}

\subsection{Descontaminação}

Todos os protocolos de descontaminação apresentaram porcentagens inferiores de contaminação residual quando comparados com o controle sem descontaminação (L-C e R-C, Tabela 1). Dentro de cada protocolo, a porcentagem de cobertura bacteriana foi inferior nos microimplantes $L$ quando comparado aos $R$ nos grupos $C$, EDTA e ETi $(p<0,05)$, não havendo diferença nos demais tratamentos $(p>0,05)$. Tanto nos microimplantes $L$ quanto nos $R$, os melhores resultados de descontaminação foram observados nos grupos GCX, RA, ETi e IP, sem diferença entre estes grupos $(p>0,05)$.

Tabela 1 - Porcentagem de cobertura bacteriana sobre a superfície dos microimplantes nos grupos controle (sem descontaminação) e experimentais (após a descontaminação)

\begin{tabular}{|c|c|c|c|c|c|c|c|c|}
\hline & C & EDTA & CX & GCX & GMQ & $\mathbf{R A}$ & ETi & IP \\
\hline L (\%) & $\begin{array}{c}29,17 \pm \\
5,07{ }^{A}\end{array}$ & $\begin{array}{c}24,48 \pm \\
3,69 \mathrm{~B}\end{array}$ & $\begin{array}{c}11,42 \pm \\
1,722^{c}\end{array}$ & $\begin{array}{l}0,19 \pm \\
0,14 \mathrm{D}\end{array}$ & $\begin{array}{c}12,13 \pm \\
2,53 \mathrm{c}\end{array}$ & $\begin{array}{l}1,04 \pm \\
0,89 \mathrm{D}\end{array}$ & $\begin{array}{l}0,16 \pm \\
0,09 \mathrm{D}\end{array}$ & $\begin{array}{l}0,04 \pm \\
0,04 \mathrm{D}\end{array}$ \\
\hline R (\%) & $\begin{array}{c}46,84 \pm \\
5,40^{A}\end{array}$ & $\begin{array}{c}38,41 \pm \\
7,43^{B}\end{array}$ & $\begin{array}{c}11,99 \pm \\
1,10^{\mathrm{C}}\end{array}$ & $\begin{array}{l}1,24 \pm \\
1,54 \mathrm{D}\end{array}$ & $\begin{array}{c}14,91 \pm \\
2,34^{\mathrm{C}}\end{array}$ & $\begin{array}{l}1,42 \pm \\
1,68 \mathrm{D}\end{array}$ & $\begin{array}{l}2,22 \pm \\
1,27^{D}\end{array}$ & $\begin{array}{l}0,08 \pm \\
0,05 \mathrm{D}\end{array}$ \\
\hline$p^{*}$ & $<0,0001$ & 0,0001 & & & & & 0.0002 & \\
\hline
\end{tabular}

ANOVA post hoc teste de comparação múltipla de Tukey. A mesma letra na mesma linha indica ausência de diferença estatisticamente significante $(p>0,05)$.

*Teste-T comparando os microimplantes L e R dentro de cada grupo controle ou experimental.

Dentre os protocolos utilizados, foi possível encontrar deformações superficiais consideráveis e presença de detritos nos grupos RA, ETi e IP. A utilização de curetas resultou em grande deformação da superfície do microimplante, promovendo o aplainamento superficial dos implantes L e R bem como a criação de margens irregulares (Figura 16). Além disto, é possível notar a presença de detritos resultantes do atrito metálico e a presença bacteriana em áreas que não foram atingidas pelos golpes da cureta (Figura 16). As escovas de titânio também promoveram o aplainamento superficial e criação de ranhuras, além de um acúmulo de detritos notável nos $\mathrm{R}$ (Figura 17). Como esperado, a implantoplastia levou a uma drástica alteração da topografia superficial, havendo a presença de ranhuras e debris mesmo após o polimento e a lavagem do microimplante (Figura 18).

As alterações superficiais e a presença de remanescente bacteriano em todos os grupos pode ser observada nas Figuras 19 e 20, respectivamente. 
Figura 16 - Superfície dos microimplantes após descontaminação com cureta metálica. Em destaque: ranhuras e aplainamento superficial (vermelho), detritos (azul) e remanescentes bacterianos (verde).

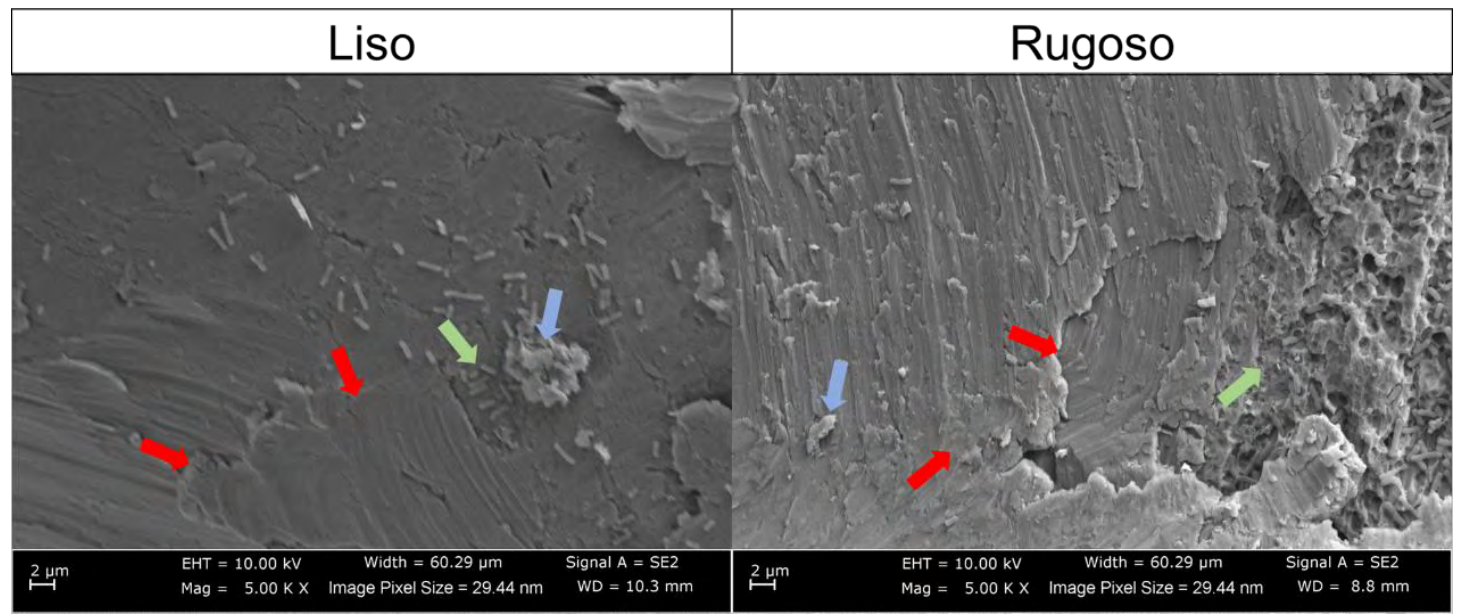

Figura 17 - Superfície dos microimplantes após descontaminação com escova de titânio. Em destaque: ranhuras (vermelho), detritos (azul) e remanescentes bacterianos (verde).

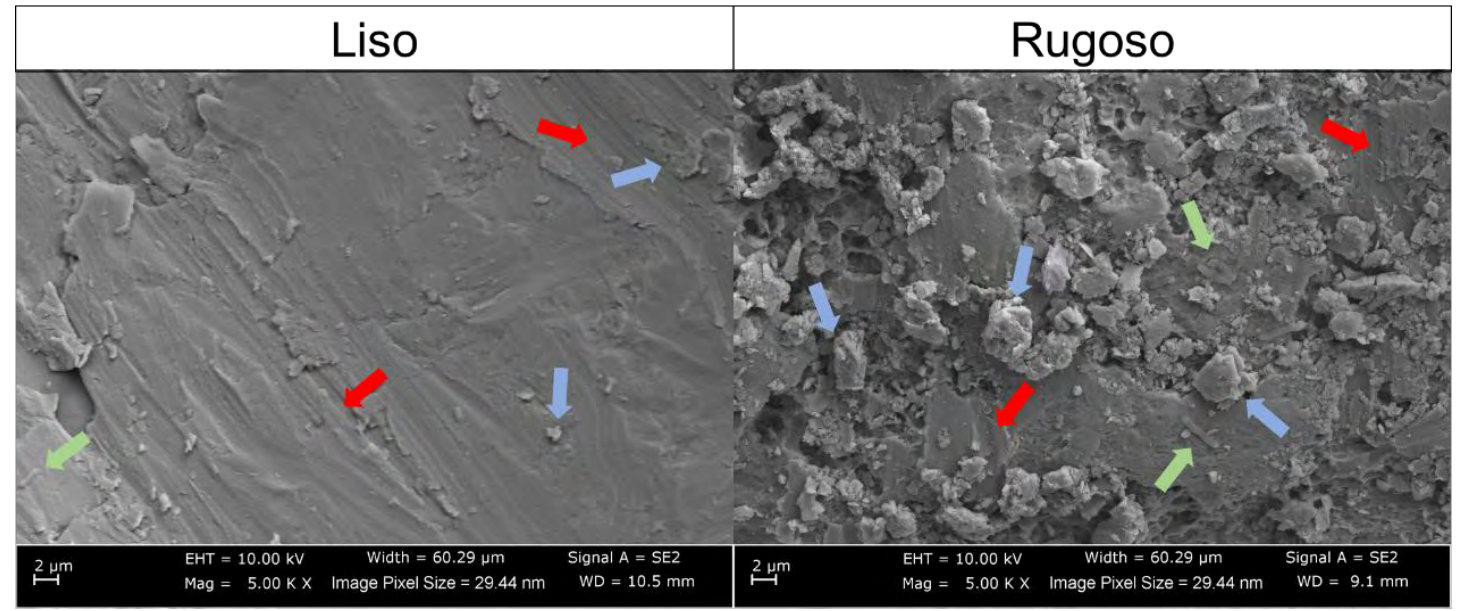

Figura 18 - Superfície dos microimplantes após implantoplastia. Em destaque: ranhuras (vermelho) e detritos (azul).

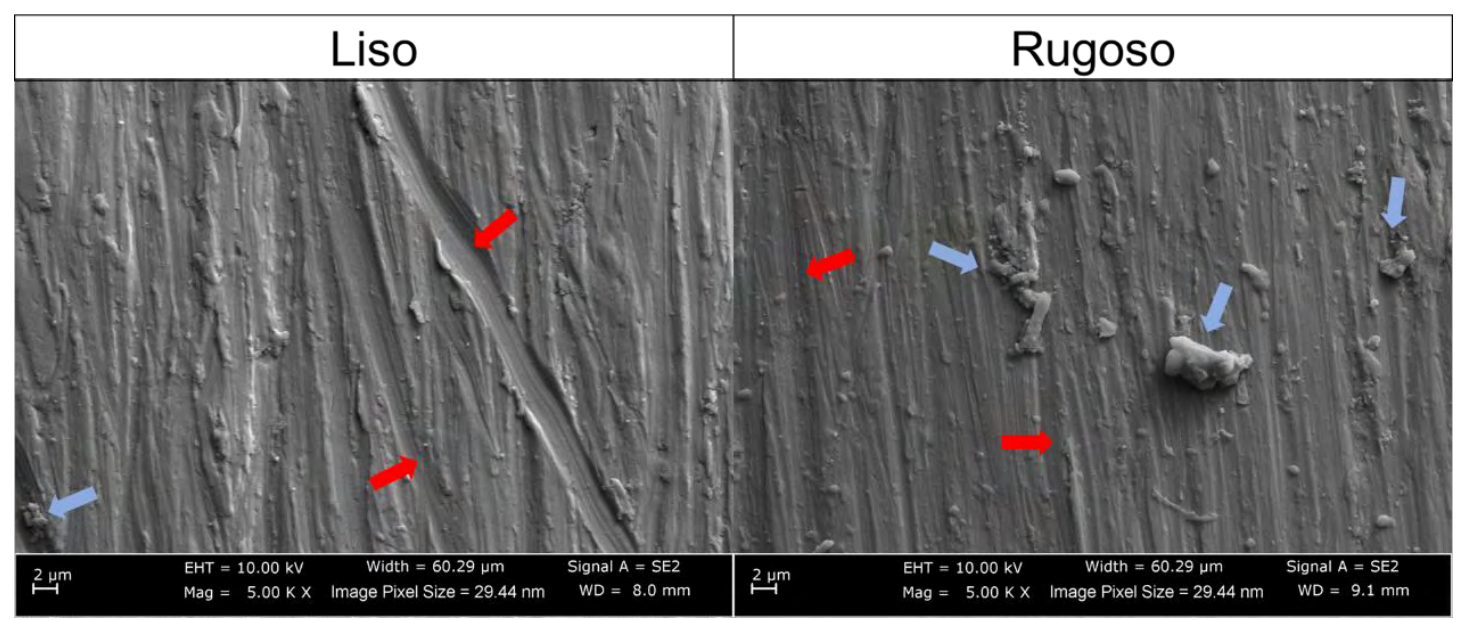


Figura 19 - Imagens de microscopia eletrônica de varredura dos microimplantes $L$ e $R$ antes e após os protocolos de descontaminação (100 x e 500 x, respectivamente).

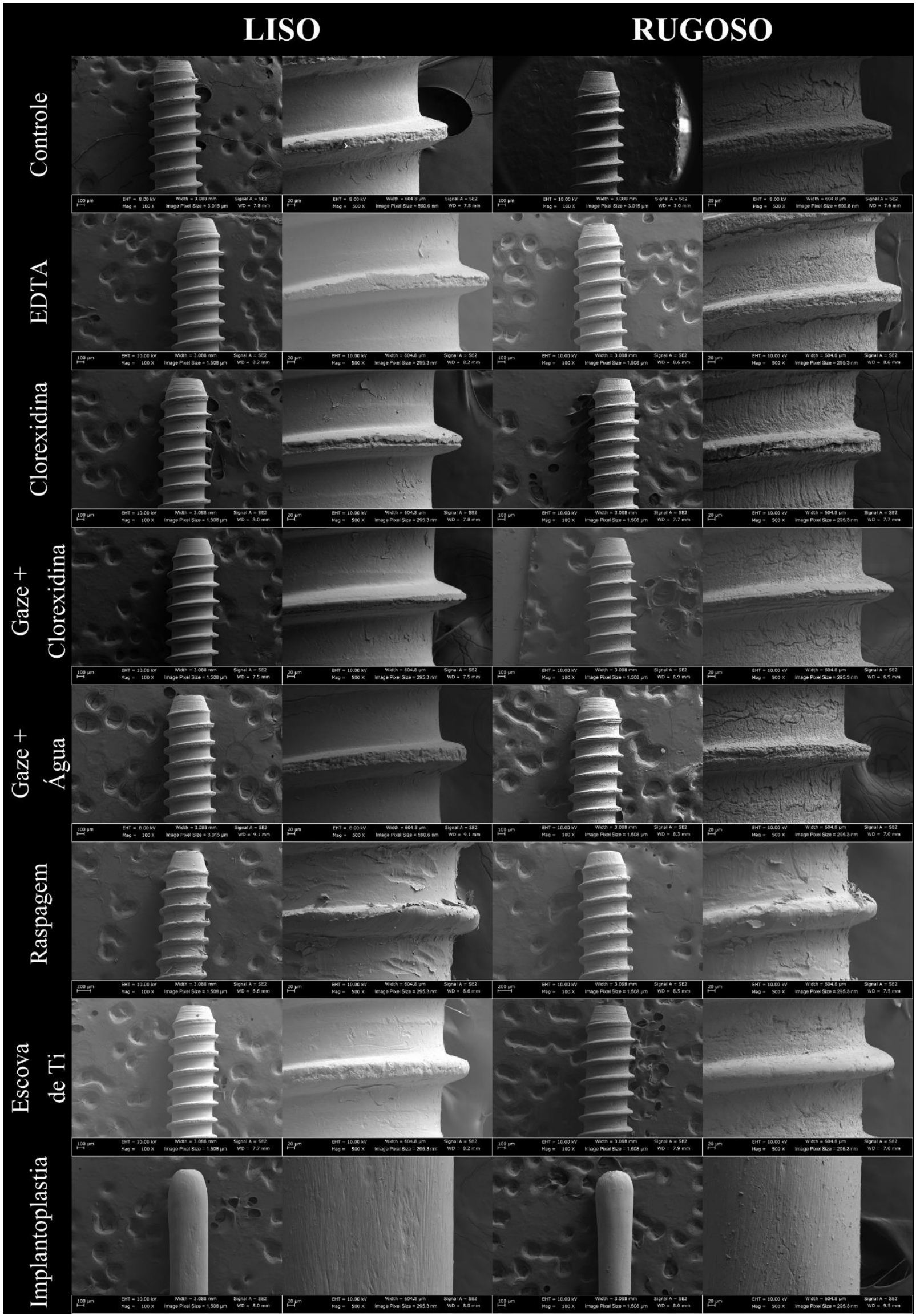


Figura 20. À esquerda, imagem de microscopia eletrônica de varredura (5.000 x) retratando a cobertura bacteriana em microimplantes não descontaminados (controle) e submetidos a descontaminação utilizando diferentes protocolos. À direita, a presença de E. coli foi evidenciada em branco para realização do cálculo porcentual.

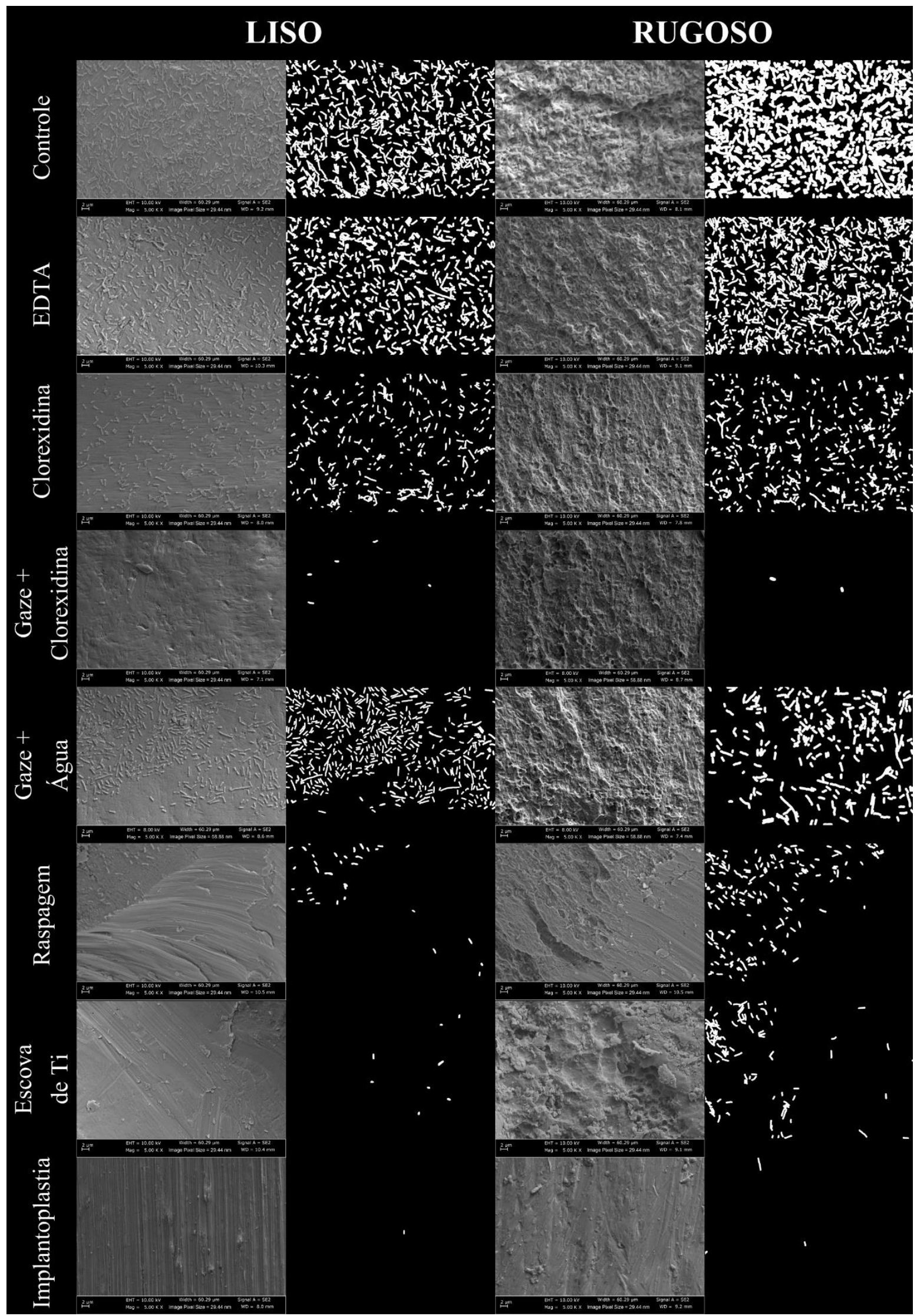




\subsection{Avaliação da composição química superficial}

Enquanto que nos microimplantes novos (L-C e R-C) apenas foram detectadas concentrações de $\mathrm{Ti}$ e $\mathrm{O}$ em suas superfícies, vários contaminantes químicos foram encontrados nos grupos experimentais (Tabela 2 e 3). Todos os protocolos de descontaminação estiveram associados com uma redução estatisticamente significante do wt\% do Ti superficial quando comparado aos grupos controle (L-C e R-C), sendo os menores valores encontrados nos grupos L-CX e R-CX (Tabela 2). Ao comparar os microimplantes S e R dentro de cada segmento, o valor de wt\% do Ti foi superior para R-C, L-GCX, L-MQ e RIP quando comparado a suas contrapartes $(p<0.002)$. Os contaminantes mais frequentes observados foram o $\mathrm{O}, \mathrm{C}, \mathrm{Na}, \mathrm{Al}$ e $\mathrm{Cl}$, além de outros elementos em menores proporção.

Tabela 2. Porcentagem de massa dos elementos químicos superficiais avaliados por EDS.

\begin{tabular}{|c|c|c|c|c|c|c|c|c|c|}
\hline \multicolumn{2}{|c|}{ Wt\% } & C & EDTA & $C X$ & GCX & GMQ & $\mathbf{R A}$ & ETi & IP \\
\hline \multirow{3}{*}{$\begin{array}{c}\mathrm{Ti} \\
(\%)\end{array}$} & $\mathrm{L}$ & $\begin{array}{c}91,48 \pm \\
0,91{ }^{\AA}\end{array}$ & $\begin{array}{c}80,39 \pm \\
2,26^{\mathrm{B}}\end{array}$ & $\begin{array}{c}38,35 \pm \\
5,58^{c}\end{array}$ & $\begin{array}{c}73,33 \pm \\
2,47^{D}\end{array}$ & $\begin{array}{c}83,97 \pm \\
0,9 \mathrm{~B}, \mathrm{E}\end{array}$ & $\begin{array}{l}82,77 \pm \\
0,09 \mathrm{~B}, \mathrm{E}\end{array}$ & $\begin{array}{c}75,77 \pm \\
0,55^{\mathrm{D}}\end{array}$ & $\begin{array}{l}74,9 \pm \\
1,11^{D}\end{array}$ \\
\hline & $\mathrm{R}$ & $\begin{array}{c}95,33 \pm \\
0,16^{\AA}\end{array}$ & $\begin{array}{l}77,91 \pm \\
3,82^{B, D}\end{array}$ & $\begin{array}{c}57,89 \pm \\
7,97 \mathrm{c}\end{array}$ & $\begin{array}{l}60,02 \pm \\
3,83 \text { CD }\end{array}$ & $\begin{array}{l}70,48 \pm \\
3,08 \mathrm{D}, \mathrm{E}\end{array}$ & $\begin{array}{l}87,41 \pm \\
2,06^{A, B}\end{array}$ & $\begin{array}{l}77,02 \pm \\
5,73^{\mathrm{B}, \mathrm{E}}\end{array}$ & $\begin{array}{l}81,66^{ \pm \pm} \\
0,86^{B, E}\end{array}$ \\
\hline & $p^{*}$ & 0,0020 & & & 0,0072 & 0,0019 & & & 0,0011 \\
\hline \multirow{3}{*}{$\begin{array}{c}0 \\
(\%)\end{array}$} & $\mathrm{L}$ & $\begin{array}{l}8,52 \pm \\
0,91 \AA\end{array}$ & $\begin{array}{c}14,12 \pm \\
1,02^{\mathrm{B}}\end{array}$ & $\begin{array}{c}17,93 \pm \\
1,57^{c}\end{array}$ & $\begin{array}{l}11,54 \pm \\
1,75^{\mathrm{B}, \mathrm{D}}\end{array}$ & $\begin{array}{l}10,83 \pm \\
0,61 \mathrm{~A}, \mathrm{D}\end{array}$ & $\begin{array}{l}12,25 \pm \\
0,43^{B, D}\end{array}$ & $\begin{array}{l}11,91 \pm \\
0,47^{\mathrm{B}, \mathrm{D}}\end{array}$ & $\begin{array}{l}12,25 \pm \\
0,31^{B, D}\end{array}$ \\
\hline & $\mathrm{R}$ & $\begin{array}{l}4,67 \pm \\
0,16 \AA\end{array}$ & $\begin{array}{c}13,39 \pm \\
1,28^{\mathrm{B}}\end{array}$ & $\begin{array}{l}11,48 \pm \\
2,49^{B, C}\end{array}$ & $\begin{array}{l}12,37 \pm \\
2,33^{B, C}\end{array}$ & $\begin{array}{c}10,17 \pm \\
1,6^{\mathrm{B}, \mathrm{C}}\end{array}$ & $\begin{array}{c}8,58 \pm \\
0,57^{A, C}\end{array}$ & $\begin{array}{c}11,03 \pm \\
0,8^{\mathrm{B}, \mathrm{C}}\end{array}$ & $8,73 \pm 0,0,26$ \\
\hline & $p^{*}$ & 0,0020 & & & & & 0,0009 & & 0,0001 \\
\hline \multirow{3}{*}{$\begin{array}{c}\text { C } \\
(\%)\end{array}$} & $\mathrm{L}$ & $\mathrm{O}^{\mathrm{A}}$ & $0^{A}$ & $\begin{array}{c}34 \pm^{8} \\
2,15^{\mathrm{B}}\end{array}$ & $\begin{array}{l}6,97 \pm \\
1,62 \mathrm{c}\end{array}$ & $\begin{array}{l}4,21 \pm \\
0,33 \mathrm{c}\end{array}$ & $0^{A}$ & $\begin{array}{l}6,98 \pm \\
0,57 \mathrm{c}\end{array}$ & $\begin{array}{c}11,45^{ \pm} \\
0,96^{\mathrm{D}}\end{array}$ \\
\hline & $\mathrm{R}$ & $0^{A}$ & $\mathrm{O}^{\mathrm{A}}$ & $\begin{array}{c}26,22 \pm \\
8,66^{\mathrm{B}}\end{array}$ & $\begin{array}{c}10,08 \pm \\
1,92 \mathrm{C}\end{array}$ & $11 \pm \underset{c}{2,58}$ & $0^{A}$ & $\begin{array}{c}5,76 \pm \\
0,74^{\mathrm{A}, \mathrm{C}}\end{array}$ & $\underset{A, C}{4,81 \pm 0,35}$ \\
\hline & $p^{*}$ & & & & & 0,0107 & & & 0,0004 \\
\hline \multirow{3}{*}{$\begin{array}{l}\mathrm{Na} \\
(\%)\end{array}$} & $\mathrm{L}$ & $0^{A}$ & $\begin{array}{c}3,11 \pm \\
0,87^{\mathrm{B}, \mathrm{C}}\end{array}$ & $\begin{array}{c}2,24 \pm 0,81 \\
A, B, C\end{array}$ & $\begin{array}{l}4,07 \pm \\
2,28 \mathrm{C}\end{array}$ & $\begin{array}{c}0,71 \pm \\
0,01 \mathrm{A,B}\end{array}$ & $\begin{array}{c}2,52 \pm \\
0,25 \mathrm{A,B,C}\end{array}$ & $\begin{array}{l}2,94 \pm \\
0,17^{\mathrm{B}, \mathrm{C}}\end{array}$ & $0,17 \underset{A}{ \pm 0,04}$ \\
\hline & $\mathrm{R}$ & $\mathrm{O}^{\mathrm{A}}$ & $\begin{array}{l}4,58 \pm \\
1,26^{\mathrm{B}}\end{array}$ & $1,71 \underset{A, B}{ \pm 0,21}$ & $\begin{array}{l}8,23 \pm \\
1,96 \mathrm{c}\end{array}$ & $\begin{array}{l}3,66 \pm \\
0,68^{\mathrm{B}}\end{array}$ & $\begin{array}{l}2,05 \pm \\
0,84^{A, B}\end{array}$ & $\underset{B}{4,07 \pm 2,5}$ & $1,87 \underset{A, B}{ \pm 0,59}$ \\
\hline & $p^{*}$ & & & & & 0,0016 & & & 0,0071 \\
\hline \multirow{3}{*}{$\begin{array}{l}\text { Al } \\
(\%)\end{array}$} & $\mathrm{L}$ & $0^{A}$ & $0^{A}$ & $0^{A}$ & $0^{A}$ & $0^{A}$ & $0,1 \underbrace{0,05}_{B}$ & $\begin{array}{c}0,07 \pm \\
0,01 \stackrel{ \pm}{A, B}\end{array}$ & $0,1 \pm 0,04^{B}$ \\
\hline & $\mathrm{R}$ & $\mathrm{O}^{\mathrm{A}}$ & $O^{A}$ & $0^{A}$ & $0^{A}$ & $O^{A}$ & $\begin{array}{l}0,05 \pm \\
0,01{ }^{A}\end{array}$ & $0,09^{A}$ & $0,05 \underset{A}{ \pm} 0,01$ \\
\hline & $p^{*}$ & & & & & & & & \\
\hline \multirow{3}{*}{$\begin{array}{l}\mathrm{Cl} \\
(\%)\end{array}$} & $\mathrm{L}$ & $0^{A}$ & $\begin{array}{c}1,87 \pm \\
0,59 \mathrm{~A}, \mathrm{~B}\end{array}$ & $\underset{\mathrm{B}, \mathrm{C}}{2,99} \underset{0,57}{0}$ & $\begin{array}{c}3,5 \pm \\
2,15^{\mathrm{B}, \mathrm{C}}\end{array}$ & $\begin{array}{l}0,16 \pm \\
0,02 \AA\end{array}$ & $\begin{array}{l}1,71 \pm \\
0,22^{A, C}\end{array}$ & $\begin{array}{l}1,91 \pm \\
0,23_{A, C}\end{array}$ & $0,09 \underset{A}{ \pm 0} 0,01$ \\
\hline & $\mathrm{R}$ & $0^{A, D}$ & $\begin{array}{l}2,95 \pm \\
1,23 \mathrm{~A}, \mathrm{~B}\end{array}$ & $1,97 \underset{A, B}{ \pm 0,29}$ & $\begin{array}{l}7,91 \pm \\
1,67 \mathrm{c}\end{array}$ & $\begin{array}{c}3,73 \pm \\
0,89^{B, D}\end{array}$ & $\begin{array}{c}1,51 \pm \\
0,74^{\mathrm{A}, \mathrm{D}}\end{array}$ & $\begin{array}{c}3,03 \pm \\
2,76^{\mathrm{A}, \mathrm{D}}\end{array}$ & $\underset{\mathrm{A}, \mathrm{D}}{\mathbf{1}, 41} \mathbf{0 , 4 8}$ \\
\hline & $p^{*}$ & & & & & 0,0023 & & & 0,008 \\
\hline \multirow{3}{*}{$\begin{array}{c}\text { Others } \\
(\%)\end{array}$} & $\mathrm{L}$ & $0^{A}$ & $\begin{array}{c}0,51 \pm \\
0,14 \stackrel{A}{A, B}\end{array}$ & $\begin{array}{l}4,5 \pm \\
0,39^{c}\end{array}$ & $\begin{array}{c}0,59 \pm \\
0,25 \mathrm{~B}, \mathrm{D}, \mathrm{E}\end{array}$ & $\begin{array}{c}0,12 \pm \\
0,02 \mathrm{~A}, \mathrm{D}\end{array}$ & $\begin{array}{c}0,65 \pm \\
0,07^{\mathrm{B}, \mathrm{D}, \mathrm{E}}\end{array}$ & $\begin{array}{c}0,44 \pm \\
0,04^{A, D}\end{array}$ & $1,13 \pm \underset{E}{ \pm 0,29}$ \\
\hline & $\mathrm{R}$ & $0^{A}$ & $\begin{array}{c}1,17 \pm \\
0,33^{\mathrm{B}, \mathrm{C}, \mathrm{D}}\end{array}$ & $\underset{\mathrm{A}, \mathrm{B}, \mathrm{C}, \mathrm{D}}{0,73 \pm 0,24}$ & $\begin{array}{c}1,38 \pm \\
0,71 \mathrm{C,D}\end{array}$ & $\begin{array}{c}0,96 \pm \\
0,17^{B, C, D}\end{array}$ & $0,4 \underset{A, B}{ \pm 0,09}$ & $\begin{array}{c}0,98 \pm \\
0,36^{\mathrm{B}, \mathrm{C}, \mathrm{D}}\end{array}$ & $1,49 \underset{\mathrm{D}}{ \pm 0,09}$ \\
\hline & $p^{*}$ & & & 0,0001 & & 0,0011 & & & \\
\hline
\end{tabular}

ANOVA post hoc teste de comparação múltipla de Tukey. A mesma letra na mesma linha indica ausência de diferença estatisticamente significante $(p>0,05)$.

*Teste-T comparando os microimplantes L e R dentro de cada grupo controle ou experimental. 
Considerando a porcentagem atômica, resultados semelhantes foram observados. Todos os tratamentos estiveram associados com uma redução da atomic\% do Ti, bem como um aumento do O. Contudo, esta diferença não foi estatisticamente significante em todos os grupos. Os microimplantes dos grupos L-CX e R-CX apresentaram um notável aumento dos valores de C, mesmo quando comparados aos grupos L-GCX e R-GCX. Pequenos valores de Al foram encontrados nos grupos onde houve algum tipo de atrito metálico (RA, ETi e IP), mas as porcentagens não foram estatisticamente significantes quando comparada aos grupos controle $(p>0,05)$. Com excessão do Al, houve uma diferença estatisticamente significante na porcentagem de todos os demais elementos quando comparando os grupos L-IP e R-IP $(p<0,05)$.

Tabela 3. Porcentagem atômica dos elementos químicos superficiais avaliados por EDS.

\begin{tabular}{|c|c|c|c|c|c|c|c|c|c|}
\hline \multicolumn{2}{|c|}{ Atomic \% } & C & EDTA & CX & GCX & GMQ & RA & ETi & IP \\
\hline \multirow{3}{*}{ Ti (\%) } & $\mathrm{L}$ & $\begin{array}{c}78,21 \pm \\
1,98^{\AA}\end{array}$ & $\begin{array}{c}60,75 \pm \\
2,99^{\mathrm{B}}\end{array}$ & $\begin{array}{c}15,43 \pm \\
2,06\end{array}$ & $\begin{array}{c}49,04 \pm \\
2,92^{\mathrm{D}}\end{array}$ & $\begin{array}{c}62,18 \pm \\
1,66^{\mathrm{B}}\end{array}$ & $\begin{array}{c}64,59 \pm \\
0,36^{\mathrm{B}}\end{array}$ & $\begin{array}{c}50,94 \pm \\
0,69^{\mathrm{D}}\end{array}$ & $\begin{array}{c}46,97 \pm \\
1,68^{\mathrm{D}}\end{array}$ \\
\hline & $\mathrm{R}$ & $\begin{array}{c}87,21 \pm \\
0,41^{A}\end{array}$ & $\begin{array}{l}58,65 \pm \\
4,77^{\mathrm{B}, \mathrm{C}}\end{array}$ & $\begin{array}{c}29,01 \pm \\
7,78^{D}\end{array}$ & $\begin{array}{c}35,95 \pm \\
2,55^{\mathrm{D}}\end{array}$ & $\begin{array}{l}44,54 \pm \\
3,99 \mathrm{C}, \mathrm{D}\end{array}$ & $\begin{array}{l}72,88 \pm \\
3,13^{A, B}\end{array}$ & $\begin{array}{c}53,59 \pm \\
11,50^{\mathrm{C}, \mathrm{E}}\end{array}$ & $\begin{array}{l}60,45 \pm \\
0,73^{B, E}\end{array}$ \\
\hline & $p^{*}$ & 0,0015 & & & 0,0043 & 0,0021 & & & 0,0002 \\
\hline \multirow{3}{*}{ O (\%) } & $\mathrm{L}$ & $\begin{array}{c}21,79 \pm \\
1,98^{\AA}\end{array}$ & $\begin{array}{c}31,90 \pm \\
1,72^{\text {B }}\end{array}$ & $\begin{array}{c}21,51 \pm \\
1,03^{A}\end{array}$ & $\begin{array}{c}23,05 \pm \\
2,94^{A}\end{array}$ & $\begin{array}{c}24,00 \pm \\
0,96^{\AA}\end{array}$ & $\begin{array}{c}28,62 \pm \\
0,87^{\mathrm{B}}\end{array}$ & $\begin{array}{c}23,98 \pm \\
1,07{ }^{A}\end{array}$ & $\begin{array}{c}22,99 \pm \\
0,09 \AA\end{array}$ \\
\hline & $\mathrm{R}$ & $\begin{array}{c}12,79 \pm \\
0,41^{\AA}\end{array}$ & $\begin{array}{c}30,09 \pm \\
1,91^{\mathrm{B}}\end{array}$ & $\begin{array}{l}17,15 \pm \\
4,87^{A, C}\end{array}$ & $\begin{array}{c}22,14 \pm \\
3,85^{\mathrm{C}}\end{array}$ & $\begin{array}{l}19,25 \pm \\
3,43^{A, C}\end{array}$ & $\begin{array}{c}21,38 \pm \\
1,01 \mathrm{c}\end{array}$ & $\begin{array}{l}23,74 \pm \\
2,09 \mathrm{~B}, \mathrm{C}\end{array}$ & $\begin{array}{l}19,34 \pm \\
0,56^{A, C}\end{array}$ \\
\hline & $p^{*}$ & 0,0015 & & & & & 0,0007 & & 0,0004 \\
\hline \multirow{3}{*}{ C (\%) } & $\mathrm{L}$ & $0^{A}$ & $0^{A}$ & $\begin{array}{c}54,34 \pm \\
1,29^{\mathrm{B}}\end{array}$ & $\begin{array}{c}18,47 \pm \\
3,59 \mathrm{c}\end{array}$ & $\begin{array}{c}12,42 \pm \\
0,78^{D}\end{array}$ & $0^{A}$ & $\begin{array}{c}18,70 \pm \\
1,42 \text { C }\end{array}$ & $\begin{array}{c}28,60 \pm \\
1,78 \mathrm{E}\end{array}$ \\
\hline & $\mathrm{R}$ & $0^{A}$ & $0^{A}$ & $\begin{array}{l}50,40 \pm \\
11,95^{B}\end{array}$ & $\begin{array}{c}24,07 \pm \\
4,57 \mathrm{C}\end{array}$ & $\begin{array}{c}27,49 \pm \\
5,41^{\mathrm{C}}\end{array}$ & $\mathrm{O}^{\mathrm{A}}$ & $\begin{array}{c}14,33 \pm \\
13,11^{A, C}\end{array}$ & $\begin{array}{l}14,21 \pm \\
1,04^{A, C}\end{array}$ \\
\hline & $p^{*}$ & & & & & 0,0088 & & & 0,0003 \\
\hline \multirow{3}{*}{$\mathrm{Na}(\%)$} & $\mathrm{L}$ & $O^{A}$ & $\begin{array}{c}4,88 \pm \\
1,29 \mathrm{~B}, \mathrm{C}\end{array}$ & $\begin{array}{c}1,87 \pm \\
0,67 \stackrel{A, B}{ }\end{array}$ & $\begin{array}{l}5,70 \pm \\
3,22 \mathrm{c}\end{array}$ & $\begin{array}{c}1,10 \pm \\
0,03 \text { A,D }\end{array}$ & $\begin{array}{c}4,10 \pm \\
0,43^{B, C, D}\end{array}$ & $\begin{array}{c}4,12 \pm \\
0,23^{B, C, D}\end{array}$ & $\begin{array}{l}0,14 \pm \\
0,13^{A}\end{array}$ \\
\hline & $\mathrm{R}$ & $0^{A}$ & $\begin{array}{c}7,14 \pm \\
1,78^{\mathrm{B}, \mathrm{D}}\end{array}$ & $\begin{array}{c}1,75 \pm \\
0,15^{\mathrm{A}, \mathrm{C}}\end{array}$ & $\begin{array}{c}10,28 \pm \\
2,48^{D}\end{array}$ & $\begin{array}{c}4,79 \pm \\
0,69 \mathrm{~B}, \mathrm{C}, \mathrm{E}\end{array}$ & $\begin{array}{c}3,54 \pm \\
1,36 \mathrm{~A}, \mathrm{~B}\end{array}$ & $\begin{array}{c}5,05 \pm \\
2,09 \mathrm{~B}, \mathrm{C}, \mathrm{E}\end{array}$ & $\begin{array}{c}2,88 \pm \\
0,91 \mathrm{~A}, \mathrm{E}\end{array}$ \\
\hline & $p^{*}$ & & & & & & & & 0,0067 \\
\hline \multirow{3}{*}{ Al (\%) } & $\mathrm{L}$ & $0^{A}$ & $0^{A}$ & $0^{A}$ & $0^{A}$ & $0^{A}$ & $\begin{array}{l}0,23 \pm \\
0,23^{A}\end{array}$ & $\begin{array}{l}0,05 \pm \\
0,05^{A}\end{array}$ & $\begin{array}{l}0,11 \pm \\
0,04{ }^{A}\end{array}$ \\
\hline & $\mathrm{R}$ & $0^{A}$ & $0^{\mathrm{A}}$ & $0^{\mathrm{A}}$ & $\mathrm{O}^{\mathrm{A}}$ & $O^{A}$ & $\begin{array}{l}0,07 \pm \\
0,01 \AA\end{array}$ & $\begin{array}{c}0,035 \pm \\
0,06^{A}\end{array}$ & $\begin{array}{l}0,04 \pm \\
0,04 \stackrel{A}{ }\end{array}$ \\
\hline & $p^{*}$ & & & & & & & & \\
\hline \multirow{3}{*}{ Cl (\%) } & $\mathrm{L}$ & $0^{\mathrm{A}}$ & $\begin{array}{c}1,90 \pm \\
0,57^{\mathrm{A}, \mathrm{B}}\end{array}$ & $\begin{array}{c}1,63 \pm \\
0,35^{A, B}\end{array}$ & $\begin{array}{l}3,18 \pm \\
1,96^{\mathrm{B}}\end{array}$ & $\begin{array}{l}0,16 \pm \\
0,02 \mathrm{~A}\end{array}$ & $\begin{array}{l}1,80 \pm \\
0,24{ }^{A}\end{array}$ & $\begin{array}{l}1,74 \pm \\
0,20^{A}\end{array}$ & $\begin{array}{c}0,05 \pm \\
0,04^{A, B}\end{array}$ \\
\hline & $\mathrm{R}$ & $0^{A}$ & $\begin{array}{l}2,97 \pm \\
1,17^{\mathrm{B}}\end{array}$ & $\begin{array}{c}1,31 \pm \\
0,17^{A, B}\end{array}$ & $\begin{array}{l}6,41 \pm \\
1,39 \mathrm{c}\end{array}$ & $\begin{array}{c}3,16 \pm \\
0,64{ }^{A, B}\end{array}$ & $\begin{array}{c}1,69 \pm \\
0,80^{A, B}\end{array}$ & $\begin{array}{c}2,34 \pm \\
1,67^{\mathrm{A}, \mathrm{B}}\end{array}$ & $\begin{array}{c}1,41 \pm \\
0,48^{A, B}\end{array}$ \\
\hline & $p^{*}$ & & & & & 0,0012 & & & 0,0083 \\
\hline \multirow{3}{*}{$\begin{array}{c}\text { Others } \\
(\%)\end{array}$} & $\mathrm{L}$ & $0^{A}$ & $\begin{array}{l}0,57 \pm \\
0,13^{B}\end{array}$ & $\begin{array}{l}5,22 \pm \\
0,33 \mathrm{c}\end{array}$ & $\begin{array}{l}0,57 \pm \\
0,23^{B}\end{array}$ & $\begin{array}{c}0,14 \pm \\
0,03^{A, B}\end{array}$ & $\begin{array}{c}0,66 \pm \\
0,09^{\mathrm{B}, \mathrm{D}}\end{array}$ & $\begin{array}{l}0,46 \pm \\
0,04 \mathrm{~A}, \mathrm{~B}\end{array}$ & $\begin{array}{l}1,13 \pm \\
0,30^{D}\end{array}$ \\
\hline & $\mathrm{R}$ & $0^{A}$ & $\begin{array}{c}1,14 \pm \\
0,09^{\mathrm{B}, \mathrm{D}}\end{array}$ & $\begin{array}{c}0,39 \pm \\
0,06 \mathrm{~A}, \mathrm{C}\end{array}$ & $\begin{array}{c}1,16 \pm \\
0,57^{\mathrm{B}, \mathrm{D}}\end{array}$ & $\begin{array}{c}0,77 \pm \\
0,07^{\mathrm{B}, \mathrm{C}}\end{array}$ & $\begin{array}{c}0,44 \pm \\
0,09 \mathrm{~A}, \mathrm{C}\end{array}$ & $\begin{array}{c}0,91 \pm \\
0,32^{\mathrm{B}, \mathrm{C}}\end{array}$ & $\begin{array}{l}1,68 \pm \\
0,10^{D}\end{array}$ \\
\hline & $p^{*}$ & & 0,0033 & 0,00001 & & 0,0001 & & & 0,0408 \\
\hline
\end{tabular}

ANOVA post hoc teste de comparação múltipla de Tukey. A mesma letra na mesma linha indica ausência de diferença estatisticamente significante $(p>0,05)$.

*Teste-T comparando os microimplantes L e R dentro de cada grupo controle ou experimental. 


\subsection{Molhabilidade}

As imagens obtidas com a análise de molhabilidade estão exemplificadas na Figura 21, e a média dos valores obtidos estão descritos na Tabela 3. O único tratamento que ocasionou uma redução estatisticamente significante da hidrofilia foi a IP, não havendo diferença entre os grupos L-IP e R-IP ( $p>0.05)$. Nos demais grupos, os microimplantes $R$ apresentaram maior hidrofilia que os $L(p<0.0023)$.

Figura 21 - Avaliação do ângulo do menisco formado pela submersão e emersão dos microimplantes.

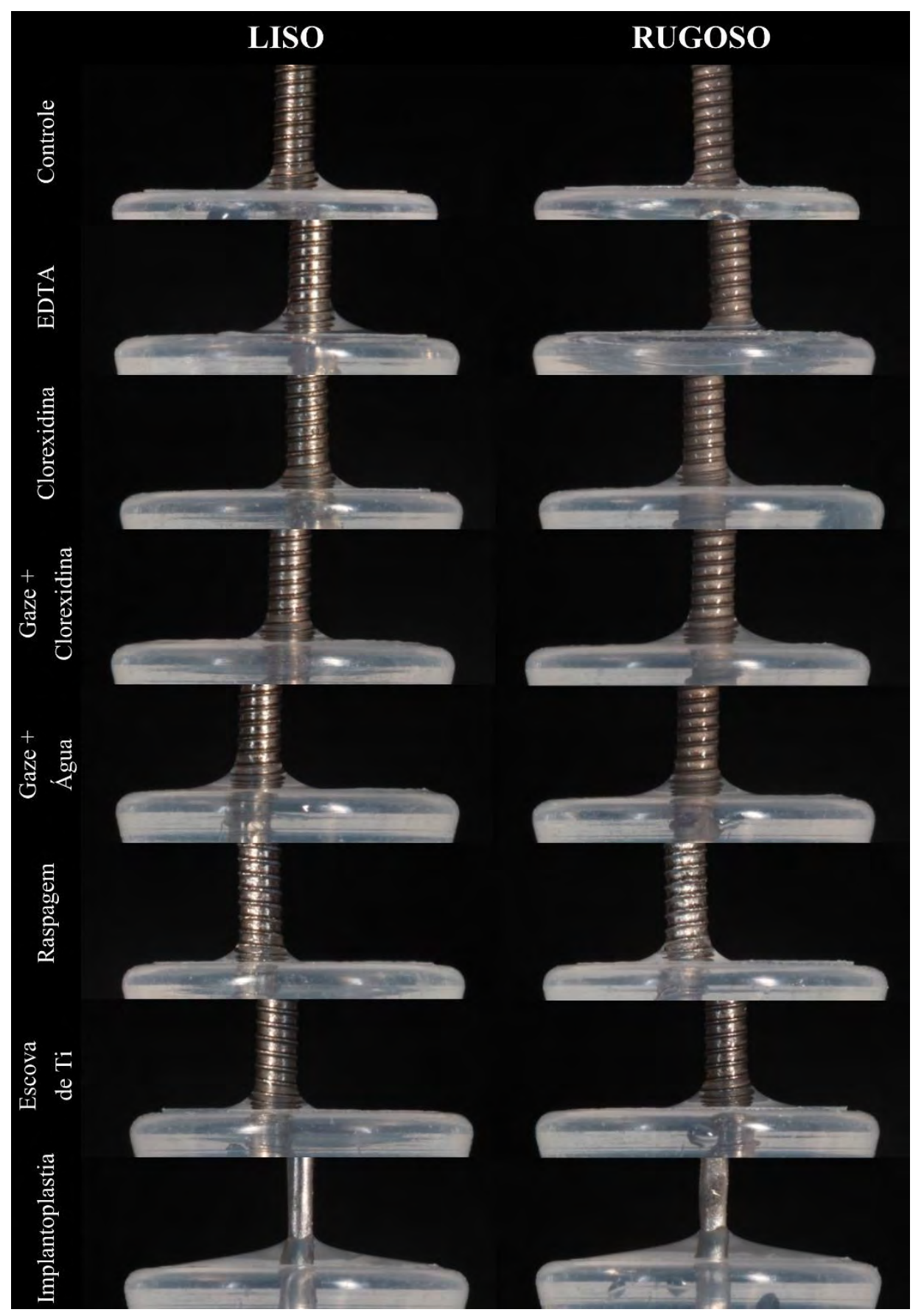


Tabela 4 - Molhabilidade avaliada pela técnica do menisco.

\begin{tabular}{|c|c|c|c|c|c|c|c|c|}
\hline & C & EDTA & CX & GCX & GMQ & RA & ETi & IP \\
\hline$L\left({ }^{\circ}\right)$ & $\begin{array}{l}39,45 \pm \\
12,30 A\end{array}$ & $\begin{array}{c}37,03 \pm \\
5,86 \text { A }\end{array}$ & $\begin{array}{c}41,67 \pm \\
5,98{ }^{A}\end{array}$ & $\begin{array}{c}40,51 \pm \\
6,09{ }^{A}\end{array}$ & $\begin{array}{c}39,69 \pm \\
4,50^{A}\end{array}$ & $\begin{array}{c}35,04 \pm \\
9,42 \mathrm{~A}\end{array}$ & $\begin{array}{c}41,48 \pm \\
4,05^{A}\end{array}$ & $\begin{array}{c}58,35 \pm \\
6,76^{\text {в }}\end{array}$ \\
\hline & $\begin{array}{c}27,58 \pm \\
9,08^{A}\end{array}$ & $\begin{array}{c}27,35 \pm \\
9,05^{A}\end{array}$ & $\begin{array}{c}25,58 \pm \\
6,94{ }^{A}\end{array}$ & $\begin{array}{c}27,83^{ \pm} \\
5,48^{A}\end{array}$ & $\begin{array}{c}29,41 \pm \\
4,05^{A}\end{array}$ & $\begin{array}{c}25,71 \pm \\
7,47^{\mathrm{A}}\end{array}$ & $\begin{array}{c}28,87 \pm \\
4,97 \AA\end{array}$ & $\begin{array}{c}53,81^{ \pm} \\
6,96^{\mathrm{B}}\end{array}$ \\
\hline & 0,0023 & 0,0006 & $<0,0001$ & $<0,0001$ & $<0,0001$ & 0,0023 & $<0,0001$ & \\
\hline
\end{tabular}

ANOVA post hoc teste de comparação múltipla de Tukey. A mesma letra na mesma linha indica ausência de diferença estatisticamente significante $(p>0,05)$.

*Teste-T comparando os microimplantes $L$ e $R$ dentro de cada grupo controle ou experimental.

\subsection{Rugosidade}

Os parâmetros tridimensionais avaliados estão descritos na Tabela 5, enquanto que os parâmetros bidimensionais estão na Tabela 6. As reconstruções das imagens topográficas podem ser vistas na Figura 22.

Tabela 5 - Parâmetros topográficos tridimensionais avaliados por perfilômetro óptico.

\begin{tabular}{|c|c|c|c|c|c|c|c|c|c|}
\hline & & C & EDTA & CX & GCX & GMQ & $\mathbf{R A}$ & ETi & IP \\
\hline \multirow{3}{*}{$\begin{array}{c}\mathrm{Sq} \\
(\mu \mathrm{m} \\
)\end{array}$} & $\mathrm{L}$ & $\begin{array}{l}0,57 \pm \\
0.02 \AA\end{array}$ & $\begin{array}{l}0,38 \pm \\
0,04^{\mathrm{B}}\end{array}$ & $\begin{array}{l}0,51 \pm \\
0,01 \AA\end{array}$ & $\begin{array}{c}0,48 \pm \\
0,04 \mathrm{A,B}\end{array}$ & $\begin{array}{c}0,49 \pm \\
0,011^{A, B}\end{array}$ & $\begin{array}{l}0,51 \pm \\
0,09 A\end{array}$ & $\begin{array}{l}0,56 \pm \\
0,02 \AA\end{array}$ & $\begin{array}{l}0,27 \pm \\
0,02 \mathrm{C}\end{array}$ \\
\hline & $\mathrm{R}$ & $\begin{array}{l}1,15 \pm \\
0,09 A\end{array}$ & $\begin{array}{l}1,05 \pm \\
0,13 \AA\end{array}$ & $\begin{array}{l}1,11 \pm \\
0,07 \mathrm{~A}\end{array}$ & $\begin{array}{l}0,96 \pm \\
0,02 \AA\end{array}$ & $\begin{array}{l}0,92 \pm \\
0,13 \AA\end{array}$ & $\begin{array}{c}0,57 \pm \\
0,11^{\mathrm{B}, \mathrm{C}}\end{array}$ & $\begin{array}{l}0,63 \pm \\
0,04^{B}\end{array}$ & $\begin{array}{l}0,31 \pm \\
0,03\end{array}$ \\
\hline & $p^{*}$ & 0,0005 & 0,0014 & 0,0002 & 0,0001 & 0,0059 & 0,0010 & & \\
\hline \multirow{3}{*}{$\begin{array}{c}\text { Ssk } \\
(\mu \mathrm{m} \\
)\end{array}$} & $\mathrm{S}$ & $\begin{array}{l}0,28 \pm \\
0,11 \mathrm{~A}\end{array}$ & $\begin{array}{c}-0,16 \pm \\
0,28 \AA\end{array}$ & $\begin{array}{l}0,23 \pm \\
0,06{ }^{A}\end{array}$ & $\begin{array}{l}0,09 \pm \\
0,13 \AA\end{array}$ & $\begin{array}{l}0,12 \pm \\
0,06 \mathrm{~A}\end{array}$ & $\begin{array}{l}0,07 \pm \\
0,29 A\end{array}$ & $\begin{array}{c}-0,12 \pm \\
0,15 \AA\end{array}$ & $\begin{array}{l}0,21 \pm \\
0,24\end{array}$ \\
\hline & $\mathrm{L}$ & $\begin{array}{c}-0,11 \pm \\
0,04{ }^{A, B, C}\end{array}$ & $\begin{array}{l}-0,68 \pm \\
0,68^{A}\end{array}$ & $\begin{array}{c}-0,22 \pm \\
0,09 \text { A,B,C }\end{array}$ & $\begin{array}{c}-0,30 \pm \\
0,32^{A, B, C}\end{array}$ & $\begin{array}{l}-0,43 \pm \\
0,17^{A, B}\end{array}$ & $\begin{array}{c}0,38 \pm \\
0,30^{B, C, D}\end{array}$ & $\begin{array}{l}-0,52 \pm \\
0,27 \mathrm{A,D}\end{array}$ & $\begin{array}{l}0,58 \pm \\
0,21\end{array}$ \\
\hline & $p^{*}$ & 0,0053 & & 0,0024 & & 0,0064 & & & \\
\hline \multirow{3}{*}{ Sku } & L & $\begin{array}{c}7,26 \pm \\
0,59 \mathrm{~A}, \mathrm{~B}\end{array}$ & $\begin{array}{l}4,79 \pm \\
0,57^{A}\end{array}$ & $\begin{array}{c}6,47 \pm \\
0,08{ }^{A, B}\end{array}$ & $\begin{array}{c}6,60 \pm \\
0,90 \mathrm{~A}, \mathrm{~B}\end{array}$ & $\begin{array}{l}7,41 \pm \\
1,45^{\mathrm{A}, \mathrm{B}}\end{array}$ & $\begin{array}{l}13,6 \pm \\
6,59^{B}\end{array}$ & $\begin{array}{l}11,72 \pm \\
5,46^{\mathrm{A}, \mathrm{B}}\end{array}$ & $\begin{array}{c}5,84 \pm \\
0,20^{A, B}\end{array}$ \\
\hline & $\mathrm{R}$ & $\begin{array}{l}5,16 \pm \\
0,76 \mathrm{~A}\end{array}$ & $\begin{array}{c}9,81 \pm \\
5,29 \mathrm{A,B}\end{array}$ & $\begin{array}{c}4,80 \pm \\
1,14^{A, C}\end{array}$ & $\begin{array}{l}14,69 \pm \\
4,42^{\mathrm{B}, \mathrm{C}}\end{array}$ & $\begin{array}{c}9,26 \pm \\
2,93^{\mathrm{A}, \mathrm{B}}\end{array}$ & $\begin{array}{c}17,62 \pm \\
4,34^{\mathrm{B}}\end{array}$ & $\begin{array}{c}6,52 \pm \\
0,45^{\mathrm{A}, \mathrm{C}}\end{array}$ & $\begin{array}{c}6,30 \pm \\
1,23^{A, C}\end{array}$ \\
\hline & $p^{*}$ & 0,0199 & & & & & & & \\
\hline \multirow{3}{*}{$\begin{array}{c}\mathrm{Sz} \\
(\mu \mathrm{m} \\
)\end{array}$} & $\mathrm{L}$ & $\begin{array}{c}6,37 \pm \\
0,14{ }^{A, D}\end{array}$ & $\begin{array}{l}3,06 \pm \\
0,31 \mathrm{~B}\end{array}$ & $\begin{array}{c}5,46 \pm \\
0,54{ }^{A, C}\end{array}$ & $\begin{array}{l}4,72 \pm \\
0,55 \mathrm{c}\end{array}$ & $\begin{array}{l}4,80 \pm \\
0,08 \stackrel{ }{C}\end{array}$ & $\begin{array}{l}7,64 \pm \\
0,58^{D}\end{array}$ & $\begin{array}{l}7,33 \pm \\
1,12^{D}\end{array}$ & $\begin{array}{l}2,89 \pm \\
0,25^{\mathrm{B}}\end{array}$ \\
\hline & $\mathrm{R}$ & $\begin{array}{c}11,51^{ \pm} \\
1,51^{A}\end{array}$ & $\begin{array}{c}12,55^{ \pm} \\
3,65^{\AA}\end{array}$ & $\begin{array}{l}10,17 \pm \\
1,36 \mathrm{~A}, \mathrm{~B}\end{array}$ & $\begin{array}{c}14,48 \pm \\
1,35^{A}\end{array}$ & $\begin{array}{l}11,03 \pm \\
1,15^{A, C}\end{array}$ & $\begin{array}{l}10,43 \pm \\
3,00 \mathrm{~A}, \mathrm{C}\end{array}$ & $\begin{array}{c}6,02 \pm \\
0,32 \mathrm{C,D}\end{array}$ & $\begin{array}{c}3,29 \pm \\
0,22^{\mathrm{B}, \mathrm{D}}\end{array}$ \\
\hline & $p^{*}$ & 0,0043 & 0,0110 & 0,0051 & 0,0003 & 0,0007 & & & \\
\hline \multirow{3}{*}{$\begin{array}{c}\text { Sa } \\
(\mu \mathrm{m} \\
{ }_{(\mu)}\end{array}$} & L & $\begin{array}{l}0,41 \pm \\
0,01 \AA\end{array}$ & $\begin{array}{l}0,32 \pm \\
0,07 \AA\end{array}$ & $\begin{array}{l}0,37 \pm \\
0,01 \AA\end{array}$ & $\begin{array}{l}0,36 \pm \\
0,03^{A}\end{array}$ & $\begin{array}{l}0,37 \pm \\
0,01 \stackrel{A}{ }\end{array}$ & $\begin{array}{l}0,33 \pm \\
0,05 \mathrm{~A}\end{array}$ & $\begin{array}{l}0,69 \pm \\
0,02 \AA\end{array}$ & $\begin{array}{l}0,20 \pm \\
0,011^{B}\end{array}$ \\
\hline & $\mathrm{R}$ & $\begin{array}{l}0,84 \pm \\
0,04 \stackrel{A}{A}\end{array}$ & $\begin{array}{l}0,72 \pm \\
0,04^{B}\end{array}$ & $\begin{array}{l}0,82 \pm \\
0,01 \stackrel{A}{ }\end{array}$ & $\begin{array}{l}0,61 \pm \\
0,03\end{array}$ & $\begin{array}{l}0,61 \pm \\
0,04 \stackrel{ }{c}\end{array}$ & $\begin{array}{l}0,38 \pm \\
0,05^{D}\end{array}$ & $\begin{array}{l}0,45 \pm \\
0,03 \pm\end{array}$ & $\begin{array}{l}0,22 \pm \\
0,02 \mathrm{E}\end{array}$ \\
\hline & $p^{*}$ & $7 E-05$ & $1 E-03$ & $2 E-06$ & $8 E-04$ & $6 E-04$ & $1 E-04$ & & \\
\hline \multirow{3}{*}{ Str } & $\mathrm{L}$ & $\begin{array}{l}0,39 \pm \\
0,05 \mathrm{~A}\end{array}$ & $\begin{array}{l}0,58 \pm \\
0,07 \AA\end{array}$ & $\begin{array}{l}0,51 \pm \\
0,08{ }^{A}\end{array}$ & $\begin{array}{l}0,51 \pm \\
0,05 \mathrm{~A}\end{array}$ & $\begin{array}{c}0,4901 \pm \\
0,12^{A}\end{array}$ & $\begin{array}{l}0,49 \pm \\
0,07 \mathrm{~A}\end{array}$ & $\begin{array}{l}0,50 \pm \\
0,02 \AA\end{array}$ & $\begin{array}{l}0,16 \pm \\
0,05^{\mathrm{B}}\end{array}$ \\
\hline & $\mathrm{R}$ & $\begin{array}{c}0,45 \pm \\
0.04{ }^{\mathrm{A}, \mathrm{B}}\end{array}$ & $\begin{array}{c}0,44 \pm \\
0,05^{\mathrm{A}, \mathrm{B}}\end{array}$ & $\begin{array}{c}0,39 \pm \\
0,07^{A, B}\end{array}$ & $\begin{array}{c}0,41 \pm \\
0,03 \mathrm{~A}, \mathrm{~B}\end{array}$ & $\begin{array}{l}0,49 \pm \\
0,07 \AA\end{array}$ & $\begin{array}{c}0,44 \pm \\
0,066^{A, B}\end{array}$ & $\begin{array}{l}0,54 \pm \\
0,03 \AA\end{array}$ & $\begin{array}{l}0,30 \pm \\
0,09^{B}\end{array}$ \\
\hline & $p^{*}$ & & & & & & & & \\
\hline \multirow{3}{*}{ Sdq } & $\mathrm{L}$ & $\begin{array}{l}0,98 \pm \\
0,05^{A}\end{array}$ & $\begin{array}{l}0,37 \pm \\
0,06^{\mathrm{B}}\end{array}$ & $\begin{array}{c}0,89 \pm \\
0,08^{A, C}\end{array}$ & $\begin{array}{c}0,66 \pm \\
0,10^{\mathrm{D}, \mathrm{E}}\end{array}$ & $\begin{array}{c}0,66 \pm \\
0,05^{\mathrm{D}, \mathrm{E}}\end{array}$ & $\begin{array}{l}0,66 \pm \\
0,05 \mathrm{E}\end{array}$ & $\begin{array}{l}1,10 \pm \\
0,13^{A}\end{array}$ & $\begin{array}{c}0,44 \pm \\
0,03^{\mathrm{B}, \mathrm{D}}\end{array}$ \\
\hline & $\mathrm{R}$ & $\begin{array}{l}2,41 \pm \\
0,18^{A}\end{array}$ & $\begin{array}{l}1,45 \pm \\
0,38^{B}\end{array}$ & $\begin{array}{l}2,37 \pm \\
0,13\end{array}$ & $\begin{array}{l}1,41 \pm \\
0,07^{\mathrm{B}}\end{array}$ & $\begin{array}{c}1,12 \pm \\
0,10^{\mathrm{B}, \mathrm{C}}\end{array}$ & $\begin{array}{c}0,86 \pm \\
0,16^{\mathrm{C}, \mathrm{D}}\end{array}$ & $\begin{array}{c}0,86 \pm \\
0,09 \mathrm{C}, \mathrm{D}\end{array}$ & $\begin{array}{l}0,51 \pm \\
0,03 \pm\end{array}$ \\
\hline & $p^{*}$ & 0,0002 & 0,00885 & 0,00010 & 0,00056 & 0,00260 & 0,00004 & & \\
\hline \multirow{3}{*}{$\begin{array}{l}\text { Sdr } \\
(\%)\end{array}$} & $\mathrm{L}$ & $\begin{array}{c}31,94 \pm \\
2,82^{A}\end{array}$ & $\begin{array}{l}7,29 \pm \\
2,49 \mathrm{~B}\end{array}$ & $\begin{array}{l}27,95 \pm \\
4,11 \text { A,C }\end{array}$ & $\begin{array}{l}18,32 \pm \\
4,63^{B, C}\end{array}$ & $\begin{array}{l}18,50 \pm \\
2,37^{B, C}\end{array}$ & $\begin{array}{c}15,43 \pm \\
2,34^{\mathrm{B}}\end{array}$ & $\begin{array}{c}39,29 \pm \\
8,11^{A}\end{array}$ & $\begin{array}{l}8,25 \pm \\
1,02 \mathrm{~B}\end{array}$ \\
\hline & $\mathrm{R}$ & $\begin{array}{c}110,65 \pm \\
7,84^{A}\end{array}$ & $\begin{array}{l}50,04 \pm \\
12,60^{B}\end{array}$ & $\begin{array}{c}108,73 \pm \\
6,14^{A}\end{array}$ & $\begin{array}{c}46,18 \pm \\
4,26^{\mathrm{B}}\end{array}$ & $\begin{array}{l}37,32 \pm \\
2,52 \mathrm{~B}, \mathrm{C}\end{array}$ & $\begin{array}{l}23,16 \pm \\
4,59 \mathrm{C}, \mathrm{D}\end{array}$ & $\begin{array}{l}28,05 \pm \\
3,86 \mathrm{C,D}\end{array}$ & $\begin{array}{c}10,91 \pm \\
1,26^{\mathrm{D}}\end{array}$ \\
\hline & $p^{*}$ & $8 E-05$ & $4 E-03$ & $5 E-05$ & $2 E-03$ & $7 E-04$ & $2 E-05$ & & \\
\hline
\end{tabular}

ANOVA post hoc teste de comparação múltipla de Tukey. A mesma letra na mesma linha indica ausência de diferença estatisticamente significante $(p>0,05)$.

*Teste-T comparando os microimplantes L e R dentro de cada grupo controle ou experimental. 
Resultados

Tabela 6 - Parâmetros topográficos bidimensionais avaliados por perfilômetro óptico.

\begin{tabular}{|c|c|c|c|c|c|c|c|c|c|}
\hline & & C & EDTA & CX & GCX & GMQ & $\mathbf{R A}$ & ETi & IP \\
\hline \multicolumn{10}{|c|}{ Perfis Oeste-Leste } \\
\hline \multirow{3}{*}{$\begin{array}{c}\mathbf{R a} \\
(\mu \mathrm{m})\end{array}$} & $\mathrm{L}$ & $\begin{array}{l}0,24 \pm \\
0,04 \stackrel{A}{A}\end{array}$ & $\begin{array}{l}0,19 \pm \\
0,01 \AA\end{array}$ & $\begin{array}{l}0,27 \pm \\
0,03 \AA\end{array}$ & $\begin{array}{l}0,26 \pm \\
0,05 \AA\end{array}$ & $0,25 \underset{A}{ \pm} 0,01$ & $0,26 \underset{A}{ \pm} 0,04$ & $\begin{array}{l}0,26 \pm \\
0,01 \AA\end{array}$ & $\begin{array}{l}0,19 \pm \\
0,01 \AA\end{array}$ \\
\hline & $\mathrm{R}$ & $\begin{array}{l}0,54 \pm \\
0,01 \stackrel{A}{A}\end{array}$ & $\begin{array}{l}0,49 \pm \\
0,066^{\mathrm{A}, \mathrm{B}}\end{array}$ & $\begin{array}{l}0,57 \pm \\
0,04 \stackrel{A}{ }\end{array}$ & $\begin{array}{c}0,40 \pm \\
0,01^{B, D, F}\end{array}$ & $0,36 \underset{\mathrm{C}, \mathrm{F}}{ \pm 0,02}$ & $0,29 \underset{\mathrm{C}, \mathrm{E}}{ \pm 0,03}$ & $\begin{array}{c}0,34 \pm \\
0,03^{\mathrm{C}, \mathrm{D}}\end{array}$ & $\begin{array}{l}0,20 \pm \\
0,02 \mathrm{E}\end{array}$ \\
\hline & $p^{*}$ & 0,0002 & 0,0009 & 0,0004 & 0,0055 & 0,0009 & & & \\
\hline \multirow{3}{*}{$\begin{array}{c}\mathbf{R q} \\
(\mu \mathrm{m})\end{array}$} & $\mathrm{L}$ & $\begin{array}{c}0,31 \pm \\
0,05^{A, B, C}\end{array}$ & $\begin{array}{l}0,23 \pm \\
0,01 \stackrel{\mathrm{B}}{ }\end{array}$ & $\begin{array}{c}0,34 \pm \\
0,03^{A, C}\end{array}$ & $\begin{array}{c}0,33 \pm \\
0,06^{\mathrm{A}, \mathrm{B}, \mathrm{C}}\end{array}$ & $\underset{A, B, C}{0,33 \pm 0,01}$ & $\underset{A, C}{0,34} \underset{A}{ \pm 0,05}$ & $\begin{array}{l}0,35 \pm \\
0,01 \pm\end{array}$ & $\begin{array}{c}0,25 \pm \\
0,01^{A, B}\end{array}$ \\
\hline & $\mathrm{R}$ & $\begin{array}{c}0,69 \pm \\
0,022^{A, E}\end{array}$ & $\begin{array}{c}0,64 \pm \\
0,10^{\mathrm{A}, \mathrm{E}}\end{array}$ & $\begin{array}{l}0,73 \pm \\
0,05 \mathrm{E}\end{array}$ & $\begin{array}{c}0,57 \pm \\
0,02 \stackrel{ \pm}{A, C}\end{array}$ & $\underset{B, C, E}{0,47 \pm 0,02}$ & $\underset{B, D}{0,38 \pm 0,05}$ & $\begin{array}{l}0,43 \pm \\
0,04^{\mathrm{B}}\end{array}$ & $\begin{array}{l}0,27 \pm \\
0,03 \pm\end{array}$ \\
\hline & $p^{*}$ & 0,0002 & 0,0022 & 0,0003 & 0,0026 & 0,0005 & & & \\
\hline \multirow{3}{*}{$\begin{array}{c}\mathbf{R v} \\
(\mu \mathrm{m})\end{array}$} & $\mathrm{L}$ & $\begin{array}{l}0,74 \pm \\
0,12^{A, B}\end{array}$ & $\begin{array}{l}0,53 \pm \\
0,03^{A}\end{array}$ & $\begin{array}{l}0,81 \pm \\
0,07^{B}\end{array}$ & $\begin{array}{c}0,77^{ \pm} \\
0,014^{B, C}\end{array}$ & $0,76 \underset{B, C}{ \pm 0,03}$ & $0,75_{B, C}^{ \pm 0} 0,10$ & $\begin{array}{l}0,87 \pm \\
0,04^{B}\end{array}$ & $\begin{array}{c}0,54 \pm \\
0,02 \stackrel{ \pm}{A, C}\end{array}$ \\
\hline & $\mathrm{R}$ & $\begin{array}{l}1,70 \pm \\
0,09^{A}\end{array}$ & $\begin{array}{l}1,64 \pm \\
0,50^{A, B}\end{array}$ & $\begin{array}{l}1,77 \pm \\
0,14^{A}\end{array}$ & $\begin{array}{l}1,59 \pm \\
0,18^{A, D}\end{array}$ & $\underset{B, C, D}{1,09 \pm 0,03}$ & $0,91 \underset{B, C}{ \pm 0,14}$ & $\begin{array}{l}0,96 \pm \\
0,08^{B}\end{array}$ & $\begin{array}{l}0,58 \pm \\
0,05 \mathrm{c}\end{array}$ \\
\hline & $p^{*}$ & 0,0004 & & 0,0004 & 0,0031 & 0,0002 & & & \\
\hline \multirow{3}{*}{$\begin{array}{c}\text { Rt } \\
(\mu \mathrm{m})\end{array}$} & $\mathrm{L}$ & $\begin{array}{c}1,49 \pm \\
0,21^{A, C}\end{array}$ & $\begin{array}{l}0,99 \pm \\
0,06^{B}\end{array}$ & $\begin{array}{l}1,65 \pm \\
0,11^{c}\end{array}$ & $\begin{array}{c}1,53 \pm \\
0,23^{A, C}\end{array}$ & $1,53 \underset{A, C}{ \pm 0,05}$ & $1,57 \underset{A, C}{ \pm 0,22}$ & $\begin{array}{l}1,81 \pm \\
0,05^{c}\end{array}$ & $\begin{array}{c}1,19 \pm \\
0,08^{\mathrm{A}, \mathrm{B}}\end{array}$ \\
\hline & $\mathrm{R}$ & $\begin{array}{l}3,34 \pm \\
0,11^{A}\end{array}$ & $\begin{array}{l}2,98 \pm \\
0,60^{A}\end{array}$ & $\begin{array}{l}3,53 \pm \\
0,21^{A}\end{array}$ & $\begin{array}{l}2,86 \pm \\
0,18^{A, B}\end{array}$ & $2,17 \underset{B, C}{ \pm 0,08}$ & $1,85 \underset{C, D}{ \pm 0,28}$ & $\begin{array}{c}1,91 \pm \\
0,17^{C, D}\end{array}$ & $\begin{array}{l}1,29 \pm \\
0,12^{D}\end{array}$ \\
\hline & $p^{*}$ & 0,0002 & 0,0047 & 0,0002 & 0,0014 & 0,0003 & & & \\
\hline \multirow{3}{*}{ Rsk } & $\mathrm{L}$ & $\begin{array}{c}0,03 \pm \\
0,09^{A, B, C}\end{array}$ & $\begin{array}{l}-0,12 \pm \\
0,001^{A}\end{array}$ & $\begin{array}{l}0,01 \pm \\
0,19^{A, B}\end{array}$ & $\begin{array}{l}0,01 \pm \\
0,12^{A, B}\end{array}$ & $0,02 \underset{A, B}{ \pm 0,08}$ & $0,19 \underset{B, C}{ \pm 0,08}$ & $\begin{array}{l}0,31 \pm \\
0,09 \frac{}{C}\end{array}$ & $\begin{array}{c}0,21 \pm \\
0,08^{\mathrm{B}, \mathrm{C}}\end{array}$ \\
\hline & $\mathrm{R}$ & $\begin{array}{l}-0,02 \pm \\
0,05^{A}\end{array}$ & $\begin{array}{r}-0,12^{ \pm} \\
0,18^{A}\end{array}$ & $\begin{array}{c}0,03 \pm \\
0,07^{A, B}\end{array}$ & $\begin{array}{l}-0,15 \pm \\
0,16^{A}\end{array}$ & $0,02 \underset{A, B}{ \pm 0,05}$ & $0,07 \underset{A, B}{ \pm 0,12}$ & $\begin{array}{l}0,01 \pm \\
0,04^{A, B}\end{array}$ & $\begin{array}{l}0,31 \pm \\
0,07^{\mathrm{B}}\end{array}$ \\
\hline & $p^{*}$ & & & & & & & 0,0055 & \\
\hline \multirow{3}{*}{ Rku } & $\mathrm{L}$ & $\begin{array}{l}4,10 \pm \\
0,25^{A}\end{array}$ & $\begin{array}{l}3,05 \pm \\
0,21^{B}\end{array}$ & $\begin{array}{l}3,91 \pm \\
0,20^{A, B}\end{array}$ & $\begin{array}{l}4,17 \pm \\
0,44^{A}\end{array}$ & $4,43 \underset{A}{ \pm} 0,28$ & $4,11 \underset{A}{ \pm} 0,28$ & $\begin{array}{l}4,79 \pm \\
0,44^{A}\end{array}$ & $\begin{array}{c}3,90 \pm \\
0,39 \mathrm{~A}, \mathrm{~B}\end{array}$ \\
\hline & $\mathrm{R}$ & $\begin{array}{l}3,56 \pm \\
0,16^{A, B}\end{array}$ & $\begin{array}{l}3,73 \pm \\
0,44^{A, B}\end{array}$ & $\begin{array}{l}3,47 \pm \\
0,17^{A}\end{array}$ & $\begin{array}{l}5,14 \pm \\
0,17^{c}\end{array}$ & $\underset{A, B, D}{4,06 \pm 0,15}$ & $4,43 \pm 0,0,22$ & $\begin{array}{l}3,67 \pm \\
0,21^{A}\end{array}$ & $\begin{array}{c}4,14 \pm \\
0,15^{\mathrm{B}, \mathrm{D}}\end{array}$ \\
\hline & $p^{*}$ & & & & 0,0235 & & & & \\
\hline \multicolumn{10}{|c|}{ Perfis Norte-Sul } \\
\hline \multirow{3}{*}{$\begin{array}{c}\mathbf{R a} \\
(\mu \mathrm{m})\end{array}$} & $\mathrm{L}$ & $\begin{array}{c}0,33 \pm \\
0,01^{A, B}\end{array}$ & $\begin{array}{l}0,26 \pm \\
0,06^{A}\end{array}$ & $\begin{array}{l}0,36 \pm \\
0,04^{\mathrm{B}}\end{array}$ & $\begin{array}{c}0,30 \pm \\
0,04^{A, B}\end{array}$ & $\begin{array}{c}0,31 \pm \\
0,025^{\mathrm{A}, \mathrm{B}}\end{array}$ & $0,27 \underset{A, B}{ \pm 0,05}$ & $\begin{array}{c}0,32 \pm \\
0,022^{A, B}\end{array}$ & $\begin{array}{l}0,12 \pm \\
0,01 \mathrm{c}\end{array}$ \\
\hline & $\mathrm{R}$ & $\begin{array}{l}0,76 \pm \\
0,04^{A}\end{array}$ & $\begin{array}{l}0,57 \pm \\
0,10^{B, C}\end{array}$ & $\begin{array}{c}0,73 \pm \\
0,09 \mathrm{~A}, \mathrm{~B}\end{array}$ & $\begin{array}{l}0,54 \pm \\
0,01 \mathrm{c}\end{array}$ & $0,46 \underset{\mathrm{C}, \mathrm{D}}{\mathbf{0}} 0,02$ & $0,29 \underset{D, E}{ \pm 0,04}$ & $\begin{array}{l}0,37 \pm \\
0,05^{D}\end{array}$ & $\begin{array}{l}0,15 \pm \\
0,01 \mathrm{E}\end{array}$ \\
\hline & $p^{*}$ & 0,0001 & 0,0103 & 0,0031 & 0,0004 & 0,0014 & & & \\
\hline \multirow{3}{*}{$\underset{(\mu \mathrm{m})}{\mathbf{R q}}$} & $\mathrm{L}$ & $\begin{array}{l}0,43 \pm \\
0,04 \mathrm{~A}\end{array}$ & $\begin{array}{l}0,33 \pm \\
0,09 \AA\end{array}$ & $\begin{array}{l}0,47 \pm \\
0,06^{A}\end{array}$ & $\begin{array}{l}0,38 \pm \\
0,04 \mathrm{~A}\end{array}$ & $0,39 \underset{A}{ \pm} 0,02$ & $0,37 \underset{A}{ \pm 0} 0,06$ & $\begin{array}{l}0,43 \pm \\
0,03 \mathrm{~A}\end{array}$ & $\begin{array}{l}0,16 \pm \\
0,011^{B}\end{array}$ \\
\hline & $\mathrm{R}$ & $\begin{array}{l}1,00 \pm \\
0,09^{A}\end{array}$ & $\begin{array}{c}0,78 \pm \\
0,18^{A, B}\end{array}$ & $\begin{array}{l}0,96 \pm \\
0,15^{\mathrm{A}}\end{array}$ & $\begin{array}{c}0,79 \pm \\
0,03^{A, E}\end{array}$ & $\underset{\mathrm{B}, \mathrm{C}, \mathrm{E}}{0,65 \pm 0,06}$ & $0,39 \underset{\mathrm{C}, \mathrm{D}}{ \pm 0,06}$ & $\begin{array}{c}0,50 \pm \\
0,06^{\mathrm{B}, \mathrm{C}}\end{array}$ & $\begin{array}{l}0,21 \pm \\
0,02{ }^{D}\end{array}$ \\
\hline & $p^{*}$ & 0,0005 & 0,0194 & 0,0072 & 0,0003 & 0,0034 & & & \\
\hline \multirow{3}{*}{$\begin{array}{c}\text { Rv } \\
(\mu \mathrm{m})\end{array}$} & $\mathrm{L}$ & $\begin{array}{l}1,10 \pm \\
0,03^{A}\end{array}$ & $\begin{array}{c}0,83 \pm \\
0,40^{A, B}\end{array}$ & $\begin{array}{l}1,21 \pm \\
0,18^{A}\end{array}$ & $\begin{array}{l}0,89 \pm \\
0,10^{A}\end{array}$ & $0,99 \underset{A}{ \pm} 0,04$ & $0,89 \pm \underset{A}{0} 0,16$ & $\begin{array}{l}1,18 \pm \\
0,10^{A}\end{array}$ & $\begin{array}{l}0,35 \pm \\
0,03^{\mathrm{B}}\end{array}$ \\
\hline & $\mathrm{R}$ & $\begin{array}{l}2,67 \pm \\
0,46^{A}\end{array}$ & $\begin{array}{l}2,19 \pm \\
0,83^{A, B}\end{array}$ & $\begin{array}{l}2,57 \pm \\
0,65^{A}\end{array}$ & $\begin{array}{l}2,59 \pm \\
0,22^{A}\end{array}$ & $1,82 \underset{A, C}{ \pm 0,30}$ & $0,92 \underset{C, D}{ \pm 0,13}$ & $\begin{array}{c}1,34 \pm \\
0,18^{B, C, D}\end{array}$ & $\begin{array}{l}0,45 \pm \\
0,04{ }^{D}\end{array}$ \\
\hline & $p^{*}$ & 0,0041 & & & 0,0003 & 0,0083 & & & \\
\hline \multirow{3}{*}{$\begin{array}{c}\mathbf{R t} \\
(\mu \mathrm{m})\end{array}$} & $\mathrm{L}$ & $\begin{array}{l}2,16 \pm \\
0,04^{A, C}\end{array}$ & $\begin{array}{l}1,45 \pm \\
0,53^{A, B}\end{array}$ & $\begin{array}{l}2,34 \pm \\
0,30^{c}\end{array}$ & $\begin{array}{c}1,74 \pm \\
0,18^{A, C}\end{array}$ & $7,82 \pm 0,08$ & $1,77_{A, C}^{ \pm 0,29}$ & $\begin{array}{l}2,29 \pm \\
0,17^{c}\end{array}$ & $\begin{array}{l}0,82 \pm \\
0,06^{\mathrm{B}}\end{array}$ \\
\hline & $\mathrm{R}$ & $\begin{array}{l}4,47 \pm \\
0,49^{A}\end{array}$ & $\begin{array}{l}3,72 \pm \\
1,04^{A, B}\end{array}$ & $\begin{array}{l}4,60 \pm \\
0,83^{A, C}\end{array}$ & $\begin{array}{l}3,94 \pm \\
0,17^{A, D}\end{array}$ & $\begin{array}{c}3,21 \pm 0,41 \\
B, C, D, E\end{array}$ & $1,85 \underset{E, F}{ \pm 0,28}$ & $\begin{array}{c}2,40 \pm \\
0,27^{B, E, F}\end{array}$ & $\begin{array}{l}1,06 \pm \\
0,09 \mathrm{~F}\end{array}$ \\
\hline & $p^{*}$ & 0,0008 & & 0,0113 & 0,0001 & 0,0044 & & & \\
\hline \multirow{3}{*}{ Rsk } & $\mathrm{L}$ & $\begin{array}{l}0,17 \pm \\
0,12^{A}\end{array}$ & $\begin{array}{r}-0,11^{ \pm} \\
0,15^{B}\end{array}$ & $\begin{array}{l}0,15 \pm \\
0,11^{A, B}\end{array}$ & $\begin{array}{l}0,02 \pm \\
0,10^{A, B}\end{array}$ & $-0,05 \pm 0,06$ & $0,07 \underset{A, B}{ \pm 0,05}$ & $\begin{array}{c}0,16 \pm \\
0,05^{A, B}\end{array}$ & $\begin{array}{l}0,48 \pm \\
0,09 \mathrm{c}\end{array}$ \\
\hline & $\mathrm{R}$ & $\begin{array}{l}-0,14 \pm \\
0,07^{A}\end{array}$ & $\begin{array}{r}-0,17 \pm \\
0,31^{A}\end{array}$ & $\begin{array}{c}-0,13 \pm \\
0,11^{A}\end{array}$ & $\begin{array}{r}-0,28 \pm \\
0,03^{A}\end{array}$ & $-0,03 \underset{A}{ \pm} 0,10$ & $\begin{array}{l}-0,21 \pm \\
0,06^{A}\end{array}$ & $\begin{array}{c}-0,38 \pm \\
0,16^{A}\end{array}$ & $\begin{array}{l}0,55 \pm \\
0,02^{\mathrm{B}}\end{array}$ \\
\hline & $p^{*}$ & 0,0169 & & & 0,0067 & & 0,0032 & 0,0048 & \\
\hline \multirow{3}{*}{ Rku } & $\mathrm{L}$ & $\begin{array}{l}4,27 \pm \\
0,31 A\end{array}$ & $\begin{array}{l}3,27 \pm \\
0,61^{B}\end{array}$ & $\begin{array}{l}4,33 \pm \\
0,15^{A}\end{array}$ & $\begin{array}{l}4,31 \pm \\
0,43^{A}\end{array}$ & $4,49 \underset{A}{ \pm} 0,14$ & $4,29 \underset{A}{ \pm} 0,15$ & $\begin{array}{l}4,96 \pm \\
0,23^{A}\end{array}$ & $\begin{array}{l}5,05 \pm \\
0,21 \AA\end{array}$ \\
\hline & $\mathrm{R}$ & $\begin{array}{l}3,65 \pm \\
0,30^{A}\end{array}$ & $\begin{array}{l}3,92 \pm \\
0,61 \pm, B\end{array}$ & $\begin{array}{l}3,57 \pm \\
0,33^{A}\end{array}$ & $\begin{array}{l}5,38 \pm \\
0,26^{c}\end{array}$ & $4,52 \underset{A, C}{ \pm 0,43}$ & $4,90 \underset{B, C}{ \pm 0,31}$ & $\begin{array}{c}4,53 \pm \\
0,22^{A, C}\end{array}$ & $\begin{array}{l}5,03 \pm \\
0,17 \mathrm{c}\end{array}$ \\
\hline & $p^{*}$ & & & & 0,0209 & & & & \\
\hline
\end{tabular}

ANOVA post hoc teste de comparação múltipla de Tukey. A mesma letra na mesma linha indica ausência de diferença estatisticamente significante $(p>0,05)$.

*Teste-T comparando os microimplantes L e R dentro de cada grupo controle ou experimental. 
Os implantes L-C apresentaram um Sa de 0,41 $\pm 0,01 \mu \mathrm{m}$ e os R-C 0,84 $\pm 0,04 \mu \mathrm{m}$, demonstrando a eficácia do tratamento superficial com duplo ataque ácido utilizado nesta metodologia. Modalidades de tratamento baseadas em ações mecânicas mais agressivas (S, TiB e IP) levaram a menores diferenças entre os implantes $L$ e $R$ de cada protocolo após a descontaminação.

Nenhuma diferença estatisticamente significante foi observada no Ra da maioria dos microimplantes $L$, com excessão do grupo L-IP nos perfis Norte-Sul $(p<0,05)$. A diferença de $\mathrm{Ra}$ foi mais significativa nos microimplantes $\mathrm{R}$, com uma redução de seu valor nos perfis Norte-Sul e Oeste-Leste nos grupos R-GX, R-GMQ, R-RA, R-ETi e R-IP, e apenas nos perfis Oeste-Leste no grupo R-EDTA. Nenhuma diferença foi observada entre a rugosidade dos implantes L e R nos tratamentos RA, ETi e IP. Nenhuma diferença entre os grupos L-IP e RIP foi notada em nenhum dos parâmetros avaliados. 
Figura 22 - Reconstruções da superfície dos microimplantes obtidas com perfilômetro óptico após aplicação de um corte de 40 x $40 \mu \mathrm{m}$ e um filtro Gaussiano de $25 \mu \mathrm{m}$.

\section{LISO}
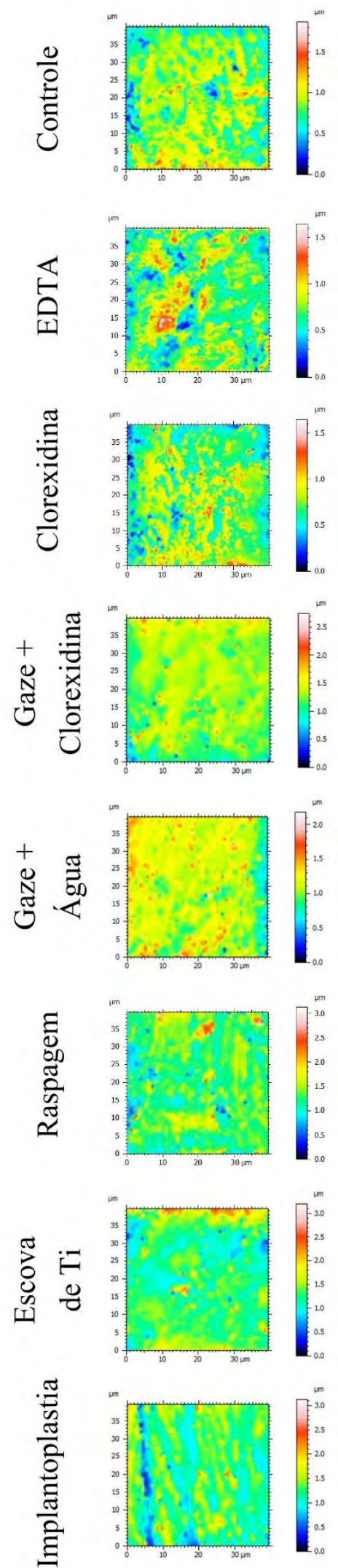
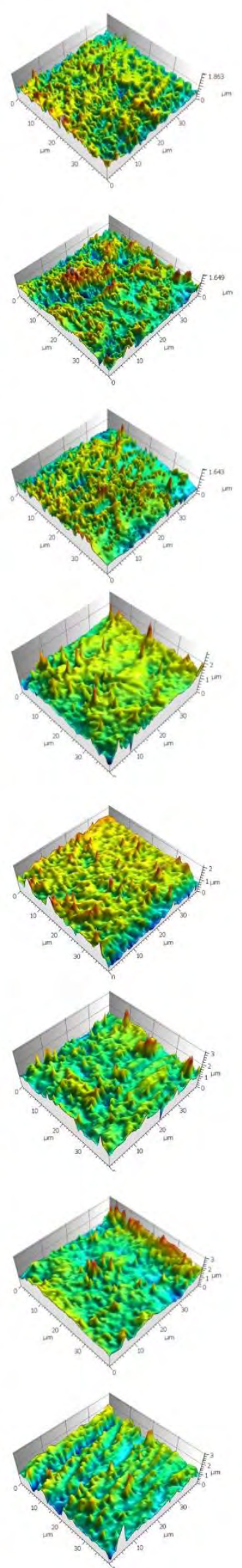

\section{RUGOSO}
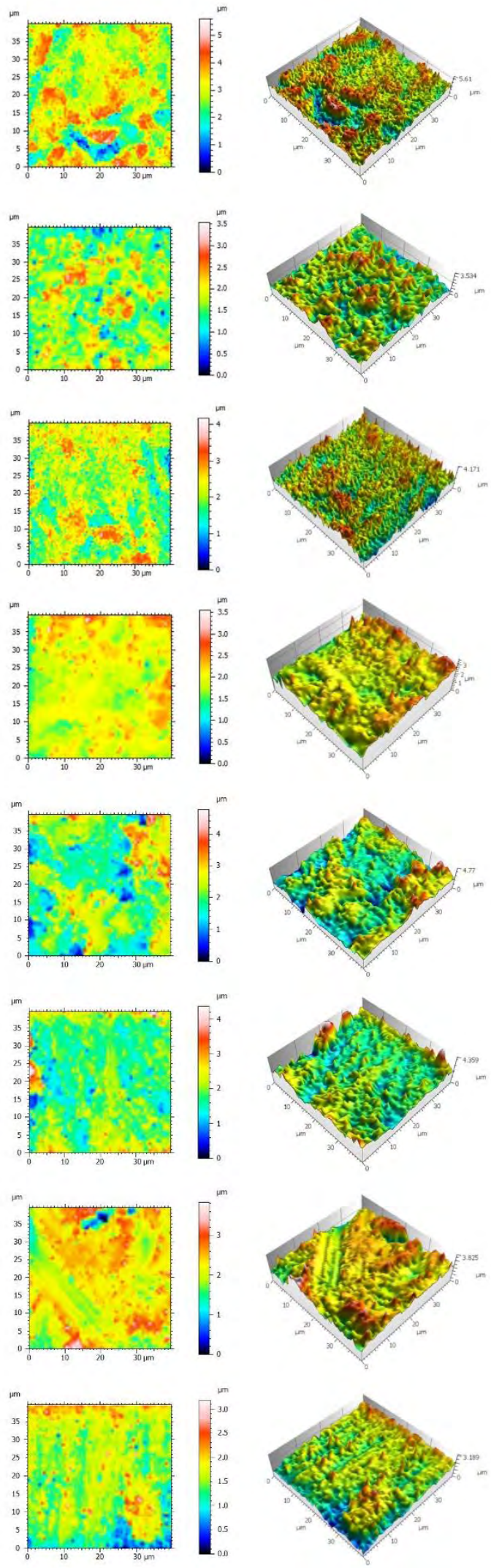


\subsection{Migração celular}

O número de células viáveis mensuradas através da quantificação de ATP está exposto na Tabela 7. Após $24 \mathrm{~h}$, apenas nos microimplantes $\mathrm{L}$ houve diferença entre os grupos, com valores inferiores nos grupos L-CX e L-IP $(p<0,05)$. Às $72 h$, os grupos L-CX, LETi e L-IP apresentaram valores estatisticamente inferiores que o grupo $L-C(p<0,05)$, enquanto que os grupos R-CX, R-GMQ, R-RA, R-ETI e R-IP tiveram desempenho pior que o R-C ( $p<0,05)$. Após 120 h, os grupos L-EDTA, L-GX, L-RA, L-ETi não apresentaram diferença estatisticamente significante com o grupo $L-C(p>0,05)$, enquanto que apenas os grupos $R$ EDTA e R-GCX não apresentaram diferença estatística do grupo R-C $(p<0,05)$. Não houve diferença entre 24 h e 120 h nos grupos L-MQ, L-RA, L-IP, R-GMQ, R-ETi e R-IP $(p<0,05)$.

Tabela 7 - Valores de luminescência obtidos com o ensaio de migração celular de arcabouço impresso em 3D para a superfície de microimplantes descontaminados ou nunca contaminados.

\begin{tabular}{|c|c|c|c|c|c|c|c|c|}
\hline & C & EDTA & CX & GCX & GMQ & $\mathbf{R A}$ & ETi & IP \\
\hline \multicolumn{9}{|c|}{ LISO } \\
\hline 24h (RLU) & $\begin{array}{l}27,44 \pm \\
4,48 \text { A/a }\end{array}$ & $\begin{array}{c}21,88 \pm \\
2,04 \mathrm{~A}, \mathrm{~B} / \mathrm{a}\end{array}$ & $\begin{array}{l}20,77 \pm \\
2,01 \mathrm{~B} / \mathrm{a}\end{array}$ & $\begin{array}{l}27,55 \pm \\
1,02 \mathrm{~A} / \mathrm{a}\end{array}$ & $\begin{array}{c}21,33 \pm \\
0,33 \mathrm{~A}, \mathrm{~B} / \mathrm{a}\end{array}$ & $\begin{array}{c}22,55 \pm \\
1,92 \mathrm{~A}, \mathrm{~B} / \mathrm{a}\end{array}$ & $\begin{array}{c}21,88 \pm \\
2,04 \text { A,B/a }\end{array}$ & $\begin{array}{l}20,55 \pm \\
1,64 \text { B/a }\end{array}$ \\
\hline 72h (RLU) & $\begin{array}{l}40,11 \pm \\
7,00 \mathrm{~A} / \mathrm{b}\end{array}$ & $\begin{array}{c}30,77 \pm \\
3,98 \text { A,B/b }\end{array}$ & $\begin{array}{c}25,77 \pm \\
3,91 \text { B/a,b }\end{array}$ & $\begin{array}{c}38,66 \pm \\
3,76 \text { A,B/a,b }\end{array}$ & $\begin{array}{c}27,44 \pm \\
7,71 \mathrm{~A}, \mathrm{~B} / \mathrm{a}\end{array}$ & $\begin{array}{c}29,88 \pm \\
4,62 \mathrm{~A}, \mathrm{~B} / \mathrm{a}\end{array}$ & $\begin{array}{c}25,55 \pm \\
3,27^{B / a, b}\end{array}$ & $\begin{array}{l}25,44 \pm \\
2,36 \text { B/a }\end{array}$ \\
\hline 120h (RLU) & $\begin{array}{l}42,22 \pm \\
4,00 \mathrm{~A} / \mathrm{b}\end{array}$ & $\begin{array}{c}39,55 \pm \\
3,17 \mathrm{~A}, \mathrm{~B} / \mathrm{c}\end{array}$ & $\begin{array}{c}26,55 \pm \\
4,3 \mathrm{C} / \mathrm{b}\end{array}$ & $\begin{array}{l}41,11 \pm \\
7,31 \mathrm{~A} / \mathrm{b}\end{array}$ & $\begin{array}{c}29,55 \pm \\
2,17^{B, C / a}\end{array}$ & $\begin{array}{c}32,22 \pm \\
4,50 \text { A,C/a }\end{array}$ & $\begin{array}{c}31,77 \pm \\
2,04 \text { A,C/b }\end{array}$ & $\begin{array}{l}28,00 \pm \\
0,88 \mathrm{C} / \mathrm{a}\end{array}$ \\
\hline \multicolumn{9}{|c|}{ RUGOSO } \\
\hline $24 h$ (RLU) & $\begin{array}{l}26,33 \pm \\
4,33 \text { A/a }\end{array}$ & $\begin{array}{l}24,11 \pm \\
1,35 \mathrm{~A} / \mathrm{a}\end{array}$ & $\begin{array}{l}22,77 \pm \\
0,51 \text { A/a }\end{array}$ & $\begin{array}{l}24,66 \pm \\
0,58 \text { A/a }\end{array}$ & $\begin{array}{l}20,66 \pm \\
0,88 \mathrm{~A} / \mathrm{a}\end{array}$ & $\begin{array}{l}23,33 \pm \\
2,33 \text { A/a }\end{array}$ & $\begin{array}{l}22,77 \pm \\
6,00 \mathrm{~A} / \mathrm{a}\end{array}$ & $\begin{array}{l}22,44 \pm \\
1,26 \text { A/a }\end{array}$ \\
\hline 72h (RLU) & $\begin{array}{l}45,77 \pm \\
7,67 \mathrm{~A} / \mathrm{b}\end{array}$ & $\begin{array}{c}33,44 \pm \\
1,17 \mathrm{~A}, \mathrm{~B} / \mathrm{b}\end{array}$ & $\begin{array}{c}24,88 \pm \\
3,66^{B / a, b}\end{array}$ & $\begin{array}{c}35,55 \pm \\
6,62 \text { A,B/a,b }\end{array}$ & $\begin{array}{c}23,11 \pm \\
5,0 \mathrm{~B} / \mathrm{a}\end{array}$ & $\begin{array}{l}29,33 \pm \\
3,00 \mathrm{~B} / \mathrm{b}\end{array}$ & $\begin{array}{l}27,22 \pm \\
3,56^{\text {B/a }}\end{array}$ & $\begin{array}{l}28,33 \pm \\
4,33 \text { B/a }\end{array}$ \\
\hline 120h (RLU) & $\begin{array}{l}50,22 \pm \\
8,37 \mathrm{~A} / \mathrm{b}\end{array}$ & $\begin{array}{c}38,00 \pm \\
6,33 \mathrm{~A}, \mathrm{~B} / \mathrm{b}\end{array}$ & $\begin{array}{l}29,88 \pm \\
3,20 \mathrm{~B} / \mathrm{b}\end{array}$ & $\begin{array}{c}36,88 \pm \\
5,32 \mathrm{~A}, \mathrm{~B} / \mathrm{b}\end{array}$ & $\begin{array}{l}28,33 \pm \\
2,33 \mathrm{~B} / \mathrm{a}\end{array}$ & $\begin{array}{l}31,77 \pm \\
6,17 \mathrm{~B} / \mathrm{b}\end{array}$ & $\begin{array}{l}31,44 \pm \\
1,68 \text { B/a }\end{array}$ & $\begin{array}{l}30,11 \pm \\
1,57 \text { B/a }\end{array}$ \\
\hline
\end{tabular}

RLU (relative luminescence unit): unidades relativas de luminescência

ANOVA post hoc teste de comparação múltipla de Tukey. A mesma letra maiúscula em cada linha significa ausência de significância estatística entre os grupos, enquanto que as mesmas letras minúsculas em cada coluna significam ausência de significância estatística em entre os tempos em cada grupo $(p>0.05)$.

As imagens obtidas por meio de microscopia eletrônica de varredura com magnificação de 2.000 x podem ser observadas na Figura 23. 
Figure 23 - MC3T3-E1 subclone 14 aderidas na superfície de implantes descontaminados ou nunca contaminados após migração a partir de arcabouços impressos em 3D.

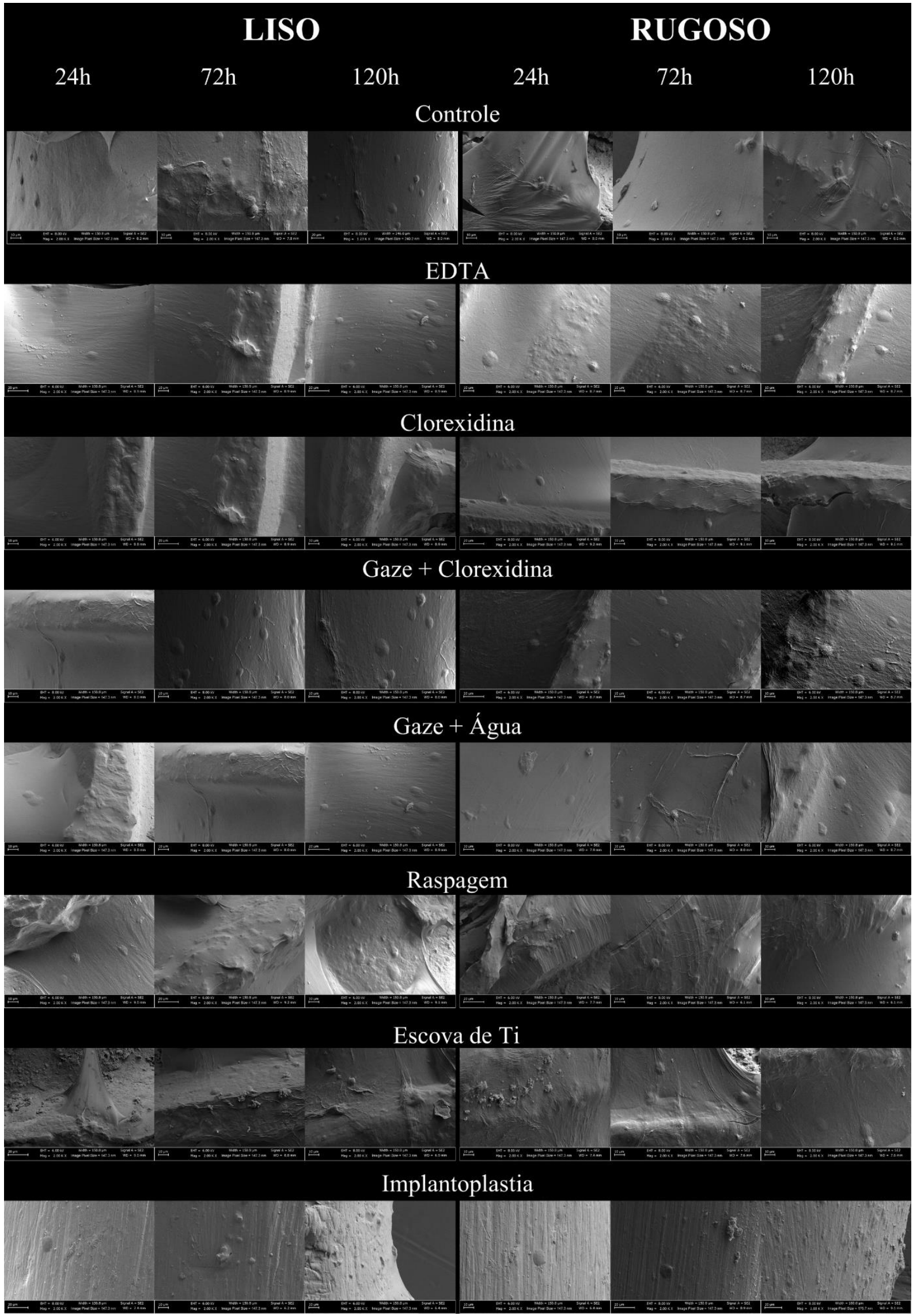





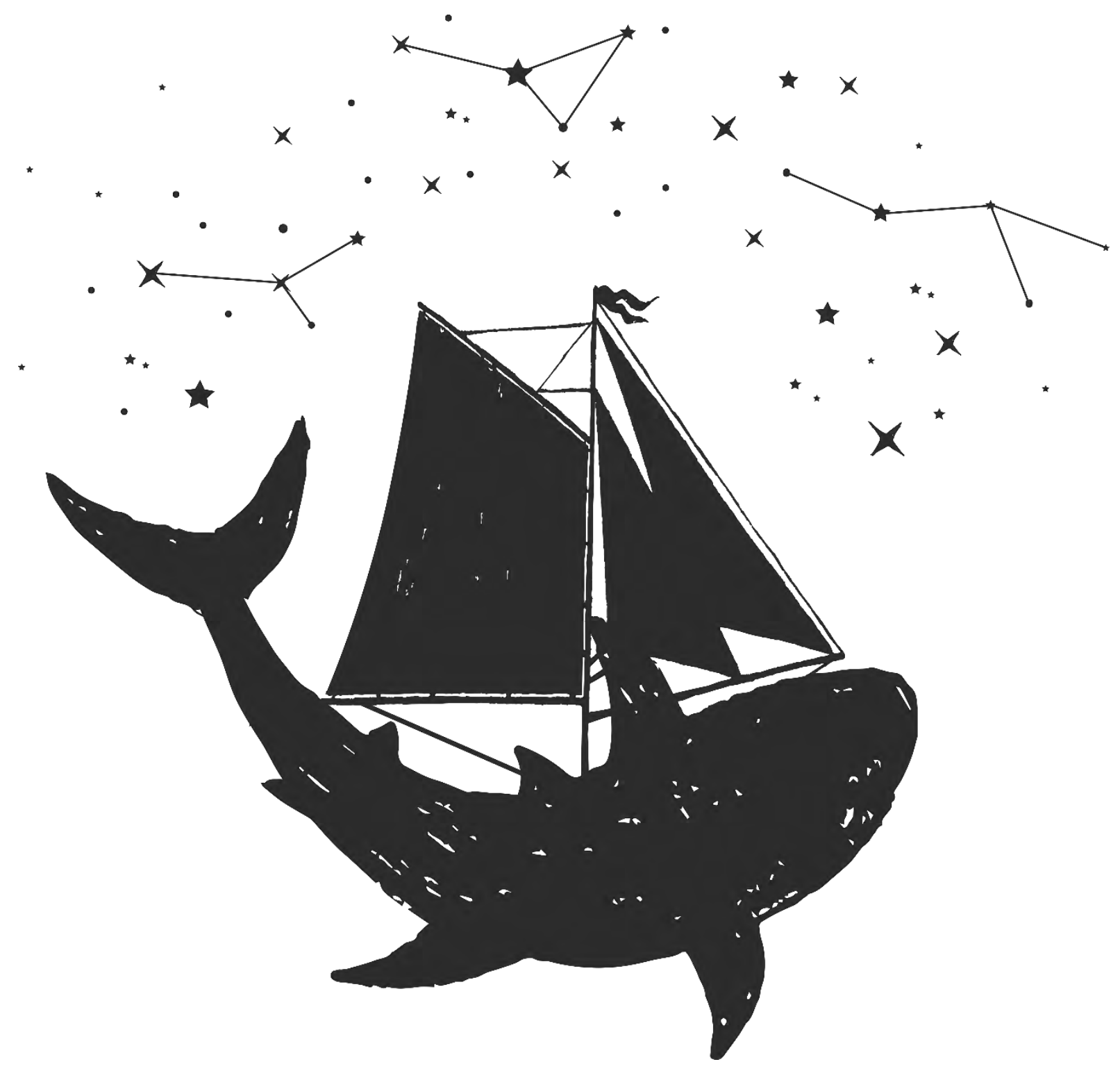

DISCUSSÁO 



\section{DISCUSSÃO}

Embora haja uma grande variedade de tratamentos para a peri-implantite, todos apresentam em comum a busca pela resolução da doença por meio do controle da inflamação através da descontaminação e restauração da biocompatibilidade da superfície do implante (ESPOSITO; GRUSOVIN; WORTHINGTON, 2012; SUBRAMANI; WISMEIJER, 2012). Contudo, a ausência de um consenso sobre qual destas abordagens é a melhor opção de tratamento sugere uma deficiência na literatura sobre as vantagens e desvantagens de cada método. Por este motivo, são necessários mais estudos para traçar um panorama de como as alterações promovidas na superfície dos implantes em decorrência dos procedimentos de descontaminação podem influenciar na interação entre o implante e os tecidos periimplantares. Por este motivo, o objetivo deste estudo foi investigar a restauração da biocompatibilidade de microimplantes previamente contaminados e relacionar os resultados obtidos com as alterações físicas e químicas infligidas as suas superfícies após o uso de diferentes protocolos de descontaminação. Isto foi feito através da avaliação da migração celular entre um arcabouço impresso em 3D para e a superfície do titânio, bem como a análise da microtopografia, composição química e molhabilidade destes microimplantes. Além disto, foi averiguado o potencial de descontaminação de cada tratamento.

A remoção ou redução da carga bacteriana por si só não é o suficiente para tornar a superfície de um implante biologicamente aceitável novamente. Isto ocorre porque os tratamentos de descontaminação podem levar a mudanças superficiais que comprometem a resposta biológica durante o processo de cicatrização (SCHWARZ et al., 2005; LOUROPOULOU; SLOT; VAN DER WEIJDEN, 2015; KOTSAKIS et al., 2016; WHEELIS et al., 2016). Por este motivo, alguns autores sugerem que a preservação das características superficiais do implante é o ponto chave para conseguir uma reosseointegração (MADI et al., 2018). Assim, além de averiguar o potencial de descontaminação de um tratamento, é importante compreender a dinâmica das modificações que ele propicia.

Dentre os métodos avaliados neste estudo, a imersão em EDTA apresentou a pior performance de descontaminação. Além disto, sua eficácia foi inferior nos microimplantes de superfície rugosa do que nos de lisa, possivelmente por 
causa da fluidez limitada do gel impossibilitar o contato com bactérias localizadas em micro-fossas e depressões (NTROUKA et al., 2011). Esta falta de eficácia está de acordo com o encontrado em outros estudos (NTROUKA et al., 2011; HENDERSON et al., 2013), o que faz o EDTA ser contraindicado para a descontaminação de implantes.

A imersão em clorexidina também mostrou taxas modestas de descontaminação, sendo similar ou levemente superior ao apontado em outros estudos (KOBAN et al., 2011; NTROUKA et al., 2011; KOTSAKIS et al., 2016; ROMANOS et al., 2016; CAl et al., 2019). Da mesma forma que foi observado por Cai et al. (2019), nenhuma diferença foi notada quanto ao seu desempenho na descontaminação em superfícies lisas ou rugosas. Mesmo demonstrando-se ineficiente, os resultados com o uso da imersão em clorexidina em nosso estudo pode ainda pode ter sido favorecido em relação a outros estudos devido à utilização de uma solução mais concentrada. Além disto, o uso de uma monocultura ao invés de um biofilme com variadas espécies bacterianas pode ter contribuído com o resultado.

A fim de superar as limitações observadas no processo de imersão, a utilização de gazes embebidas em antimicrobianos químicos possui o potencial de otimizar esses resultados (PERSSON et al., 1999; SCHWARZ et al., 2005; SCHWARZ et al., 2006a; DUARTE et al., 2009; SUBRAMANI; WISMEIJER, 2012; VALDERRAMA; WILSON, 2013; KOTSAKIS et al., 2016). Neste estudo, este efeito foi observado com a utilização de gazes embebidas em clorexidina. Muito desta ação pode ser atribuída à remoção mecânica das bactérias, sendo que até mesmo o uso de gazes embebidas em água ultrapura levou a um certo grau de descontaminação.

De maneira geral, os resultados deste estudo indicaram que os melhores desempenhos de descontaminação foram obtidos com os protocolos que fizeram uso de forças mecânicas (GCX, RA, ETi e IP), com exceção do grupo GMQ. Isto sugere que uma intervenção física pode ser necessária para obter bons resultados, podendo esta ser feita isoladamente ou em combinação com um agente químico.

Na necessidade de realizar a raspagem de um implante, alguns autores recomendam o uso de curetas plásticas, visto que elas não promovem mudanças drásticas na microtopografia do implante (RUHLING et al., 1994; AUGTHUN; TINSCHERT; HUBER, 1998; MENGEL et al., 1998; TOMA et al., 2018). No entanto, 
seu uso não está relacionado a uma descontaminação efetiva (TOMA et al., 2018). Embora o uso de curetas metálicas cause danos definitivos à superfície de titânio, aplainando a superfície, removendo arestas e irregularidades e levando a uma menor porosidade visível, uma alta taxa de descontaminação pode ser conseguida com seu uso. Por este motivo, optamos pelo uso de curetas metálicas neste estudo, mesmo sabendo dos possíveis danos que levariam à superfície dos microimplantes. Este protocolo resultou em bons resultados tanto na descontaminação de implantes lisos quanto na de rugosos. No entanto, foi possível observar que a descontaminação estava restrita aos sítios que receberam os golpes da cureta, havendo remanescentes bacterianos em regiões não raspadas com eficácia. Por este motivo, o uso de microimplantes em nossa metodologia pode ter favorecido a descontaminação decorrente desta terapia quando comparada com sua aplicação em implantes regulares. Isto porque as roscas dos microimplantes são menos proeminentes e seus vales mais rasos, tornando o processo de raspagem mais fácil.

O uso de escovas de titânio foi indicado por alguns autores como uma alternativa mecânica de alto potencial de descontaminação que não leva a mudanças microtopográficas significantes (JOHN; BECKER; SCHWARZ, 2014; TOMA et al., 2018). Neste experimento, ambos os grupos tratados com escovas de titânio apresentaram alto grau de descontaminação, havendo menos bactérias residuais nos microimplantes lisos do que nos rugosos $(p<0.05)$. No entanto, a presença de ranhuras e um grande acúmulo de detritos pode ser observado nas imagens da microscopia eletrônica de varredura, sendo mais marcante nos microimplantes rugosos. Esta particularidade possivelmente se deu em decorrência da superfície rugosa do microimplante gerar mais atrito com as cerdas de titânio, e em decorrência formar e levar a uma maior deposição de detritos.

Outra modalidade mecânica de tratamento avaliada neste estudo foi a implantoplastia, técnica que busca aplainar e polir a porção do implante que está externa ao tecido ósseo utilizando instrumentação rotatória, tornando assim a superfície menos propensa ao acúmulo de biofilme (ROMEO et al., 2005; SCHWARZ et al., 2011b; MATARASSO et al., 2014; SCHWARZ; JOHN; BECKER, 2017). O uso de instrumentação rotatória em implantes é seguro para os tecidos peri-implantares desde que utilizada a refrigeração adequada (SHARON et al., 2013). Dentre os protocolos avaliados por Toma et al. (2018) em seu estudo, a implantoplastia foi o 
método mais efetivo na remoção do biofilme. Da mesma forma, no experimento aqui apresentado, quase nenhum remanescente bacteriano pode ser encontrado nos grupos L-IP e R-IP. Contudo, a presença de detritos também pode ser notada nas superfícies de ambos os grupos nas imagens de microscopia eletrônica de varredura, em especial no grupo R-IP. Da mesma forma que observado no grupo R-ETi, possivelmente essa diferença se deu por causa da superfície rugosa gerar mais atrito para as brocas diamantadas e taças de polimento.

Embora a descontaminação seja um aspecto fundamental para a seleção de um tratamento para a peri-implantite, é igualmente importante compreender como as células dos tecidos adjacentes se comportarão junto a futura superfície descontaminada. A migração celular pode ser descrita como um processo sequencial e cíclico que se inicia com a formação de projeções da membrana celular, seguida pelo estabelecimento de uma adesão mediada por integrinas na superfície adjancente à célula, a desunião da porção posterior da célula do substrato e, finalmente, a translocação do corpo celular (ESTEVEZ et al., 2015).

Em um cenário de peri-implantite, é sabido que a presença de biofilme tem o potencial de inibir a migração e adesão celular (KOTSAKIS et al., 2016). Além disto, células são entidades mecanosensitivas que apresentem seu padrão de migração influenciado por estímulos mecânicos micro e nanométricos da superfície sobre a qual se encontra, engatilhando mudanças no comportamento celular e na organização do citoesqueleto (ESTEVEZ et al., 2015). Por sua vez, os osteoblastos, em particular, tem sua atividade celular favorecida em superfícies rugosas quando comparado às lisas (MADI et al., 2018).

Pearsson et al. (2001b) encontraram valores similares no preenchimento de defeitos ósseos ao redor de implantes lisos (72 \%) e rugosos (76 \%), mas o valor da reosseointegração foi muito maior nos implantes rugosos $(22 \%$ e $84 \%$, respectivamente). Estes resultados estão de acordo com o indicado por outros autores (WETZEL et al., 1999; SHIBLI et al., 2003; PERSSON et al., 2004; SENNERBY et al., 2005), sugerindo que as características superficiais do implante exercem uma grande influência sobre os resultados dos procedimentos regenerativos. Assim, é sensato considerar que a seleção de um protocolo de descontaminação que preserve as características superficiais de um implante são desejáveis para se obter a reosseointegração. No entanto, de um ponto de vista clínico, este cenário é muito mais 
complexo ao considerar que superfícies rugosas também são mais propensas ao acúmulo de biofilme e mais difíceis de descontaminar (RENVERT; POLYZOIS; MAGUIRE, 2009).

As alterações topográficas promovidas durante a descontaminação dos implantes é um tópico constantemente abordado na literatura. Neste estudo, vários parâmetros bidimensionais foram avaliados. O valor de Ra é definido pela média de todos os vales e picos no perfil de uma superfície, não sendo desta forma tão específico. No entanto, este parâmetro é um dos mais utilizados para definir a rugosidade superficial (TOMA et al., 2018). Ambos os grupos L-C e R-C apresentaram um Ra superior a 0,2 $\mu \mathrm{m}$, que é tido como o limiar de rugosidade para uma efetiva colonização bacteriana e possibilitando o estudo (BURGERS et al., 2010). Além disto, parâmetros tridimensionais também foram utilizados, como o Sa. Em todos os protocolos foram observadas mudanças maiores ou menores na topografia dos microimplantes, tanto por possível deposição de residuais químicos quanto por ação mecânica.

Abordagens mecânicas tendem a levar a mudanças mais marcantes na microtopografia dos implantes. No entanto, neste estudo poucas mudanças foram observadas no $\mathrm{Ra}$ dos microimplantes lisos tratados mecanicamente, sendo observada uma redução estatisticamente significante apenas nos casos de implantoplastia observado nos perfils com sentido Norte-Sul. Possivelmente, apenas uma orientação apresentou essa diferença devido à posição fixa e movimentação unidirecional das brocas durante o desgaste das roscas. Já nos microimplantes rugosos, apenas os tratamentos químicos com imersão em EDTA e clorexidina não apresentaram diferença significativa nos perfils Oeste-Leste, e a clorexidina nos perfils Norte-Sul. Isto indica que todos os microimplantes rugosos que receberam intervenção mecânica (GCX, GMQ, R, ETi e IP) apresentaram redução no Ra. A redução estatisticamente significante de Ra nos perfis Norte-Sul dos microimplantes rugosos tratados com EDTA podem ser um reflexo de algum gel residual acumulado sobre sua superfície que gerou um impacto nos resultados.

Ao contrário de nossos resultados, Duarte et al. (2009) apenas notaram mudanças na rugosidade em superfícies lisas submetidas à raspagem, e não nas rugosas. Contudo, os autores descrevem a presença de mudanças óbvias na superfície de ambos os grupos de implantes quando avaliadas imagens de 
microscopia eletrônica de varredura. Já outros autores obtiveram resultados semelhantes ao obtido neste experimento, com as curetas de metal criando irregularidades em implantes lisos e aplainando as superfícies rugosas (HOMIAK; COOK; DEBOER, 1992; RUHLING et al., 1994; MESCHENMOSER et al., 1996; DUARTE et al., 2009).

Não foi observada diferença estatisticamente significante nos perfis NorteSul ou Oeste-Leste ou nas avaliações tridimensionais entre os microimplantes lisos e rugosos que receberam a implantoplastia, sugerindo que a implantoplastia de superfícies lisas e rugosas resulta em uma mesma rugosidade final. Além disto, a superfície após a implantoplastia se apresentou mais polida até mesmo que a dos microimplantes lisos do grupo controle, da mesma forma que observado em outros estudos (RAMEL et al., 2016; TOMA et al., 2018).

A mudança de rugosidade nos tratamentos que fizeram uso de ação mecânica pode ser justificada pela subtração de massa superficial em decorrência do atrito. Já os protocolos que apenas fizeram uso de imersão em agentes antimicrobianos, essas mudanças possivelmente decorreram das propriedades destas soluções, como baixo $\mathrm{pH}$, que pode levar a eluição das camadas superficiais (BURBANO et al., 2014).

Esta redução na rugosidade observada em alguns grupos possivelmente foi um dos fatores que contribuíram para uma migração celular estatisticamente inferior nos grupos R-IP, R-ETi, R-RA e R-GMQ quando comparado aos grupos R-C, e no grupo L-IP quando comparado ao grupo L-C. Além da mudança de rugosidade, outra possibilidade é que a intervenção mecânica tenha danificado a camada de óxido do implante (HOMIAK; COOK; DEBOER, 1992) e também sido prejudicada pelos depósitos metálicos ou resíduos das brocas e borrachas de polimento (VALDERRAMA et al., 2014). Alguns achados histológicos indicam a deposição de partículas de titânio no tecido conjuntivo adjacente ao defeito ósseo após a implantoplastia, sendo isto associado a presença de um infiltrado crônico de células inflamatórias contendo linfócitos e células plasmáticas (SCHWARZ et al., 2011a). Embora neste estudo não tenha sido possível determinar a quantidade de detritos que potencialmente poderiam ser depositados nos tecidos adjacentes, os resultados do EDS e das imagens de microscopia eletrônica de varredura sugerem uma deposição de detritos ao longo dos microimplantes nos grupos RA, ETi e IP. 
Embora a rugosidade superficial esteja vinculada à molhabilidade do microimplante, parece que estas alterações não foram o suficiente para impactar nesta característica na maioria dos protocolos $(p>0,05)$. A implantoplastia foi a única modalidade terapêutica que levou a uma hidrofilia estatisticamente inferior quando comparada ao grupo controle tanto em microimplantes lisos quanto em rugosos $(p<0.05)$, porém sem diferença entre os grupos L-IP e R-IP $(p>0,05)$. A redução da hidrofilia após a implantoplastia também pode ser um dos motivos do desempenho limitado dos grupos L-IP e R-IP no ensaio de migração (GITTENS et al., 2014).

Em oposição a estes resultados, Wheelis et al. (2016) observaram um aumento da molhabilidade de discos de titânio tratados com agentes químicos. A possível explicação para essa divergência de resultados pode ser a diferença de metodologia utilizada nos estudos. Devido à configuração das espiras dos microimplantes, não é possível avaliar a molhabilidade através do gotejamento de água em sua superfície. Ainda assim, a metodologia utilizada neste estudo não é livre de falhas e pode ter comprometido os resultados dos grupos L-IP e R-IP devido ao aplainamento das roscas, levando a perda do suporte horizontal fornecido pelas mesmas e podendo influenciar no ângulo formado pelo menisco.

Quanto às mudanças químicas observadas na superfície dos microimplantes, pode-se notar que foram mais marcantes nos grupos tratados com agentes antimicrobianos. Uma das características que favorece o uso do titânio na implantodontia é a formação e manutenção de uma camada de óxido em sua superfície na presença de ar ou meio aquoso (WHEELIS et al., 2016). Sua importância se dá pela inibição da corrosão do metal e contribuição no aumento da rugosidade superficial (WHEELIS et al., 2016). No entanto, alguns dos protocolos de descontaminação mais efetivos não preservam essa integridade elemental, afetando a interação do implante com os tecidos circundantes (VALDERRAMA; WILSON, 2013; VALDERRAMA et al., 2014; KOTSAKIS et al., 2016; WHEELIS et al., 2016).

Alguns protocolos de descontaminação antimicrobianos utilizam materiais ácidos, favorecendo a liberação de íons $\mathrm{H}^{+}$e a dissolução da camada de óxido, levando à descoloração do metal, corrosão, dissolução iônica e liberação de detritos nos tecidos adjacentes (MATHEW et al., 2012; RODRIGUES et al., 2013; SUITO et al., 2013; WHEELIS et al., 2016). Estes pontos merecem grande reflexão, visto alguns autores sugerem que a dissolução iônica pode favorecer quadros de peri-implantite e 
mucosite peri-implantar (RODRIGUES et al., 2013; WILSON; VALDERRAMA; RODRIGUES, 2014; WHEELIS et al., 2016).

Em outras modalidades de tratamento com agentes antimicrobianos, é notada a deposição de vários contaminantes químicos na superfície do implante, podendo alterar suas propriedades (MOUHYI et al., 1998; SCHWARZ et al., 2006a; KOTSAKIS et al., 2016). Wheelis et al. (2016) investigaram o uso de vários agente antimicrobianos para a descontaminação do titânio. Em seus resultados, foi notado que todos os protocolos invariavelmente deixavam contaminantes sobre a superfície, o que por sua vez influenciou as propriedades físicas dos espécimes. Ao fim do experimento, concluíram que todos os tratamentos levaram a uma redução no sinal do Ti e um aumento no sinal de moléculas carbonadas quando comparados aos espécimes não tratados. Em nossa avaliação, todos os protocolos também levaram a mudanças da composição química superficial. Em todos os grupos experimentais foi observada uma redução na porcentagem atômica e de peso do Ti nos microimplantes, bem como uma deposição de $\mathrm{O}, \mathrm{C}, \mathrm{Al}, \mathrm{Na}, \mathrm{Cl}$ e outros contaminantes. Este cenário merece atenção, visto que estas mudanças podem comprometer a viabilidade celular (ZHAO et al., 2005)

A utilização do EDTA nesse estudo levou a uma redução do wt\% e atomic\% do $\mathrm{Ti}$, acompanhado por um aumento de $\mathrm{O}$ e outros contaminantes. No entanto, estas mudanças não pareceram exercer influência suficiente para inibir a migração celular, sendo que o resultado após $120 \mathrm{~h}$ dos grupos L-EDTA e R-EDTA mostraram ausência de diferença estatística quando comparado aos seus respectivos grupos controle $(p>0.05)$. No entanto, vale relembrar que mesmo sendo favoráveis, estes resultados pouco representam frente a baixa eficácia do EDTA na descontaminação da superfícies dos implantes (NTROUKA et al., 2011; HENDERSON et al., 2013).

O uso da clorexidina, por sua vez, esteve associado a uma alta deposição de $\mathrm{C}$ e outros contaminantes nos microimplantes. Uma propriedade bem estabelecida da clorexidina é a sua substantividade, e essa particularidade também ocorre ao redor de implantes (KOZLOVSKY et al., 2006; RYU et al., 2015; KOTSAKIS et al., 2016). Como em nosso experimento, outros estudos observaram um acúmulo residual de constituintes da clorexidina na superfície do titânio, indicando a presença de adsorção da clorexidina até mesmo após os processos de lavagem (KOZLOVSKY et al., 2006; KOTSAKIS et al., 2016). Como observado por Kozlovsky et al. (2006), a irrigação do 
implante após o uso da clorexidina não é capaz de anular seu impacto nas propriedades fisio-químicas e na biocompatibilidade do implante.

Ao contrário de nossos resultados, Saffapour et al. (SAFFARPOUR et al., 2018) não encontraram evidências da presença de clorexidina no titânio após o seu uso. Contudo, nossos achados estão em concordância com o encontrado por outros autores, sugerindo também que a substantividade pode levar à criação de ambientes citotóxicos para os osteoblastos (KOZLOVSKY et al., 2006; GIANNELLI et al., 2008; LEE, T. H. et al., 2010; RYU et al., 2015). Este efeito foi observado em nosso ensaio de migração, havendo uma contagem celular comprometida após 120 h nos grupos L-CX e R-CX. Por outro lado, a utilização de gazes embebidas em clorexidina reduziram consideravelmente a porcentagem de contaminantes na superfície dos microimplantes, possivelmente devido à fricção. Desta forma, a migração celular nos grupos L-GCX e R-GCX não apresentaram diferença estatisticamente significante dos grupos L-C e R-C após 120h ( $p>0.05$ ). Em um ambiente clínico, esta associação entre abordagem física e química também é interessante e necessária para a remoção de depósitos endurecidos, como cálculos, ou moles, como tecido de granulação e biofilme (SUBRAMANI; WISMEIJER, 2012).

O uso de gaze embebida em água ultrapura apresentou resultados medianos quanto à migração celular. Ao contrário deste resultados, Persson et al. (PERSSON et al., 2004) encontrou em um estudo pré-clínico resultados de BIC, mensurações histométricas e morfométricas do tecido ósseo peri-implantar de implantes tratados com laser de dióxido de carbono + peróxido de hidrogênio ou algodão embebido em soro fisiológico, não encontrando diferença entre os resultados.

Uma possível justificativa para o $\mathrm{Na}$ e o $\mathrm{Cl}$ residual na superfície dos microimplantes neste estudo pode ser a utilização do PBS nos protocolos de lavagem. O $\mathrm{NaCl}$ proveniente do PBS pode se depositar sobre as superfícies do implante, contudo sem desencadear nenhuma reação física ou química com o Ti (SAFFARPOUR et al., 2018). Isto porque o Ti é resistente à corrosão do íon $\mathrm{Cl}^{-}$, de modo a não desencadear nenhum efeito destrutivo ao microimplante (SAFFARPOUR et al., 2018). Assim, embora não seja deletério, o uso de lavagens com água ultrapura talvez fossem uma melhor opção para a metodologia deste estudo por exercer menor influência sobre os resultados. 
De modo geral, os resultados obtidos neste estudo sugerem um potencial benéfico no uso da metodologia in-vitro desenvolvida para análises preliminares da descontaminação e restabelecimento da biocompatibilidade de implantes. A utilização de modelos animais para a compreensão da etiopatogenia, progressão e tratamento das doenças periodontias e peri-implantares é algo consagrado no meio científico (SCHWARZ; SAGER; BECKER, 2011). Os modelos mais utilizados atualmente são os realizados em ratos, cachorros e mini porcos (SCHWARZ; SAGER; BECKER, 2011; KANTARCI; HASTURK; VAN DYKE, 2015). A fim de se avaliar o impacto dos inúmeros protocolos de descontaminação frente aos variados tipos de superfície de implante encontrados no mercado, muitos espécimes seriam necessários para uma completa investigação. Isto implicaria de imediato em dois grandes entraves: o alto custo operacional e os comprometimentos éticos.

Seguindo o princípio dos 3 R's (do inglês: Reduction, Refinement and Replacement), é preferível que a avaliação dos efeitos da descontaminação de implantes seja inicialmente feita in vitro (CAl et al., 2019). O princípio dos 3 R's foi apresentado pela primeira para a comunidade científica em 1959 pelos pesquisadores William M. Russel e Rex L. Burch (RUSSELL; BURCH, 1959). Ao longo de seu texto, os autores propuseram a prática de três princípios que deveriam reger a pesquisa com uso de animais. O primeiro ponto é a diminuição (reduction) do número de espécimes utilizados em um estudo. Neste princípio também se encaixa a reutilização dos animais para a coleta da maior quantidade de dados possível em um mesmo experimento, obtendo-se diferentes "endpoints". O segundo ponto abordado é o refinamento (refinement), que preconiza o aprimoramento metodológico para minimizar os efeitos dos procedimentos a que os animais são submetidos. Por fim, o terceiro ponto é a substituição (replacement) do emprego de animais por organismos não-sensíveis, substituindo assim quando possível métodos in vivo por outros in vitro.

Contudo, em muitos casos ainda não há tecnologia que substitua a realização de estudo em animais. Estudos in vitro consegue avaliar com sucesso a resposta celular frente a bactérias e seus subprodutos, bem como a via de sinalização que envolve as dinâmicas da peri-implantite (KANTARCl; HASTURK; VAN DYKE, 2015); no entanto, ainda é impossível simular toda a complexidade da doença periimplantar utilizando métodos reducionistas in vitro (KANTARCl; HASTURK; VAN DYKE, 2015). Por este motivo, a metodologia descrita nesta tese buscou contemplar 
os critérios de redução e refinamento para a experimentação com animais na avaliação da descontaminação e reosseointegração de implantes previamente contaminados, sendo que estudos pré-clínicos ainda são um passo fundamental na transposição da pesquisa básica para sua aplicação clínica. Assim, por enquanto o principal mérito de metodologias alternativas nesta área de pesquisa seria impactar na redução no número de animais utilizados em um estudo pré-clínico ao indicar quais são os tratamentos de melhor eficácia.

Embora a metodologia adotada neste estudo tenha buscado replicar com maior fidelidade o cenário clínico em menor escala utilizando microimplantes posicionados verticalmente, devem ser destacadas algumas limitações. Ao contrário do que é observado na cavidade bucal, este experimento utilizou uma monocultura ao invés de um biofilme complexo com diversas espécies bacterianas. Alguns estudos sugerem que o efeito de terapias antimicrobianas utilizando agentes químicos é menos eficiente em biofilmes com múltiplas espécies do que em monoculturas (KOBAN et al., 2011; NTROUKA et al., 2011; KOTSAKIS et al., 2016). Desta forma, pode ser que alguns de nossos resultados estejam superestimados.

Assim como Kuo et al. (2017), que também validaram uma metodologia para avaliação de peri-implantite, a opção por utilizar Escherichia coli neste estudo se baseou na necessidade de uma cultura bacteriana de fácil inoculação, controle e estabilidade no implante, ao passo que o cultivo de bactérias anaeróbicas se mostra mais complexo e sensível.

Somado a isto, as particularidades da cavidade oral, como a complexa microbiota, qualidade do biofilme, ação salivar e influência de forças mecânicas externas não são fielmente reprodutíveis em estudos in vitro (AL-AHMAD et al., 2007). Também não é possível determinar a partir destes resultados qual protocolo apresentaria melhor desempenho em um cenário clínico, visto que este estudo se concentrou em avaliar a descontaminação do titânio, não levando em conta a presença de remanescentes bacterianos nas adjacências peri-implantares. Contudo, é possível afirmar que os resultados observados neste estudo e a metodologia elaborada são úteis para guiar a elaboração de estudos pré-clínicos que possam responder a estas questões. 

CONCLUSOEES 



\section{CONCLUSÕES}

A seleção de um tratamento para peri-impalntite não pode ser baseado unicamente em seu potencial antibacterianao, visto que a efetividade na descontaminação não está diretamente ligada a predileção pelo sucesso biológico (SCHWARZ et al., 2005; SCHWARZ et al., 2006a; KOTSAKIS et al., 2016). Neste estudo, IP, ETi, RA e GCX apresentaram os melhores níveis de descontaminação, mas também estiveram relacionados a mudanças topográficas e na composição química superficial. Os grupos RA, ETi e IP também estiveram associados a presença de detritos observáveis por imagens de microscopia eletrônica de varredura em decorrência da intervenção mecânica. Os grupos EDTA, CX e GMQ não obtiveram uma descontaminação satisfatória, não podendo assim serem recomendados como uma terapia independente.

Quanto à migração celular, os melhores resultados após $120 \mathrm{~h}$ foram encontrados nos grupos L-EDTA, L-GCX, L-RA e L-ETi quando comparado ao grupo L-C, e nos grupos R-EDTA e R-GCX comparado ao grupo R-C. No entanto, estes resultados apenas refletem a resposta biológica após a realização de cada protocolo, sendo igualmente importante considerar o potencial de descontaminação anteriormente citado. Por isto, visto a superposição dos resultados citados, é possível sugerir o uso dos protocolos GCX, RA e ETi em superfícies lisas e GCX nas rugosas.

Além disto, este projeto demonstrou com sucesso a utilização de um modelo experimental in vitro utilizando arcabouços impressos em 3D e microimplantes para avaliar a migração de pré-osteoblastos após a descontaminação do titânio, parecendo ser uma interessante metodologia alternativa para estudos preliminares antes de desenvolver estudos com animais. Ao contrário do comumente observado na literatura, este é um modelo mais fisicamente fiel à disposição clínica e estrutural de um implante do que o uso de discos de titânio.

O conceito incial deste experimento foi criar uma metodologia experimental para a pesquisa da periimplantite aproveitando técnicas de impressão 3D. Recentemente, grandes avanços estão sendo feitos em experimentos in vitro com o uso de tecnologias como o lab-on-a-chip e o organ-on-a-chip. Estes processos ainda não são tão explorados na odontologia, mas certamente são grandes ferramentas nas pesquisas sobre biomateriais e regeneração. Embora este projeto não detenha o 
mesmo nível de sofisticação, alguns princípios em comum com estas técnicas técnicas podem ser destacados, como o uso de dispositivos sintéticos customizáveis manufaturados a partir de modelos digitais, a busca pela a redução da experimentação animal e o controle de custo. Futuros experimentos ainda são necessários para avaliar os benefícios e limitações desta metodologia. 


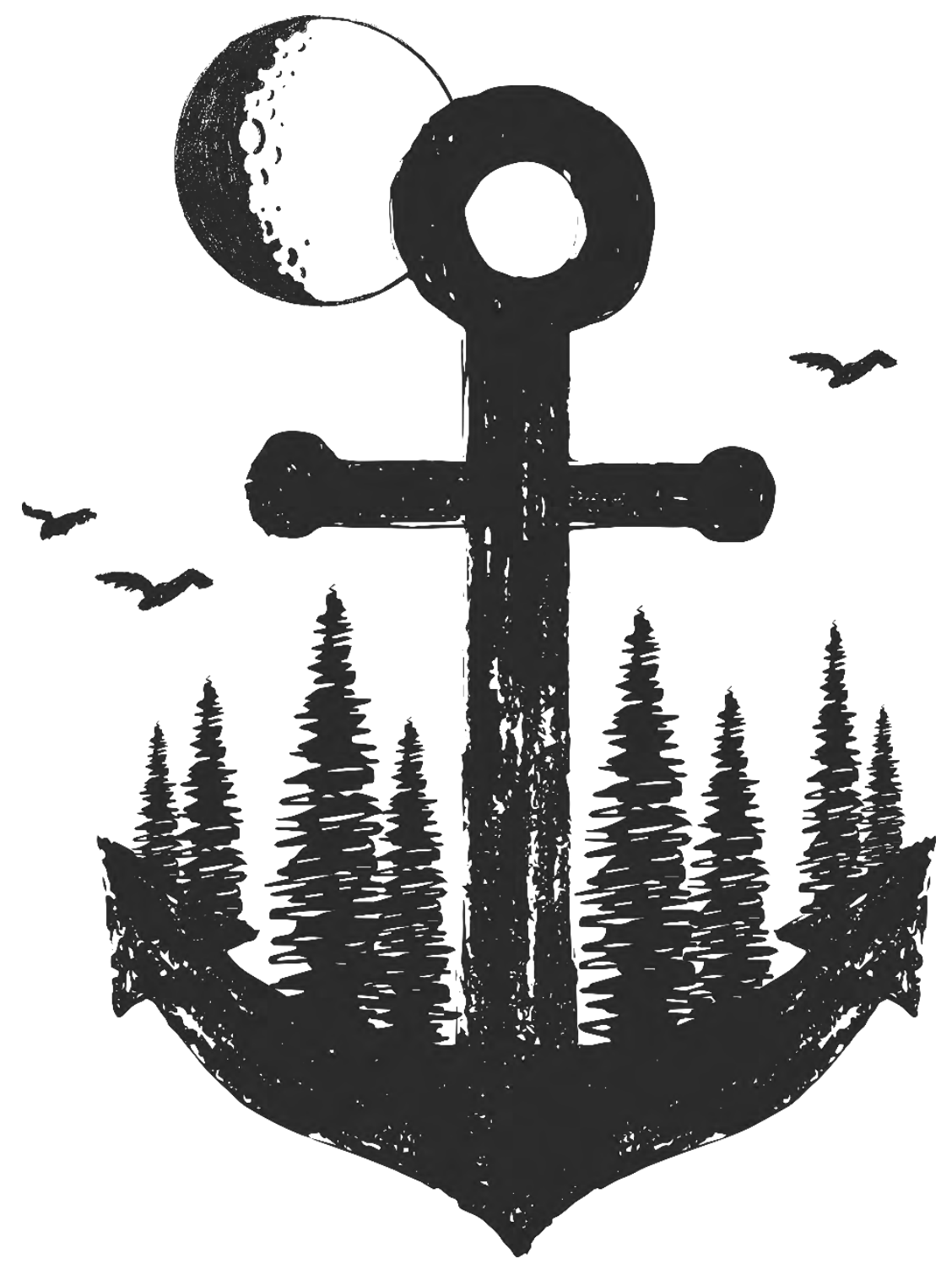

REFERENCIAS 



\section{REFERÊNCIAS}

AL-AHMAD, A.; WUNDER, A.; AUSCHILL, T. M.; FOLLO, M.; BRAUN, G.; HELLWIG, E.; ARWEILER, N. B. The in vivo dynamics of Streptococcus spp., Actinomyces naeslundii, Fusobacterium nucleatum and Veillonella spp. in dental plaque biofilm as analysed by fivecolour multiplex fluorescence in situ hybridization. J Med Microbiol, v. 56, n. Pt 5, p. 681-687, 2007.

ALBREKTSSON, T.; WENNERBERG, A. Oral implant surfaces: Part 1--review focusing on topographic and chemical properties of different surfaces and in vivo responses to them. Int $\mathbf{J}$ Prosthodont, v. 17, n. 5, p. 536-543, 2004.

ALBREKTSSON, T.; DONOS, N.; WORKING, G. Implant survival and complications. The Third EAO consensus conference 2012. Clin Oral Implants Res, v. 23 Suppl 6, n., p. 63-65, 2012.

ALHAG, M.; RENVERT, S.; POLYZOIS, I.; CLAFFEY, N. Re-osseointegration on rough implant surfaces previously coated with bacterial biofilm: an experimental study in the dog. Clin Oral Implants Res, v. 19, n. 2, p. 182-187, 2008.

AMINI, A. R.; LAURENCIN, C. T.; NUKAVARAPU, S. P. Bone tissue engineering: recent advances and challenges. Crit Rev Biomed Eng, v. 40, n. 5, p. 363-408, 2012.

ARWEILER, N. B.; AUSCHILL, T. M.; DONOS, N.; SCULEAN, A. Antibacterial effect of an enamel matrix protein derivative on in vivo dental biofilm vitality. Clin Oral Investig, v. 6, n. 4, p. 205-209, 2002.

ASA'AD, F.; PAGNI, G.; PILIPCHUK, S. P.; GIANNI, A. B.; GIANNOBILE, W. V.; RASPERINI, G. 3D-Printed Scaffolds and Biomaterials: Review of Alveolar Bone Augmentation and Periodontal Regeneration Applications. Int J Dent, v. 2016, n., p. 1239842, 2016.

ASADI-EYDIVAND, M.; SOLATI-HASHJIN, M.; SHAFIEI, S. S.; MOHAMMADI, S.; HAFEZI, M.; ABU OSMAN, N. A. Structure, Properties, and In Vitro Behavior of Heat-Treated Calcium Sulfate Scaffolds Fabricated by 3D Printing. PLoS One, v. 11, n. 3, p. e0151216, 2016.

ATIEH, M. A.; ALSABEEHA, N. H.; FAGGION, C. M., JR.; DUNCAN, W. J. The frequency of peri-implant diseases: a systematic review and meta-analysis. J Periodontol, v. 84, n. 11, p. 1586-1598, 2013.

ATSUTA, I.; AYUKAWA, Y.; KONDO, R.; OSHIRO, W.; MATSUURA, Y.; FURUHASHI, A.; TSUKIYAMA, Y.; KOYANO, K. Soft tissue sealing around dental implants based on histological interpretation. J Prosthodont Res, v. 60, n. 1, p. 3-11, 2016.

AUGTHUN, M.; TINSCHERT, J.; HUBER, A. In vitro studies on the effect of cleaning methods on different implant surfaces. J Periodontol, v. 69, n. 8, p. 857-864, 1998.

BARFEIE, A.; WILSON, J.; REES, J. Implant surface characteristics and their effect on osseointegration. Br Dent J, v. 218, n. 5, p. E9, 2015.

BENLI, M.; PETIT, C.; TENENBAUM, H.; HUCK, O. In vitro assessment of peri-implantitis treatment procedures: a review. Open Dent J, v. 13, n. 1, p. 267-273, 2019. 
BERGLUNDH, T.; LINDHE, J.; ERICSSON, I.; MARINELLO, C. P.; LILJENBERG, B.; THOMSEN, P. The soft tissue barrier at implants and teeth. Clin Oral Implants Res, v. 2, n. 2, p. 81-90, 1991.

BERGLUNDH, T.; ARMITAGE, G.; ARAUJO, M. G.; AVILA-ORTIZ, G.; BLANCO, J.; CAMARGO, P. M.; CHEN, S.; COCHRAN, D.; DERKS, J.; FIGUERO, E.; HAMMERLE, C. H. F.; HEITZ-MAYFIELD, L. J. A.; HUYNH-BA, G.; IACONO, V.; KOO, K. T.; LAMBERT, F.; MCCAULEY, L.; QUIRYNEN, M.; RENVERT, S.; SALVI, G. E.; SCHWARZ, F.; TARNOW, D.; TOMASI, C.; WANG, H. L.; ZITZMANN, N. Peri-implant diseases and conditions: Consensus report of workgroup 4 of the 2017 World Workshop on the Classification of Periodontal and Peri-Implant Diseases and Conditions. J Periodontol, v. 89 Suppl 1, n., p. S313-S318, 2018.

BERMEJO, P.; SANCHEZ, M. C.; LLAMA-PALACIOS, A.; FIGUERO, E.; HERRERA, D.; SANZ ALONSO, M. Biofilm formation on dental implants with different surface microtopography: An in vitro study. Clin Oral Implants Res, v. 30, n. 8, p. 725-734, 2019.

BHOLA, R.; BHOLA, S. M.; MISHRA, B.; OLSON, D. L. Corrosion in titanium dental implants/prostheses - a review. Trends Biomater Artif Organs, v. 25, n., p. 34-46, 2011.

BHOLA, S. M.; KUNDU, S.; ALABBAS, F.; MISHRA, B.; OLSON, D. L. An electrochemical study on chlorhexidine gluconate addition to normal saline for oral implant applications. Int. J. Electrochem. Sci, v. 8, n., p. 5172-5182, 2013.

BHUTDA, G.; DEO, V. Five years clinical results following treatment of human intra-bony defects with an enamel matrix derivative: a randomized controlled trial. Acta Odontol Scand, v. 71, n. 3-4, p. 764-770, 2013.

BRANEMARK, P. I.; HANSSON, B. O.; ADELL, R.; BREINE, U.; LINDSTROM, J.; HALLEN, O.; OHMAN, A. Osseointegrated implants in the treatment of the edentulous jaw. Experience from a 10-year period. Scand J Plast Reconstr Surg Suppl, v. 16, n., p. 1-132, 1977.

BRUNELLO, G.; SIVOLELLA, S.; MENEGHELLO, R.; FERRONI, L.; GARDIN, C.; PIATTELLI, A.; ZAVAN, B.; BRESSAN, E. Powder-based 3D printing for bone tissue engineering. Biotechnol Adv, v. 34, n. 5, p. 740-753, 2016.

BURBANO, M.; RUSSELL, R.; HUO, M.; WELCH, R.; ROY, D.; RODRIGUES, D. C. Surface Characterization of Retrieved Metal-on-Metal Total Hip Implants from Patients with Adverse Reaction to Metal Debris. Materials (Basel), v. 7, n. 3, p. 1866-1879, 2014.

BURGERS, R.; GERLACH, T.; HAHNEL, S.; SCHWARZ, F.; HANDEL, G.; GOSAU, M. In vivo and in vitro biofilm formation on two different titanium implant surfaces. Clin Oral Implants Res, v. 21, n. 2, p. 156-164, 2010.

BUSER, D.; WEBER, H. P.; DONATH, K.; FIORELLINI, J. P.; PAQUETTE, D. W.; WILLIAMS, R. C. Soft tissue reactions to non-submerged unloaded titanium implants in beagle dogs. $\mathbf{J}$ Periodontol, v. 63, n. 3, p. 225-235, 1992.

CAI, Z.; LI, Y.; WANG, Y.; CHEN, S.; JIANG, S.; GE, H.; LEI, L.; HUANG, X. Disinfect Porphyromonas gingivalis Biofilm on Titanium Surface with Combined Application of Chlorhexidine and Antimicrobial Photodynamic Therapy. Photochem Photobiol, v. 95, n. 3, p. 839-845, 2019.

CERBASI, K. P. Bacterial etiology and treatment of peri-implantitis. Innov. Implant. J., Biomater. Esthet., v. 5, n. 1, p. 50-55, 2010. 
CHARALAMPAKIS, G.; LEONHARDT, A.; RABE, P.; DAHLEN, G. Clinical and microbiological characteristics of peri-implantitis cases: a retrospective multicentre study. Clin Oral Implants Res, v. 23, n. 9, p. 1045-1054, 2012.

CLAFFEY, N.; CLARKE, E.; POLYZOIS, I.; RENVERT, S. Surgical treatment of periimplantitis. J Clin Periodontol, v. 35, n. 8 Suppl, p. 316-332, 2008.

COX, S. C.; THORNBY, J. A.; GIBBONS, G. J.; WILLIAMS, M. A.; MALLICK, K. K. 3D printing of porous hydroxyapatite scaffolds intended for use in bone tissue engineering applications. Mater Sci Eng C Mater Biol Appl, v. 47, n., p. 237-247, 2015.

DAUBERT, D. M.; WEINSTEIN, B. F.; BORDIN, S.; LEROUX, B. G.; FLEMMING, T. F. Prevalence and predictive factors for peri-implant disease and implant failure: a cross-sectional analysis. J Periodontol, v. 86, n. 3, p. 337-347, 2015.

DAUBERT, D. M.; WEINSTEIN, B. F. Biofilm as a risk factor in implant treatment. Periodontol 2000, v. 81, n. 1, p. 29-40, 2019.

DERKS, J.; TOMASI, C. Peri-implant health and disease. A systematic review of current epidemiology. J Clin Periodontol, v. 42 Suppl 16, n., p. S158-171, 2015.

DERKS, J.; SCHALLER, D.; HAKANSSON, J.; WENNSTROM, J. L.; TOMASI, C.; BERGLUNDH, T. Effectiveness of Implant Therapy Analyzed in a Swedish Population: Prevalence of Peri-implantitis. J Dent Res, v. 95, n. 1, p. 43-49, 2016.

DONOS, N.; KOSTOPOULOS, L.; KARRING, T. Augmentation of the rat jaw with autogeneic cortico-cancellous bone grafts and guided tissue regeneration. Clin Oral Implants Res, v. 13, n. 2, p. 192-202, 2002.

DONOS, N.; KOSTOPOULOS, L.; TONETTI, M.; KARRING, T. Long-term stability of autogenous bone grafts following combined application with guided bone regeneration. Clin Oral Implants Res, v. 16, n. 2, p. 133-139, 2005.

DONOS, N.; HAMLET, S.; LANG, N. P.; SALVI, G. E.; HUYNH-BA, G.; BOSSHARDT, D. D.; IVANOVSKI, S. Gene expression profile of osseointegration of a hydrophilic compared with a hydrophobic microrough implant surface. Clin Oral Implants Res, v. 22, n. 4, p. 365-372, 2011.

DUARTE, P. M.; REIS, A. F.; DE FREITAS, P. M.; OTA-TSUZUKI, C. Bacterial adhesion on smooth and rough titanium surfaces after treatment with different instruments. J Periodontol, v. 80, n. 11, p. 1824-1832, 2009.

EICK, S.; GOLTZ, S.; NIETZSCHE, S.; JENTSCH, H.; PFISTER, W. Efficacy of chlorhexidine digluconate-containing formulations and other mouthrinses against periodontopathogenic microorganisms. Quintessence Int, v. 42, n. 8, p. 687-700, 2011.

EL-SHERBINY, I. M.; YACOUB, M. H. Hydrogel scaffolds for tissue engineering: Progress and challenges. Glob Cardiol Sci Pract, v. 2013, n. 3, p. 316-342, 2013.

ERICSSON, I.; PERSSON, L. G.; BERGLUNDH, T.; EDLUND, T.; LINDHE, J. The effect of antimicrobial therapy on periimplantitis lesions. An experimental study in the dog. Clin Oral Implants Res, v. 7, n. 4, p. 320-328, 1996. 
ESPOSITO, M.; GRUSOVIN, M. G.; WORTHINGTON, H. V. Treatment of peri-implantitis: what interventions are effective? A Cochrane systematic review. Eur J Oral Implantol, v. 5 Suppl, n., p. S21-41, 2012.

ESPOSITO, M.; ARDEBILI, Y.; WORTHINGTON, H. V. Interventions for replacing missing teeth: different types of dental implants. Cochrane Database Syst Rev, v., n. 7, p. CD003815, 2014.

ESTEVEZ, M.; MARTINEZ, E.; YARWOOD, S. J.; DALBY, M. J.; SAMITIER, J. Adhesion and migration of cells responding to microtopography. J Biomed Mater Res A, v. 103, n. 5, p. 1659-1668, 2015.

FERNANDES, M. H.; GOMES, P. S. Bone Cells Dynamics during Peri-Implantitis: a Theoretical Analysis. J Oral Maxillofac Res, v. 7, n. 3, p. e6, 2016.

FINI, M.; GIARDINO, R.; BORSARI, V.; TORRICELLI, P.; RIMONDINI, L.; GIAVARESI, G.; NICOLI ALDINI, N. In vitro behaviour of osteoblasts cultured on orthopaedic biomaterials with different surface roughness, uncoated and fluorohydroxyapatite-coated, relative to the in vivo osteointegration rate. Int J Artif Organs, v. 26, n. 6, p. 520-528, 2003.

FIORELLINI, J. P.; PAQUETTE, D. W. The potential role of controlled-release delivery systems for chemotherapeutic agents in periodontics. Curr Opin Dent, v. 2, n., p. 63-79, 1992.

FLETCHER, P.; DELUIZ, D.; TINOCO, E. M.; RICCI, J. L.; TARNOW, D. P.; TINOCO, J. M. Human Histologic Evidence of Reosseointegration Around an Implant Affected with Periimplantitis Following Decontamination with Sterile Saline and Antiseptics: A Case History Report. Int J Periodontics Restorative Dent, v. 37, n. 4, p. 499-508, 2017.

FROUM, S. J.; ROSEN, P. S. Reentry evaluation following treatment of peri-implantitis with a regenerative approach. Int J Periodontics Restorative Dent, v. 34, n. 1, p. 47-59, 2014.

FU, J. H.; HSU, Y. T.; WANG, H. L. Identifying occlusal overload and how to deal with it to avoid marginal bone loss around implants. Eur J Oral Implantol, v. 5 Suppl, n., p. S91-103, 2012.

FURST, M. M.; SALVI, G. E.; LANG, N. P.; PERSSON, G. R. Bacterial colonization immediately after installation on oral titanium implants. Clin Oral Implants Res, v. 18, n. 4, p. 501-508, 2007.

GARG, H.; BEDI, G.; GARG, A. Implant surface modifications : a review. J Clin Diagn Res, v. 6, n., p. 319-324, 2012.

GIANNELLI, M.; CHELLINI, F.; MARGHERI, M.; TONELLI, P.; TANI, A. Effect of chlorhexidine digluconate on different cell types: a molecular and ultrastructural investigation. Toxicol In Vitro, v. 22, n. 2, p. 308-317, 2008.

GITTENS, R. A.; SCHEIDELER, L.; RUPP, F.; HYZY, S. L.; GEIS-GERSTORFER, J.; SCHWARTZ, Z.; BOYAN, B. D. A review on the wettability of dental implant surfaces II: Biological and clinical aspects. Acta Biomater, v. 10, n. 7, p. 2907-2918, 2014.

GOFFIN, G. Efficacy of a sustained local delivery of chlorhexidine Periochip as an adjunct to scaling and root planing in the treatment of chronic periodontal disease. Int Dent Rev, v., n., p. 1-18, 1998. 
GOSAU, M.; HAHNEL, S.; SCHWARZ, F.; GERLACH, T.; REICHERT, T. E.; BURGERS, R. Effect of six different peri-implantitis disinfection methods on in vivo human oral biofilm. Clin Oral Implants Res, v. 21, n. 8, p. 866-872, 2010.

GUTWEIN, L. G.; WEBSTER, T. J. Increased viable osteoblast density in the presence of nanophase compared to conventional alumina and titania particles. Biomaterials, v. 25, n. 18, p. 4175-4183, 2004.

HALLMON, W. W.; REES, T. D. Local anti-infective therapy: mechanical and physical approaches. A systematic review. Ann Periodontol, v. 8, n. 1, p. 99-114, 2003.

HAMMERLE, C. H.; FOURMOUSIS, I.; WINKLER, J. R.; WEIGEL, C.; BRAGGER, U.; LANG, N. P. Successful bone fill in late peri-implant defects using guided tissue regeneration. A short communication. J Periodontol, v. 66, n. 4, p. 303-308, 1995.

HAN, A. F.; TSOI, J. K. H.; RODRIGUES, F. P.; LEPRINCE, J. G.; PALIN, W. M. Bacterial adhesion mechanisms on dental implant surfaces and the influencing factors. Int $\mathbf{J}$ Adhes Adhes, v. 69, n., p. 58-71, 2016.

HANISCH, O.; TATAKIS, D. N.; BOSKOVIC, M. M.; ROHRER, M. D.; WIKESJO, U. M. Bone formation and reosseointegration in peri-implantitis defects following surgical implantation of rhBMP-2. Int J Oral Maxillofac Implants, v. 12, n. 5, p. 604-610, 1997.

HEITZ-MAYFIELD, L. J.; LANG, N. P. Comparative biology of chronic and aggressive periodontitis vs. peri-implantitis. Periodontol 2000, v. 53, n., p. 167-181, 2010.

HENCH, L. L. Bioceramics: from concept to clinic. Journal of the American Ceramic Society, v. 74, n. 7, p. 1487-1510, 1991.

HENDERSON, E.; SCHNEIDER, S.; PETERSEN, F. C.; HAUGEN, H. J.; WOHLFAHRT, J. C.; EKSTRAND, K.; EKFELDT, A. Chemical debridement of contaminated titanium surfaces: an in vitro study. Acta Odontol Scand, v. 71, n. 3-4, p. 957-964, 2013.

HOMIAK, A. W.; COOK, P. A.; DEBOER, J. Effect of hygiene instrumentation on titanium abutments: a scanning electron microscopy study. J Prosthet Dent, v. 67, n. 3, p. 364-369, 1992.

JOHN, G.; BECKER, J.; SCHWARZ, F. Rotating titanium brush for plaque removal from rough titanium surfaces--an in vitro study. Clin Oral Implants Res, v. 25, n. 7, p. 838-842, 2014.

KANTARCI, A.; HASTURK, H.; VAN DYKE, T. E. Animal models for periodontal regeneration and peri-implant responses. Periodontol 2000, v. 68, n. 1, p. 66-82, 2015.

KASEMO, B. Biocompatibility of titanium implants: surface science aspects. J Prosthet Dent, v. 49, n. 6, p. $832-837,1983$.

KIM, H. W.; LEE, E. J.; JUN, I. K.; KIM, H. E.; KNOWLES, J. C. Degradation and drug release of phosphate glass/polycaprolactone biological composites for hard-tissue regeneration. $\mathbf{J}$ Biomed Mater Res B Appl Biomater, v. 75, n. 1, p. 34-41, 2005.

KIM, S.; HU, K. S.; JUNG, U. W. Reosseointegration After Regenerative Surgical Therapy Using a Synthetic Bone Substitute for Peri-implantitis: Human Autopsy Study. Int J Periodontics Restorative Dent, v. 38, n. 4, p. 585-591, 2018. 
KOBAN, I.; HOLTFRETER, B.; HUBNER, N. O.; MATTHES, R.; SIETMANN, R.; KINDEL, E.; WELTMANN, K. D.; WELK, A.; KRAMER, A.; KOCHER, T. Antimicrobial efficacy of nonthermal plasma in comparison to chlorhexidine against dental biofilms on titanium discs in vitro - proof of principle experiment. J Clin Periodontol, v. 38, n. 10, p. 956-965, 2011.

KOLONIDIS, S. G.; RENVERT, S.; HAMMERLE, C. H.; LANG, N. P.; HARRIS, D.; CLAFFEY, $\mathrm{N}$. Osseointegration on implant surfaces previously contaminated with plaque. An experimental study in the dog. Clin Oral Implants Res, v. 14, n. 4, p. 373-380, 2003.

KONONEN, M.; HORMIA, M.; KIVILAHTI, J.; HAUTANIEMI, J.; THESLEFF, I. Effect of surface processing on the attachment, orientation, and proliferation of human gingival fibroblasts on titanium. J Biomed Mater Res, v. 26, n. 10, p. 1325-1341, 1992.

KONSTANTINIDIS, I. K.; KOTSAKIS, G. A.; GERDES, S.; WALTER, M. H. Cross-sectional study on the prevalence and risk indicators of peri-implant diseases. Eur $\mathbf{J}$ Oral Implantol, v. 8, n. 1, p. 75-88, 2015.

KORSCH, M.; OBST, U.; WALTHER, W. Cement-associated peri-implantitis: a retrospective clinical observational study of fixed implant-supported restorations using a methacrylate cement. Clin Oral Implants Res, v. 25, n. 7, p. 797-802, 2014.

KOTSAKIS, G. A.; LAN, C.; BARBOSA, J.; LILL, K.; CHEN, R.; RUDNEY, J.; APARICIO, C. Antimicrobial Agents Used in the Treatment of Peri-Implantitis Alter the Physicochemistry and Cytocompatibility of Titanium Surfaces. J Periodontol, v. 87, n. 7, p. 809-819, 2016.

KOZLOVSKY, A.; ARTZI, Z.; MOSES, O.; KAMIN-BELSKY, N.; GREENSTEIN, R. B. Interaction of chlorhexidine with smooth and rough types of titanium surfaces. J Periodontol, v. 77, n. 7, p. 1194-1200, 2006.

KRAYER, J. W.; LEITE, R. S.; KIRKWOOD, K. L. Non-surgical chemotherapeutic treatment strategies for the management of periodontal diseases. Dent Clin North Am, v. 54, n. 1, p. 13-33, 2010.

KUO, H. N.; MEI, H. I.; LIU, T. K.; LIU, T. Y.; LO, L. J.; LIN, C. L. In Vitro Laser Treatment Platform Construction with Dental Implant Thread Surface on Bacterial Adhesion for PeriImplantitis. Biomed Res Int, v. 2017, n., p. 4732302, 2017.

LANG, N. P.; BERGLUNDH, T.; WORKING GROUP 4 OF SEVENTH EUROPEAN WORKSHOP ON, P. Periimplant diseases: where are we now?--Consensus of the Seventh European Workshop on Periodontology. J Clin Periodontol, v. 38 Suppl 11, n., p. 178-181, 2011.

LANG, N. P.; SALVI, G. E.; HUYNH-BA, G.; IVANOVSKI, S.; DONOS, N.; BOSSHARDT, D. D. Early osseointegration to hydrophilic and hydrophobic implant surfaces in humans. Clin Oral Implants Res, v. 22, n. 4, p. 349-356, 2011.

LEE, C. T.; HUANG, Y. W.; ZHU, L.; WELTMAN, R. Prevalences of peri-implantitis and periimplant mucositis: systematic review and meta-analysis. J Dent, v. 62, n., p. 1-12, 2017.

LEE, J. B.; KWEON, H. H.; CHO, H. J.; KIM, C. S.; KIM, Y. T. Characteristics of Local Delivery Agents for Treating Peri-Implantitis on Dental Implant Surfaces: A Preclinical Study. J Oral Implantol, v. 45, n. 2, p. 116-126, 2019.

LEE, S. J.; LEE, D.; YOON, T. R.; KIM, H. K.; JO, H. H.; PARK, J. S.; LEE, J. H.; KIM, W. D.; KWON, I. K.; PARK, S. A. Surface modification of 3D-printed porous scaffolds via mussel- 
inspired polydopamine and effective immobilization of rhBMP-2 to promote osteogenic differentiation for bone tissue engineering. Acta Biomater, v. 40, n., p. 182-191, 2016.

LEE, T. H.; HU, C. C.; LEE, S. S.; CHOU, M. Y.; CHANG, Y. C. Cytotoxicity of chlorhexidine on human osteoblastic cells is related to intracellular glutathione levels. Int Endod J, v. 43, n. 5, p. 430-435, 2010.

LEHMANN, B.; BRAGGER, U.; HAMMERLE, C. H.; FOURMOUSIS, I.; LANG, N. P. Treatment of an early implant failure according to the principles of guided tissue regeneration (GTR). Clin Oral Implants Res, v. 3, n. 1, p. 42-48, 1992.

LEONHARDT, A.; RENVERT, S.; DAHLEN, G. Microbial findings at failing implants. Clin Oral Implants Res, v. 10, n. 5, p. 339-345, 1999.

LIN, G. H.; CHAN, H. L.; WANG, H. L. The significance of keratinized mucosa on implant health: a systematic review. J Periodontol, v. 84, n. 12, p. 1755-1767, 2013.

LINDHE, J.; BERGLUNDH, T.; ERICSSON, I.; LILJENBERG, B.; MARINELLO, C. Experimental breakdown of peri-implant and periodontal tissues. A study in the beagle dog. Clin Oral Implants Res, v. 3, n. 1, p. 9-16, 1992.

LINDHE, J.; MEYLE, J.; GROUP, D. O. E. W. O. P. Peri-implant diseases: Consensus Report of the Sixth European Workshop on Periodontology. J Clin Periodontol, v. 35, n. 8 Suppl, p. 282-285, 2008.

LOUROPOULOU, A.; SLOT, D. E.; VAN DER WEIJDEN, F. Influence of mechanical instruments on the biocompatibility of titanium dental implants surfaces: a systematic review. Clin Oral Implants Res, v. 26, n. 7, p. 841-850, 2015.

MACHTEI, E. E.; KIM, D. M.; KARIMBUX, N.; ZIGDON-GILADI, H. The use of endothelial progenitor cells combined with barrier membrane for the reconstruction of peri-implant osseous defects: an animal experimental study. J Clin Periodontol, v. 43, n. 3, p. 289-297, 2016.

MADI, M.; HTET, M.; ZAKARIA, O.; ALAGL, A.; KASUGAI, S. Re-osseointegration of Dental Implants After Periimplantitis Treatments: A Systematic Review. Implant Dent, v. 27, n. 1, p. 101-110, 2018.

MARTINEZ-HERNANDEZ, M.; OLIVARES-NAVARRETE, R.; ALMAGUER-FLORES, A. Influence of the Periodontal Status on the Initial-Biofilm Formation on Titanium Surfaces. Clin Implant Dent Relat Res, v. 18, n. 1, p. 174-181, 2016.

MATARASSO, S.; IORIO SICILIANO, V.; AGLIETTA, M.; ANDREUCCETTI, G.; SALVI, G. E. Clinical and radiographic outcomes of a combined resective and regenerative approach in the treatment of peri-implantitis: a prospective case series. Clin Oral Implants Res, v. 25, n. 7, p. 761-767, 2014.

MATHEW, M. T.; ABBEY, S.; HALLAB, N. J.; HALL, D. J.; SUKOTJO, C.; WIMMER, M. A. Influence of $\mathrm{pH}$ on the tribocorrosion behavior of $\mathrm{CpTi}$ in the oral environment: synergistic interactions of wear and corrosion. J Biomed Mater Res B Appl Biomater, v. 100, n. 6, p. 1662-1671, 2012.

MATZELLE, M. M.; GALLANT, M. A.; CONDON, K. W.; WALSH, N. C.; MANNING, C. A.; STEIN, G. S.; LIAN, J. B.; BURR, D. B.; GRAVALLESE, E. M. Resolution of inflammation induces osteoblast function and regulates the Wnt signaling pathway. Arthritis Rheum, v. 64, n. 5, p. 1540-1550, 2012. 
MEIRELLES, L.; ARVIDSSON, A.; ALBREKTSSON, T.; WENNERBERG, A. Increased bone formation to unstable nano rough titanium implants. Clin Oral Implants Res, v. 18, n. 3, p. 326-332, 2007.

MELLADO-VALERO, A.; BUITRAGO-VERA, P.; SOLA-RUIZ, M. F.; FERRER-GARCIA, J. C. Decontamination of dental implant surface in peri-implantitis treatment: a literature review. Med Oral Patol Oral Cir Bucal, v. 18, n. 6, p. e869-876, 2013.

MENGEL, R.; BUNS, C. E.; MENGEL, C.; FLORES-DE-JACOBY, L. An in vitro study of the treatment of implant surfaces with different instruments. Int J Oral Maxillofac Implants, v. 13, n. 1, p. 91-96, 1998.

MESCHENMOSER, A.; D'HOEDT, B.; MEYLE, J.; ELSSNER, G.; KORN, D.; HAMMERLE, $\mathrm{H}$.; SCHULTE, W. Effects of various hygiene procedures on the surface characteristics of titanium abutments. J Periodontol, v. 67, n. 3, p. 229-235, 1996.

MOMBELLI, A.; LANG, N. P. Microbial aspects of implant dentistry. Periodontol 2000, v. 4, n., p. 74-80, 1994.

MOMBELLI, A.; LANG, N. P. The diagnosis and treatment of peri-implantitis. Periodontol 2000, v. 17, n., p. 63-76, 1998.

MOMBELLI, A. Microbiology and antimicrobial therapy of peri-implantitis. Periodontol 2000, v. 28, n., p. 177-189, 2002.

MOUHYI, J.; SENNERBY, L.; PIREAUX, J. J.; DOUROV, N.; NAMMOUR, S.; VAN RECK, J. An XPS and SEM evaluation of six chemical and physical techniques for cleaning of contaminated titanium implants. Clin Oral Implants Res, v. 9, n. 3, p. 185-194, 1998.

MOUHYI, J.; DOHAN EHRENFEST, D. M.; ALBREKTSSON, T. The peri-implantitis: implant surfaces, microstructure, and physicochemical aspects. Clin Implant Dent Relat Res, v. 14, n. 2, p. 170-183, 2012.

MUSCHLER, G. F.; NAKAMOTO, C.; GRIFFITH, L. G. Engineering principles of clinical cellbased tissue engineering. J Bone Joint Surg Am, v. 86-A, n. 7, p. 1541-1558, 2004.

NADDEO, P.; LAINO, L.; LA NOCE, M.; PIATTELLI, A.; DE ROSA, A.; IEZZI, G.; LAINO, G.; PAINO, F.; PAPACCIO, G.; TIRINO, V. Surface biocompatibility of differently textured titanium implants with mesenchymal stem cells. Dent Mater, v. 31, n. 3, p. 235-243, 2015.

NAIR, L. S.; LAURENCIN, C. T. Biodegradable polymers as biomaterials. Progress in Polymer Science, v. 32, n. 8-9, p. 762-798, 2007.

NOVAES, A. B., JR.; DE SOUZA, S. L.; DE BARROS, R. R.; PEREIRA, K. K.; IEZZI, G.; PIATTELLI, A. Influence of implant surfaces on osseointegration. Braz Dent J, v. 21, n. 6, p. 471-481, 2010.

NTROUKA, V.; HOOGENKAMP, M.; ZAURA, E.; VAN DER WEIJDEN, F. The effect of chemotherapeutic agents on titanium-adherent biofilms. Clin Oral Implants Res, v. 22, n. 11, p. 1227-1234, 2011.

OKADA, A.; NIKAIDO, T.; IKEDA, M.; OKADA, K.; YAMAUCHI, J.; FOXTON, R. M.; SAWADA, H.; TAGAMI, J.; MATIN, K. Inhibition of biofilm formation using newly developed coating materials with self-cleaning properties. Dent Mater J, v. 27, n. 4, p. 565-572, 2008. 
OLEFJORD, I.; HANSSON, S. Surface analysis of four dental implant systems. Int J Oral Maxillofac Implants, v. 8, n. 1, p. 32-40, 1993.

PERSSON, L. G.; ERICSSON, I.; BERGLUNDH, T.; LINDHE, J. Guided bone regeneration in the treatment of periimplantitis. Clin Oral Implants Res, v. 7, n. 4, p. 366-372, 1996.

PERSSON, L. G.; ARAUJO, M. G.; BERGLUNDH, T.; GRONDAHL, K.; LINDHE, J. Resolution of peri-implantitis following treatment. An experimental study in the dog. Clin Oral Implants Res, v. 10, n. 3, p. 195-203, 1999.

PERSSON, L. G.; ERICSSON, I.; BERGLUNDH, T.; LINDHE, J. Osseintegration following treatment of peri-implantitis and replacement of implant components. An experimental study in the dog. J Clin Periodontol, v. 28, n. 3, p. 258-263, 2001a.

PERSSON, L. G.; BERGLUNDH, T.; LINDHE, J.; SENNERBY, L. Re-osseointegration after treatment of peri-implantitis at different implant surfaces. An experimental study in the dog. Clin Oral Implants Res, v. 12, n. 6, p. 595-603, 2001 b.

PERSSON, L. G.; MOUHYI, J.; BERGLUNDH, T.; SENNERBY, L.; LINDHE, J. Carbon dioxide laser and hydrogen peroxide conditioning in the treatment of periimplantitis: an experimental study in the dog. Clin Implant Dent Relat Res, v. 6, n. 4, p. 230-238, 2004.

POZHITKOV, A. E.; DAUBERT, D.; BROCHWICZ DONIMIRSKI, A.; GOODGION, D.; VAGIN, M. Y.; LEROUX, B. G.; HUNTER, C. M.; FLEMMIG, T. F.; NOBLE, P. A.; BRYERS, J. D. Interruption of Electrical Conductivity of Titanium Dental Implants Suggests a Path Towards Elimination Of Corrosion. PLoS One, v. 10, n. 10, p. e0140393, 2015.

QUIRYNEN, M.; VOGELS, R.; PEETERS, W.; VAN STEENBERGHE, D.; NAERT, I.; HAFFAJEE, A. Dynamics of initial subgingival colonization of 'pristine' peri-implant pockets. Clin Oral Implants Res, v. 17, n. 1, p. 25-37, 2006.

RAMEL, C. F.; LUSSI, A.; OZCAN, M.; JUNG, R. E.; HAMMERLE, C. H.; THOMA, D. S. Surface roughness of dental implants and treatment time using six different implantoplasty procedures. Clin Oral Implants Res, v. 27, n. 7, p. 776-781, 2016.

RENVERT, S.; ROOS-JANSAKER, A. M.; CLAFFEY, N. Non-surgical treatment of peri-implant mucositis and peri-implantitis: a literature review. J Clin Periodontol, v. 35, n. 8 Suppl, p. 305315, 2008.

RENVERT, S.; POLYZOIS, I.; MAGUIRE, R. Re-osseointegration on previously contaminated surfaces: a systematic review. Clin Oral Implants Res, v. 20 Suppl 4, n., p. 216-227, 2009.

RENVERT, S.; HIROOKA, H.; POLYZOIS, I.; KELEKIS-CHOLAKIS, A.; WANG, H. L.; WORKING, G. Diagnosis and non-surgical treatment of peri-implant diseases and maintenance care of patients with dental implants - Consensus report of working group 3. Int Dent J, v. 69 Suppl 2, n., p. 12-17, 2019.

ROCCUZZO, M.; PITTONI, D.; ROCCUZZO, A.; CHARRIER, L.; DALMASSO, P. Surgical treatment of peri-implantitis intrabony lesions by means of deproteinized bovine bone mineral with 10\% collagen: 7-year-results. Clin Oral Implants Res, v. 28, n. 12, p. 1577-1583, 2017.

RODRIGUES, D. C.; URBAN, R. M.; JACOBS, J. J.; GILBERT, J. L. In vivo severe corrosion and hydrogen embrittlement of retrieved modular body titanium alloy hip-implants. J Biomed Mater Res B Appl Biomater, v. 88, n. 1, p. 206-219, 2009. 
RODRIGUES, D. C.; VALDERRAMA, P.; WILSON, T. G.; PALMER, K.; THOMAS, A.; SRIDHAR, S.; ADAPALLI, A.; BURBANO, M.; WADHWANI, C. Titanium Corrosion Mechanisms in the Oral Environment: A Retrieval Study. Materials (Basel), v. 6, n. 11, p. 5258-5274, 2013.

ROMANOS, G. E.; BILTUCCI, M. T.; KOKARAS, A.; PASTER, B. J. Bacterial Composition at the Implant-Abutment Connection under Loading in vivo. Clin Implant Dent Relat Res, v. 18, n. 1, p. 138-145, 2016.

ROMEO, E.; GHISOLFI, M.; CARMAGNOLA, D. Peri-implant diseases. A systematic review of the literature. Minerva Stomatol, v. 53, n. 5, p. 215-230, 2004.

ROMEO, E.; GHISOLFI, M.; MURGOLO, N.; CHIAPASCO, M.; LOPS, D.; VOGEL, G. Therapy of peri-implantitis with resective surgery. A 3-year clinical trial on rough screw-shaped oral implants. Part I: clinical outcome. Clin Oral Implants Res, v. 16, n. 1, p. 9-18, 2005.

ROMEO, E.; LOPS, D.; STORELLI, S.; GHISOLFI, M. Clinical peri-implant sounding accuracy in the presence of chronic inflammation of peri-implant tissues. Clinical observation study. Minerva Stomatol, v. 58, n. 3, p. 81-91, 2009.

RUHLING, A.; KOCHER, T.; KREUSCH, J.; PLAGMANN, H. C. Treatment of subgingival implant surfaces with Teflon-coated sonic and ultrasonic scaler tips and various implant curettes. An in vitro study. Clin Oral Implants Res, v. 5, n. 1, p. 19-29, 1994.

RUPP, F.; SCHEIDELER, L.; OLSHANSKA, N.; DE WILD, M.; WIELAND, M.; GEISGERSTORFER, J. Enhancing surface free energy and hydrophilicity through chemical modification of microstructured titanium implant surfaces. J Biomed Mater Res A, v. 76, n. 2, p. 323-334, 2006.

RUSSELL, W. M. S.; BURCH, R. The principles of humane experimental technique. Londres, Inglaterra: Methuen, 1959

RYU, H. S.; KIM, Y. I.; LIM, B. S.; LIM, Y. J.; AHN, S. J. Chlorhexidine Uptake and Release From Modified Titanium Surfaces and Its Antimicrobial Activity. J Periodontol, v. 86, n. 11, p. 1268-1275, 2015.

SAFFARPOUR, A.; NOZARI, A.; FEKRAZAD, R.; SAFFARPOUR, A.; HEIBATI, M. N.; IRANPARVAR, K. Microstructural Evaluation of Contaminated Implant Surface Treated by Laser, Photodynamic Therapy, and Chlorhexidine 2 percent. Int J Oral Maxillofac Implants, v. 33, n. 5, p. 1019-1026, 2018.

SAFIOTI, L. M.; KOTSAKIS, G. A.; POZHITKOV, A. E.; CHUNG, W. O.; DAUBERT, D. M. Increased Levels of Dissolved Titanium Are Associated With Peri-Implantitis - A CrossSectional Study. J Periodontol, v. 88, n. 5, p. 436-442, 2017.

SARTORETTO, S. C.; ALVES, A. T.; RESENDE, R. F.; CALASANS-MAIA, J.; GRANJEIRO, J. M.; CALASANS-MAIA, M. D. Early osseointegration driven by the surface chemistry and wettability of dental implants. J Appl Oral Sci, v. 23, n. 3, p. 279-287, 2015.

SATO, M.; WEBSTER, T. J. Designing orthopedic implant surfaces: harmonization of nanotopographical and chemical aspects. Nanomedicine (Lond), v. 1, n. 3, p. 351-354, 2006.

SATO, N. Toward a more fundamental understanding of corrosion process. Corrosion, v. 45, n., p. 354-368, 1989. 
SCHMINKE, B.; VOM ORDE, F.; GRUBER, R.; SCHLIEPHAKE, H.; BURGERS, R.; MIOSGE, N. The pathology of bone tissue during peri-implantitis. J Dent Res, v. 94, n. 2, p. 354-361, 2015.

SCHOU, S.; HOLMSTRUP, P.; JORGENSEN, T.; SKOVGAARD, L. T.; STOLTZE, K.; HJORTING-HANSEN, E.; WENZEL, A. Anorganic porous bovine-derived bone mineral (BioOss) and ePTFE membrane in the treatment of peri-implantitis in cynomolgus monkeys. Clin Oral Implants Res, v. 14, n. 5, p. 535-547, 2003.

SCHWARTZ-FILHO, H. O.; MORANDINI, A. C.; RAMOS-JUNIOR, E. S.; JIMBO, R.; SANTOS, C. F.; MARCANTONIO, E., JR.; WENNERBERG, A.; MARCANTONIO, R. A. Titanium surfaces with nanotopography modulate cytokine production in cultured human gingival fibroblasts. J Biomed Mater Res A, v. 100, n. 10, p. 2629-2636, 2012.

SCHWARZ, F.; ROTHAMEL, D.; SCULEAN, A.; GEORG, T.; SCHERBAUM, W.; BECKER, J. Effects of an Er:YAG laser and the Vector ultrasonic system on the biocompatibility of titanium implants in cultures of human osteoblast-like cells. Clin Oral Implants Res, v. 14, n. 6, p. 784792, 2003.

SCHWARZ, F.; SCULEAN, A.; ROMANOS, G.; HERTEN, M.; HORN, N.; SCHERBAUM, W.; $B E C K E R$, J. Influence of different treatment approaches on the removal of early plaque biofilms and the viability of SAOS2 osteoblasts grown on titanium implants. Clin Oral Investig, v. 9, n. 2, p. 111-117, 2005.

SCHWARZ, F.; PAPANICOLAU, P.; ROTHAMEL, D.; BECK, B.; HERTEN, M.; BECKER, J. Influence of plaque biofilm removal on reestablishment of the biocompatibility of contaminated titanium surfaces. J Biomed Mater Res A, v. 77, n. 3, p. 437-444, $2006 a$.

SCHWARZ, F.; JEPSEN, S.; HERTEN, M.; SAGER, M.; ROTHAMEL, D.; BECKER, J. Influence of different treatment approaches on non-submerged and submerged healing of ligature induced peri-implantitis lesions: an experimental study in dogs. J Clin Periodontol, v. 33 , n. 8, p. 584-595, 2006b.

SCHWARZ, F.; WIELAND, M.; SCHWARTZ, Z.; ZHAO, G.; RUPP, F.; GEIS-GERSTORFER, J.; SCHEDLE, A.; BROGGINI, N.; BORNSTEIN, M. M.; BUSER, D.; FERGUSON, S. J.; BECKER, J.; BOYAN, B. D.; COCHRAN, D. L. Potential of chemically modified hydrophilic surface characteristics to support tissue integration of titanium dental implants. $\mathbf{J}$ Biomed Mater Res B Appl Biomater, v. 88, n. 2, p. 544-557, 2009.

SCHWARZ, F.; SAGER, M.; BECKER, J. Peri-implantitis Defect Model. In: Giannobile, W. V. e Nevins, M. (Ed.). Osteology guidelines for oral \& maxillofacial regeneration: preclinical models for translational research. Londres, Inglaterra: Quintessence Pub Co, 2011, p.197224.

SCHWARZ, F.; SAHM, N.; MIHATOVIC, I.; GOLUBOVIC, V.; BECKER, J. Surgical therapy of advanced ligature-induced peri-implantitis defects: cone-beam computed tomographic and histological analysis. J Clin Periodontol, v. 38, n. 10, p. 939-949, 2011 a.

SCHWARZ, F.; SAHM, N.; IGLHAUT, G.; BECKER, J. Impact of the method of surface debridement and decontamination on the clinical outcome following combined surgical therapy of peri-implantitis: a randomized controlled clinical study. J Clin Periodontol, v. 38, n. 3, p. 276-284, 2011b.

SCHWARZ, F.; HEGEWALD, A.; JOHN, G.; SAHM, N.; BECKER, J. Four-year follow-up of combined surgical therapy of advanced peri-implantitis evaluating two methods of surface decontamination. J Clin Periodontol, v. 40, n. 10, p. 962-967, 2013. 
SCHWARZ, F.; JOHN, G.; BECKER, J. The influence of implantoplasty on the diameter, chemical surface composition, and biocompatibility of titanium implants. Clin Oral Investig, v. 21, n. 7, p. 2355-2361, 2017.

SCHWARZ, F.; JOHN, G.; SCHMUCKER, A.; SAHM, N.; BECKER, J. Combined surgical therapy of advanced peri-implantitis evaluating two methods of surface decontamination: a 7year follow-up observation. J Clin Periodontol, v. 44, n. 3, p. 337-342, 2017.

SEARS, N. A.; SESHADRI, D. R.; DHAVALIKAR, P. S.; COSGRIFF-HERNANDEZ, E. A Review of Three-Dimensional Printing in Tissue Engineering. Tissue Eng Part B Rev, v. 22, n. 4, p. 298-310, 2016.

SENNERBY, L.; LEKHOLM, U. The soft tissue response to titanium abutments retrieved from humans and reimplanted in rats. A light microscopic study. Clin Oral Implants Res, v. 4, n. 1, p. 23-27, 1993.

SENNERBY, L.; PERSSON, L. G.; BERGLUNDH, T.; WENNERBERG, A.; LINDHE, J. Implant stability during initiation and resolution of experimental periimplantitis: an experimental study in the dog. Clin Implant Dent Relat Res, v. 7, n. 3, p. 136-140, 2005.

SHARON, E.; SHAPIRA, L.; WILENSKY, A.; ABU-HATOUM, R.; SMIDT, A. Efficiency and thermal changes during implantoplasty in relation to bur type. Clin Implant Dent Relat Res, v. 15, n. 2, p. 292-296, 2013.

SHIBLI, J. A.; MARTINS, M. C.; NOCITI, F. H., JR.; GARCIA, V. G.; MARCANTONIO, E., JR. Treatment of ligature-induced peri-implantitis by lethal photosensitization and guided bone regeneration: a preliminary histologic study in dogs. J Periodontol, v. 74, n. 3, p. 338-345, 2003.

SHIE, M. Y.; CHANG, W. C.; WEI, L. J.; HUANG, Y. H.; CHEN, C. H.; SHIH, C. T.; CHEN, Y. W.; SHEN, Y. F. 3D Printing of Cytocompatible Water-Based Light-Cured Polyurethane with Hyaluronic Acid for Cartilage Tissue Engineering Applications. Materials (Basel), v. 10, n. 2, p., 2017.

SMEETS, R.; HENNINGSEN, A.; JUNG, O.; HEILAND, M.; HAMMACHER, C.; STEIN, J. M. Definition, etiology, prevention and treatment of peri-implantitis--a review. Head Face Med, v. 10, n., p. 34, 2014.

SRIDHAR, S.; WILSON, T. G., JR.; PALMER, K. L.; VALDERRAMA, P.; MATHEW, M. T.; PRASAD, S.; JACOBS, M.; GINDRI, I. M.; RODRIGUES, D. C. In Vitro Investigation of the Effect of Oral Bacteria in the Surface Oxidation of Dental Implants. Clin Implant Dent Relat Res, v. 17 Suppl 2, n., p. e562-575, 2015.

SRINIVASAN, M.; VAZQUEZ, L.; RIEDER, P.; MORAGUEZ, O.; BERNARD, J. P.; BELSER, U. C. Survival rates of short $(6 \mathrm{~mm})$ micro-rough surface implants: a review of literature and meta-analysis. Clin Oral Implants Res, v. 25, n. 5, p. 539-545, 2014.

STAVROPOULOS, A.; BERTL, K.; EREN, S.; GOTFREDSEN, K. Mechanical and biological complications after implantoplasty-A systematic review. Clin Oral Implants Res, v. 30, n. 9, p. 833-848, 2019.

SUAREZ, F.; MONJE, A.; GALINDO-MORENO, P.; WANG, H. L. Implant surface detoxification: a comprehensive review. Implant Dent, v. 22, n. 5, p. 465-473, 2013. 
SUBRAMANI, K.; JUNG, R. E.; MOLENBERG, A.; HAMMERLE, C. H. Biofilm on dental implants: a review of the literature. Int J Oral Maxillofac Implants, v. 24, n. 4, p. 616-626, 2009.

SUBRAMANI, K.; WISMEIJER, D. Decontamination of titanium implant surface and reosseointegration to treat peri-implantitis: a literature review. Int J Oral Maxillofac Implants, v. 27, n. 5, p. 1043-1054, 2012.

SUITO, H.; IWAWAKI, Y.; GOTO, T.; TOMOTAKE, Y.; ICHIKAWA, T. Oral factors affecting titanium elution and corrosion: an in vitro study using simulated body fluid. PLoS One, v. 8, n. 6, p. e66052, 2013.

SWAMINATHAN, V.; GILBERT, J. L. Fretting corrosion of CoCrMo and Ti6Al4V interfaces. Biomaterials, v. 33, n. 22, p. 5487-5503, 2012.

TABASSUM, A.; WALBOOMERS, F.; WOLKE, J. G.; MEIJER, G. J.; JANSEN, J. A. The influence of surface roughness on the displacement of osteogenic bone particles during placement of titanium screw-type implants. Clin Implant Dent Relat Res, v. 13, n. 4, p. 269278, 2011.

TARNOW, D. P. Increasing Prevalence of Peri-implantitis: How Will We Manage? J Dent Res, v. 95, n. 1, p. 7-8, 2016.

TEUGHELS, W.; VAN ASSCHE, N.; SLIEPEN, I.; QUIRYNEN, M. Effect of material characteristics and/or surface topography on biofilm development. Clin Oral Implants Res, v. 17 Suppl 2, n., p. 68-81, 2006.

TING, M.; CRAIG, J.; BALKIN, B. E.; SUZUKI, J. B. Peri-implantitis: A Comprehensive Overview of Systematic Reviews. J Oral Implantol, v. 44, n. 3, p. 225-247, 2018.

TOMA, S.; BEHETS, C.; BRECX, M. C.; LASSERRE, J. F. In Vitro Comparison of the Efficacy of Peri-Implantitis Treatments on the Removal and Recolonization of Streptococcus gordonii Biofilm on Titanium Disks. Materials (Basel), v. 11, n. 12, p., 2018.

VALDERRAMA, P.; WILSON, T. G., JR. Detoxification of implant surfaces affected by periimplant disease: an overview of surgical methods. Int J Dent, v. 2013, n., p. 740680, 2013.

VALDERRAMA, P.; BLANSETT, J. A.; GONZALEZ, M. G.; CANTU, M. G.; WILSON, T. G. Detoxification of Implant Surfaces Affected by Peri-Implant Disease: An Overview of Nonsurgical Methods. Open Dent J, v. 8, n., p. 77-84, 2014.

VAN WINKELHOFF, A. J.; GOENE, R. J.; BENSCHOP, C.; FOLMER, T. Early colonization of dental implants by putative periodontal pathogens in partially edentulous patients. Clin Oral Implants Res, v. 11, n. 6, p. 511-520, 2000.

VERDUGO, F.; SAEZ-ROSON, A.; URIBARRI, A.; MARTINEZ-CONDE, R.; CABEZASOLCOZ, J.; MORAGUES, M. D.; PONTON, J. Bone microbial decontamination agents in osseous grafting: an in vitro study with fresh human explants. J Periodontol, v. 82, n. 6, p. 863-871, 2011.

WANDIYANTO, J. V.; TRUONG, V. K.; AL KOBAISI, M.; JUODKAZIS, S.; THISSEN, H.; BAZAKA, O.; BAZAKA, K.; CRAWFORD, R. J.; IVANOVA, E. P. The Fate of Osteoblast-Like MG-63 Cells on Pre-Infected Bactericidal Nanostructured Titanium Surfaces. Materials (Basel), v. 12, n. 10, p., 2019. 
WENNERBERG, A.; ALBREKTSSON, T. Suggested guidelines for the topographic evaluation of implant surfaces. Int J Oral Maxillofac Implants, v. 15, n. 3, p. 331-344, 2000.

WENNERBERG, A.; FROJD, V.; OLSSON, M.; NANNMARK, U.; EMANUELSSON, L.; JOHANSSON, P.; JOSEFSSON, Y.; KANGASNIEMI, I.; PELTOLA, T.; TIRRI, T.; PANKALAINEN, T.; THOMSEN, P. Nanoporous TiO(2) thin film on titanium oral implants for enhanced human soft tissue adhesion: a light and electron microscopy study. Clin Implant Dent Relat Res, v. 13, n. 3, p. 184-196, 2011.

WETZEL, A. C.; VLASSIS, J.; CAFFESSE, R. G.; HAMMERLE, C. H.; LANG, N. P. Attempts to obtain re-osseointegration following experimental peri-implantitis in dogs. Clin Oral Implants Res, v. 10, n. 2, p. 111-119, 1999.

WHEELIS, S. E.; GINDRI, I. M.; VALDERRAMA, P.; WILSON, T. G., JR.; HUANG, J.; RODRIGUES, D. C. Effects of decontamination solutions on the surface of titanium: investigation of surface morphology, composition, and roughness. Clin Oral Implants Res, v. 27, n. 3, p. 329-340, 2016.

WIDODO, A.; SPRATT, D.; SOUSA, V.; PETRIE, A.; DONOS, N. An in vitro study on disinfection of titanium surfaces. Clin Oral Implants Res, v. 27, n. 10, p. 1227-1232, 2016.

WILSON, T. G., JR.; VALDERRAMA, P.; RODRIGUES, D. B. The case for routine maintenance of dental implants. J Periodontol, v. 85, n. 5, p. 657-660, 2014.

WOHLFAHRT, J. C.; AASS, A. M.; RONOLD, H. J.; LYNGSTADAAS, S. P. Micro CT and human histological analysis of a peri-implant osseous defect grafted with porous titanium granules: a case report. Int J Oral Maxillofac Implants, v. 26, n. 1, p. e9-e14, 2011.

WOHLFAHRT, J. C.; LYNGSTADAAS, S. P.; RONOLD, H. J.; SAXEGAARD, E.; ELLINGSEN, J. E.; KARLSSON, S.; AASS, A. M. Porous titanium granules in the surgical treatment of periimplant osseous defects: a randomized clinical trial. Int J Oral Maxillofac Implants, v. 27, n. 2, p. 401-410, 2012.

WOODARD, J. R.; HILLDORE, A. J.; LAN, S. K.; PARK, C. J.; MORGAN, A. W.; EURELL, J. A.; CLARK, S. G.; WHEELER, M. B.; JAMISON, R. D.; WAGONER JOHNSON, A. J. The mechanical properties and osteoconductivity of hydroxyapatite bone scaffolds with multi-scale porosity. Biomaterials, v. 28, n. 1, p. 45-54, 2007.

WU, Q.; QU, Y.; GONG, P.; WANG, T.; GONG, T.; MAN, Y. Evaluation of the efficacy of keratinized mucosa augmentation techniques around dental implants: a systematic review. $\mathbf{J}$ Prosthet Dent, v. 113, n. 5, p. 383-390, 2015.

WU, X.; GU, Q.; CHEN, X.; MI, W.; WU, T.; HUANG, H. MiR-27a targets DKK2 and SFRP1 to promote reosseointegration in the regenerative treatment of peri-implantitis. $\mathbf{J}$ Bone Miner Res, v. 34, n. 1, p. 123-134, 2019.

YANG, S. M.; PARK, J. B.; KO, Y. Use of confocal microscopy for quantification of plastic remnants on rough titanium after instrumentation and evaluation of efficacy of removal. Int $\mathbf{J}$ Oral Maxillofac Implants, v. 30, n. 3, p. 519-525, 2015.

YOU, T. M.; CHOI, B. H.; ZHU, S. J.; JUNG, J. H.; LEE, S. H.; HUH, J. Y.; LEE, H. J.; LI, J. Treatment of experimental peri-implantitis using autogenous bone grafts and platelet-enriched fibrin glue in dogs. Oral Surg Oral Med Oral Pathol Oral Radiol Endod, v. 103, n. 1, p. 3437, 2007. 
ZHAO, G.; SCHWARTZ, Z.; WIELAND, M.; RUPP, F.; GEIS-GERSTORFER, J.; COCHRAN, D. L.; BOYAN, B. D. High surface energy enhances cell response to titanium substrate microstructure. J Biomed Mater Res A, v. 74, n. 1, p. 49-58, 2005. 